\title{
Beethoven's 'Kreutzer' Sonata: \\ Nineteenth-century Art of Arrangement - One Piece, Three Ways.
}

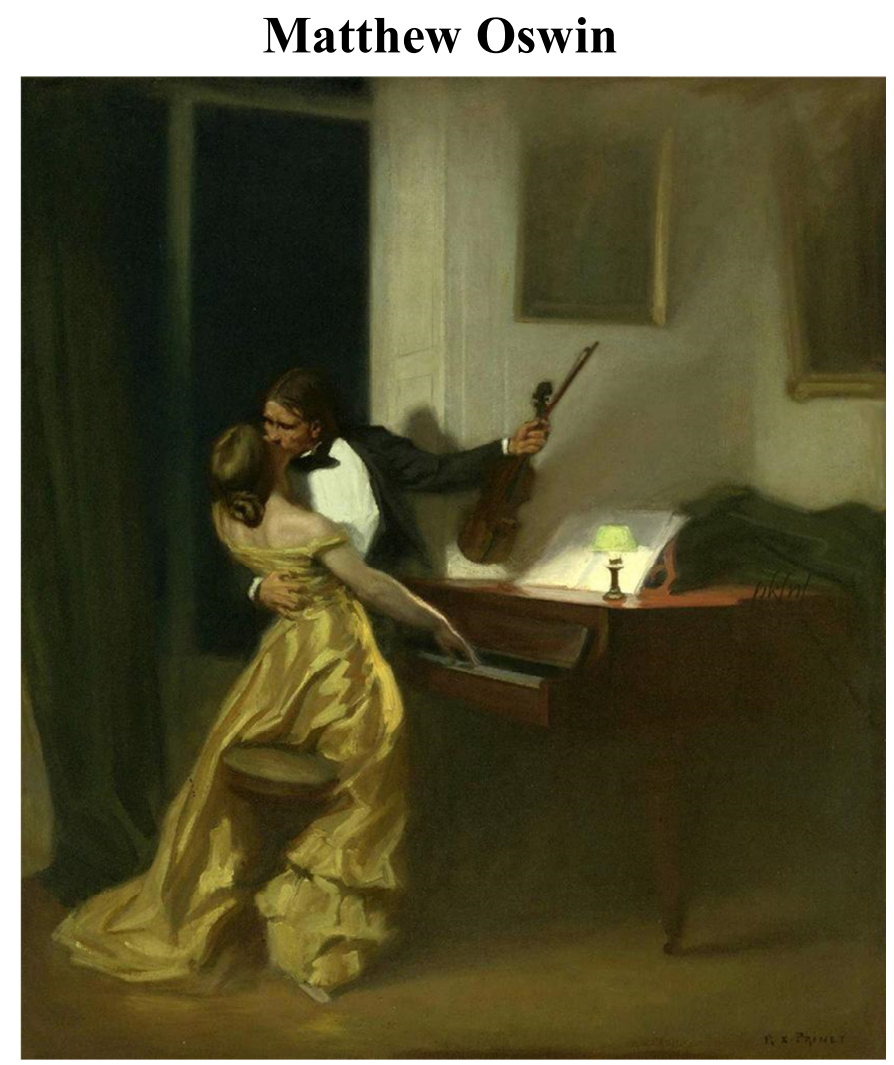

A thesis submitted to Massey University and Victoria University of Wellington in partial fulfilment of the degree Master of Music in Musicology

New Zealand School of Music 



\section{For my family}

The cover image is a cropped version of Rene Prinet's Sonata Kreutzer (1901), which is available in the public domain. Image source: http://commons.wikimedia.org/wiki/File:Prinet -

Kreutzer_Sonata_.jpg (accessed January 14, 2013) 



\section{Contents}

\section{Acknowledgements}

\section{Index of Musical Examples}

\section{Abstract}

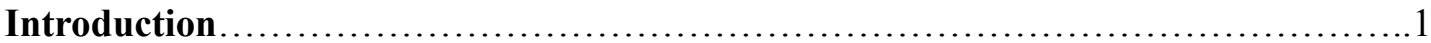

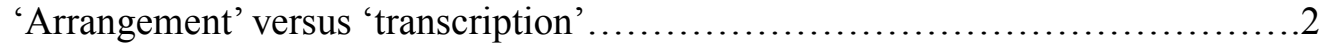

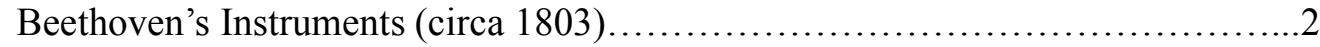

Beethoven and arrangements.............................................

Beethoven's 'Kreutzer' Sonata: Reception..................................6 6

Overview of the following chapters........................................

\section{Chapter One: Beethoven's 'Kreutzer' Sonata}

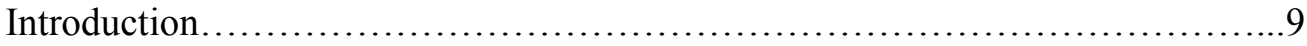

Beethoven's Vienna...................................................... 9

Social Context of the Piano and Violin Sonata: Changing Equality................11

Beethoven, Bridgetower, Kreutzer, and 'Kreutzer' ........................... 14

Overview of Beethoven's 'Kreutzer' Sonata................................... 18

Analysis of Beethoven's 'Kreutzer' Sonata....................................22

Third Movement............................................. 22

First Movement..............................................27

Second Movement................................................ 38

Conclusion:............................................................

\section{Chapter Two: The Quintet Transcription}

Introduction.............................................................. 42

The Quintet in Beethoven's Vienna: streichquartett plus one...................43

The Kreutzer Sonata: duo concertante transformed into chamber music for five musicians......................................................47

Comparison between the quintet arrangement and Beethoven's original

'Kreutzer' ..........................................................48

First Movement..........................................49

Second Movement........................................58

Third Movement................................................59

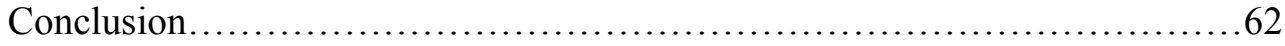

\section{Chapter Three: Czerny and 'Kreutzer'; à quatre mains}

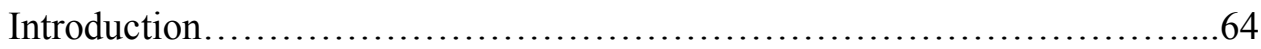

Writing (or re-writing) for four-hand piano..............................64

The Rise of the Pianoforte; or the Pedagogue in the Home....................67

Czerny: the collected works............................................69

Czerny: Master and Apprentice...........................................71

à quatre mains: the four-hand transcription of Beethoven's 'Kreutzer' Sonata.72 
First Movement.............................................. 74

Second Movement........................................ 80

Third Movement........................................ 83

Conclusion.............................................................

Conclusion: One ‘Kreutzer', Three Ways....................................... 87

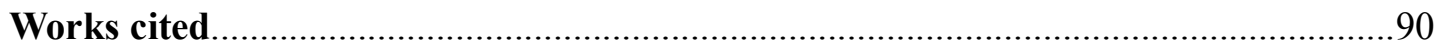




\section{Acknowledgements:}

Many thanks are due to my supervisors, Dr Erin Helyard and Dr Inge van Rij. Both played a significant part in bringing this dissertation to fruition, with Inge helping get it off the ground and Erin bringing it to completion. Their comments and criticism have been extremely helpful and supportive. Erin was also instrumental in forming an understanding of the four-hand arrangement, for reading it through with me. I am honoured to have had each of them as my supervisor.

Thanks to Jun He, for permitting me to perform Beethoven's 'Kreutzer' Sonata with her for her mid-year 2012 DMA recital. This performance was critical in the completion of this thesis as it allowed me to create the performative ethnography and gain a fluent working understanding of the 'Kreutzer' as a performance piece. Thanks also to Dr Martin Riseley for providing instruction in the 'Kreutzer', and to Richard Mapp and Dr Diedre Irons for teaching me the piano at the New Zealand School of Music.

Thanks also to my office-mates Amos Mann and Imogen Thirlwall, both of whom have listened to me rant and rave about my ideas, and provided useful sanity-checks on my plans and workload. Also my students: though they will never actually read my thesis, they probably learned far more than they ever wanted to know about Beethoven and the 'Kreutzer' Sonata.

Thanks are owed to Coburg Bibliotheke for the scanned facsimile provided of Czerny's arrangement of Beethoven's Kreutzer Sonata for Four Hands published in 1829.

Finally, many thanks to my parents - my father in particular for reading through the Czerny arrangement with me; and to Hannah Mason, for being as supportive of this project as any person could hope for. 


\section{Index of Musical Examples:}

\section{Chapter One:}

$\underline{\text { Third Movement: }}$

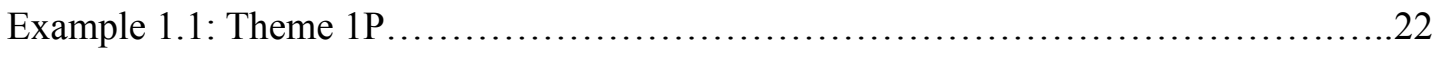

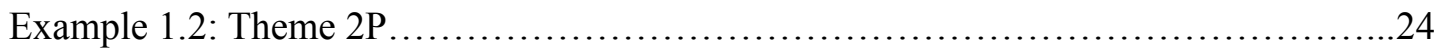

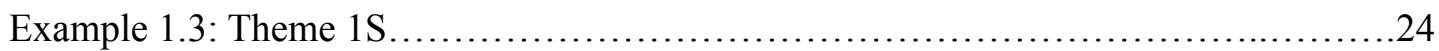

First Movement:

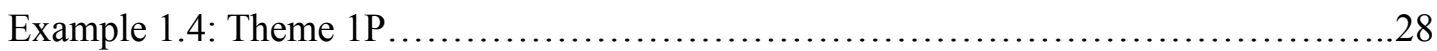

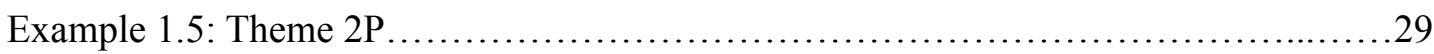

Example 1.6: Theme 1S.................................................... 30

Example 1.7: Theme 2S................................................ 31

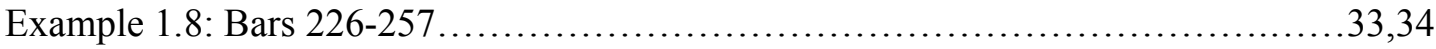

Second Movement:

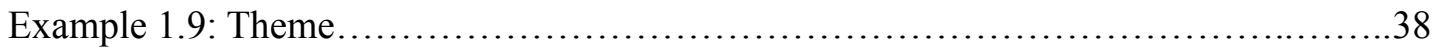

\section{Chapter Two:}

\section{First Movement:}

Example 2.1: Adagio....................................................... 51

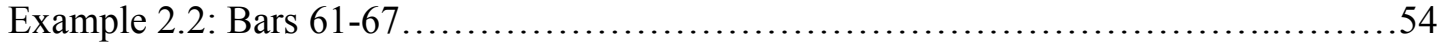

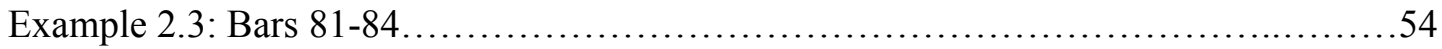

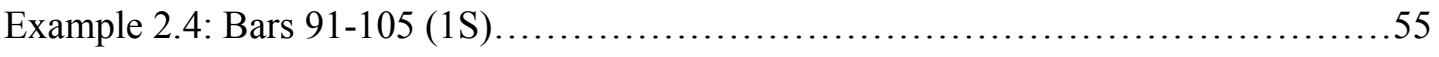

Example 2.5 Bars 251-258, quintet transcription................................56

Example 2.6 Bars 251-258, original sonata................................... 57

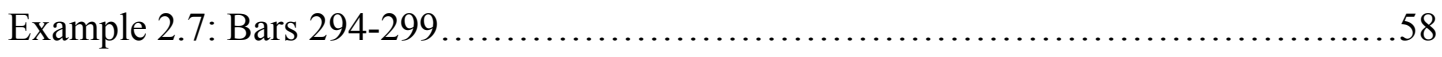


Third Movement:

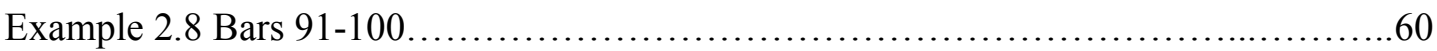

Example 2.9 Bars 166 - 177.....................................................61

\section{Chapter Three}

First Movement:

Example 3.1: Adagio......................................................... 75

Example 3.2: The Cadenza................................................... 76

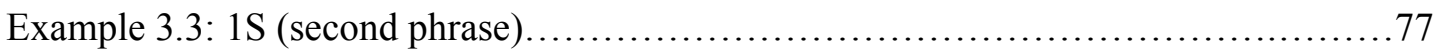

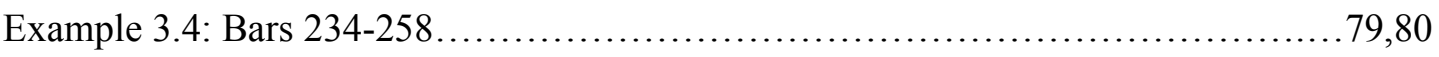

Second Movement:

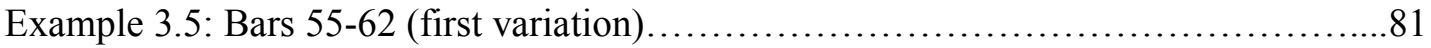

Example 3.6: Czerny's augmented cadenza..................................... 83

Third Movement:

Example 3.7: Bars 114-126.............................................. 84

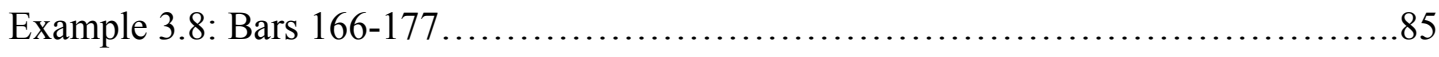




\begin{abstract}
$\underline{\text { Abstract }}$
Beethoven's 'Kreutzer' Sonata transgressed the expectations - and likely captivated the minds - of early nineteenth-century musicians and audiences alike. The 'Kreutzer' is stylistically removed from his Op. 10 No. 1 composed less than six years earlier; it demands virtuosic technical proficiency from both performers. Through the combination of harmonic evasion playing on audience expectations in the first movement and the conversational interplay between the personalities of both performers and instrumental parts alike, this audacious work has fascinated the minds of both listener and critic from the 1803 premiere through to the modern day.
\end{abstract}

In 1805 an Allgemeine musikalische Zeitung review suggested that it would require two virtuosi to study the work in order to communicate the 'Groteskeste' work to an audience this is indicative of not just technical difficulty but also the importance of the dynamic relationship between the two partners of the duo to the 'Kreutzer'. This highly charged relationship inspired Tolstoy and Prinet (and by extension Janacek and many twentiethcentury film and multimedia artists) to create adaptations of 'Kreutzer'.

High-quality musical arrangements of 'Kreutzer' appeared as early as 1827, when Carl Czerny completed a four-hand version of 'Kreutzer'. This was closely followed by an anonymous string quintet arrangement released by the Simrock publishing house in 1832 . These arrangements translated the virtuosic sonata into different mediums for wider dissemination, making it more readily available to both musicians active in the chamber music scene, and domestic students and dilettantes proficient at the piano. Both arrangements manage to transform the 'Kreutzer' into a different format while retaining aspects of both the conversational relationship between musicians as well as the technical demands of Beethoven's original sonata.

The string quintet arrangement tends to fragment melodic ideas between parts, rather than transplanting entire phrases or providing a direct transcription - exceptions generally occurring at important transitions or particularly special moments. This generates a highly differentiated conversational landscape to that the original, which manifests also in the visual shift to five performers. While the arranger also reworks some of the piano writing 
into more idiomatic string writing, it still demands a high level of technical proficiency from all five players.

The four-hand arrangement reworks the same dialogue and thematic ideas into a more intimate setting, taking an almost entirely opposite approach to the quintet. As the two instrumental parts are combined for one instrument, the difficulties from Beethoven's piano part are divided quite literally between primo and secondo. In a similar manner, the conversational and thematic interplay resemble Beethoven's original in a far more direct manner than the quintet. Although the four-hands medium is recognised more for study and wider transmission of concert pieces, it is difficult enough that the virtuosic essence of Beethoven's 'Kreutzer' is maintained.

This dissertation closely examines the relationship between the two instruments within Beethoven's 'Kreutzer' Sonata, and the manner in which both the contemporary arrangements above maintain and alter that relationship through the transformation into another format. In addition, it explores why the textural and idiomatic changes in both arrangements - fundamental and ornamental - remove none of the virtuosic and captivating essence of Beethoven's 'Kreutzer', while simultaneously allowing them to bridge the divide between the emergent nineteenth-century concert hall scene, close study of the score, and domestic music-making. 



\section{$\underline{\text { Introduction }}$}

Beethoven's Kreutzer Sonata for violin and piano was composed within six years of his first violin sonata. Stylistically, however, it sits far apart from those origins as it is heavily influenced by the French concertante style, in part due to Beethoven's association with George Bridgetower, the violinist who played the premiere performance together with Beethoven at the piano. The striking and challenging combination of personalities and technical demands - and the links between sonata and other forms of artistic media attracted the curiosity and interest of the public over the course of the next century. As an example, this interested spawned both an anonymous arrangement for string quintet (published by Simrock in 1832) and a four-hand piano arrangement by Czerny.

This dissertation will examine the genre of the original sonata, alongside the social situation surrounding the creation of the initial sonata and publishing of the two arrangements mentioned above. This will include an examination of the general reception of the Kreutzer and Beethoven in nineteenth-century Vienna. It will then explore the relationship between the initial sonata and both settings, paying particular attention to the manner with which the original was arranged for both four-hand piano and string quintet. This will involve an investigation of both the generic implications of the transcriptions, and the idiomatic translation from the original to the arrangements.

In the following chapters I will examine arrangement of the 'Kreutzer' Sonata for two different forums and formats. One was an anonymous transcription released by Beethoven's publisher for string quintet, which was targeted both at skilled amateur musicians and the professional musician; in the latter case it would have been for performing in the concert hall. The second: for four-hand piano by Czerny, which while still complex is designed for the home, salon or student/teacher lessons; as such it was created for consumption on a skilled yet non-professional level by both middle- and upperclass musicians. It shares stylistic similarities with Czerny's arrangements of symphonies for the same four-hand format, and as such is another representation of the need for consumption on a scale smaller - and also more accessible - than the orchestral concert hall. 


\section{'Arrangement' versus 'transcription'}

Transcription is commonly considered to be the act of notating music exactly as it appears in original form. At the point where a change of medium is involved, Grove redirects us to 'arrangement'. Grove defines arrangement as 'the reworking of a musical composition, usually for a different medium from that of the original.' However, it also mentions that the distinction between the two is 'by no means universally accepted' and both transcription and arrangement have been affixed to similar publications around the period in which this study is interested. ${ }^{1}$ Busoni likens the transformation of musical arrangement into different types of musical medium (or 'agency') to the choice between careers for a human adult suggesting that it is still the same music, with a few changes to the specific details. ${ }^{2}$ As such when referring to the anonymous string quintet as a transcription, I imply that the quintet version is more faithful to Beethoven's original sonata as it involves less additional material. ${ }^{3}$ In actuality, both of these versions are arrangements - the quintet as it is a reworking for a different medium, and the four-hands both as a reworking for a new medium, but also due to the numerous additions Czerny makes to his score. This study demonstrates the nineteenth-century art of arrangement through the exploration and comparison of these three works and the social functions of their respective genres.

\section{Beethoven's Instruments (circa 1803)}

The piano changed dramatically over the course of Beethoven's lifetime. Beethoven himself may have never actually paid for a piano. ${ }^{4}$ His Erard, commonly referred to as a gift, has recently been proven to have been ordered by Beethoven but never paid for, with

\footnotetext{
${ }^{1}$ Ter Ellingson, 'Transcription (i)': Grove Music Online. Oxford Music Online. Oxford University Press, available from http://www.oxfordmusiconline.com/subscriber/article/grove/music/28268; accessed January 2, 2013. Also: Malcolm Boyd, 'Arrangement': Grove Music Online. Oxford Music Online. Oxford University Press, available from http://www.oxfordmusiconline.com/subscriber/article/grove/music/01332; accessed January 4, 2013.

2 Ferruccio Busoni, 'Sketch of a New Esthetic of Music', in Three Classics in the Aesthetic of Music, trans. Dr. Th. Baker, New York: Dover Publications, Inc., 1962, pp. 85-86.

${ }^{3}$ This is despite some of the figures being rewritten to be more idiomatic for a string quintet (as I will demonstrate in Chapter Two).

${ }^{4}$ William S. Newman, Beethoven on Beethoven: Playing His Piano Music His Way, New York: Norton, 1988, p. 53.
} 
Beethoven himself perpetuating the gift myth. ${ }^{5}$ During his lifetime he owned a number of different pianos from makers of varying nationalities: a Parisian Erard grand piano, made using an English action and set-up; an English Broadwood grand piano; a Viennese Graf grand piano, with Viennese action; and William Newman suggests there was likely a Stein or two, a Streicher, a Walter, and perhaps a Kirshbaum at some point. ${ }^{6}$ The suggestion has frequently been made that Beethoven was a (possibly the) driving force behind the development of the piano during the early 1800s, and also that the Broadwood (which was a present) had a large influence on Beethoven. Edwin Good states that he knows 'of not one shred of evidence that Beethoven influenced any piano maker... to enlarge the range of any piano. ${ }^{7}$ The consensus seems to be that the changes in pianos were reflected in Beethoven's writing and not the other way around. These changes are most obvious in the widening range for which his compositions are written: prior to 1803 compositions are restricted to the standard five-octave compass of the keyboard, with the occasional $\mathrm{g}^{3}$; in 1803 Beethoven began to write for a range of F'-c"'”; by 1808 his compositions used a six octave range. ${ }^{8}$

The Kreutzer Sonata was the last major work including a keyboard to be written prior to Beethoven's acquisition of his Erard grand piano, and possesses the corresponding five octave range of an early 1800s Viennese piano: F'-f". Beethoven was presumably using a Viennese piano at this stage - probably a Walter - and as such it would have had a backcheck; such an addition would be necessary to accommodate the demands of the Kreutzer. ${ }^{9}$ This uncertainty in make is not crucial to the understanding of tone and touch or the action of the instrument, as the Stein and Walter (the two most likely candidates for instruments in Beethoven's possession in 1802) are both Viennese instruments possessing the light action typical of the Viennese makers of the late eighteenth century.

The violin changed less dramatically over the course of the composition of Beethoven's

\footnotetext{
${ }^{5}$ Tilman Skowroneck, Beethoven the Pianist, Cambridge: Cambridge University Press, 2010, pp. 86-87.

${ }^{6}$ William S. Newman, Beethoven on Beethoven, pp. 52-53.

${ }^{7}$ Edwin M. Good, Giraffes, Black Dragons, and Other Pianos, Pianos: A Technological History from Cristofori to the Modern Concert Grand, Stanford: Stanford University Press, 1982, pp. 69-70.

${ }^{8}$ Edwin M. Good, Giraffes, Black Dragons, and Other Pianos, p. 70.

${ }^{9}$ Sandra Rosenblum, Performance Practices in Classic Piano Music, Bloomington: Indiana University Press, 1988, p. 51. This addition to the action catches the hammer as it falls away from the string, preventing it from unintentionally rebounding into the string a second time.
} 
violin sonatas. To some extent this is a reflection of the rise of the pianist-composer virtuoso, but mostly a sign of the prevalence of pianos in the middle-class home and their dominance of the domestic market.

\section{Beethoven and arrangements}

Lockwood mentions in his Beethoven: the Music and the Life that Beethoven wrote to Breitkopf and Härtel about his string quartet arrangement of his Opus 14 no. 1 piano sonata (complete with transposition from $\mathrm{E}$ to $\mathrm{F}$ major) stating that:

I firmly maintain that only Mozart himself could translate his works from the keyboard to other instruments, and Haydn could do this too - and without wishing to compare myself to these two great men, I claim the same about my keyboard sonatas. ${ }^{10}$

Further to this, Beethoven reprimanded Czerny after a farewell concert for Schuppanzigh, in which Czerny had played the piano part for his Wind Quintet, for making additions to his score.

in youthful folly I allowed myself some changes - complications to passagework, use of the higher octave and so on. Beethoven reprimanded me right there, in the presence of Schuppanzigh, Linke and the others. ${ }^{11}$

Beethoven apologised in a letter the following day, but Czerny maintained that this

cured me of the passion to permit myself any kind of change when performing [Beethoven's] works. ${ }^{12}$

${ }^{10}$ Lewis Lockwood, Beethoven: The Music and the Life, New York: Norton, 2003, pp. 131-132.

${ }^{11}$ The translation is my own. Original German is as follows: [E]rlaubte ich mir im jugendlichen Leichtsinn manche Änderungen,-Erschwerung der Passagen, Benützung der höheren Oktave etc. Beethoven warf es mir mit Recht in Gegenwart des Schuppanzigh, Linke und der anderen Begleitenden mit Strenge vor..See next footnote for source.

${ }^{12}$ Ingrid Fuchs, 'Beethoven's Ambassador Posthumous', in David Gramit (ed.), Beyond the Art of Finger Dexterity: Reassessing Carl Czerny, Rochester: University of Rochester Press, 2008, p. 91. The above German quote can be found on page 103 of the same text, and is from Wiener allgemeine Musik Zeitung in 1845. 
Fuchs quotes a section from Czerny's pianoforte school where arrangements are discussed:

When performing his works... the player must by no means allow himself any change in the composition, any addition, any abbreviation. Also [in compositions for pianos of limited ranged, use of] the sixth octave through additions has always proved detrimental in the same way that all embellishments, mordents, trills, etc., that the author did not indicate rightly seem superfluous... for one wants to hear the work in its original guise, the way the master conceived and wrote it. ${ }^{13}$

These two anecdotes show that Beethoven did not appear to approve of arrangements when created by someone other than the composer, even if one was as dear a friend to him as Czerny (and Beethoven did apologise to Czerny for his reprimand, though only to say it was not a criticism of his playing). ${ }^{14}$ As I will demonstrate in Chapter Three, while Czerny said he after that 1816 concert he resolved to never again alter Beethoven's works - and repeated similar sentiment in his pedagogic writings much later in life - what Czerny said and did were two entirely different things.

Beethoven himself was not wholly opposed to arrangements of his compositions provided that either they were his own arrangements, or he had directly approved their creation. He reworked his Op. 14 no. 1 piano sonata for string quartet, and the Marcia funebre from his Op. 26 piano sonata for orchestra. On the other hand, he rejected an arrangement of his Op. 1 no. 1 piano trio by Kaufmann out of hand as unsatisfactory. ${ }^{15}$ In a similar fashion he objected to a four-hand piano arrangement of his Op. 124 Overture in C Major in 1825:

... totally inappropriate four-handed piano score of my last overture, which deviates from the original score, ... the completely faithful two- and four-hand piano scores written by Herr Carl Czerny ... will shortly be published. ${ }^{16}$

\footnotetext{
${ }^{13}$ Ingrid Fuchs, 'Beethoven's Ambassador Posthumous', p. 91.

14 Ibid.

${ }^{15}$ William Kinderman, Beethoven, New York: Oxford University Press, 2009, pp. 67, 100, 221.

${ }^{16}$ Ingrid Fuchs, 'Beethoven's Ambassador Posthumous', p. 94.
} 


\section{Beethoven's ‘Kreutzer' Sonata: Reception}

The 'Kreutzer' Sonata made a lasting impression on society, directly and indirectly in both musical culture and other artistic and intellectual forums. The most prominent of these is Leo Tolstoy's novella The Kreutzer Sonata, published in 1889. Conceived some 85 years after the premiere of Beethoven's 'Kreutzer' Sonata, the Tolstoy novella has been wellpublicised, in part as a result of censorship rulings in both Russia (from the Czar of Russia) and the United States of America banning the release and shipping of the work. The Postmaster General in the United States banned the mailing of newspapers containing portions of the novel, a ruling which was upheld by the Attorney General prior to being overturned by the courts. Tolstoy himself expressed his opinion of Beethoven's 'Kreutzer' Sonata the

supreme example of the power of music (a dangerous power, in his view) to arouse erotic feelings. ${ }^{17}$

With this in mind, it is not hard to imagine that such a novella would spark such controversy. A Philadelphian judge ruled that it was not inappropriate, denying the idea that it was an 'obscene libel,' as while it contained 'absurd and foolish views about marriage' it 'denounces obscenity of every description on almost every page.' 18

The Tolstoy novella sparked widespread excitement for both itself and the original Beethoven sonata in artistic and literary circles. To date a veritable multitude of films, drama productions and screenplays have been created which were inspired by the novella and Beethoven sonata (either independently or otherwise). ${ }^{19}$ One painting is of particular importance: in 1901 Rene Prinet created a paint depicting a passionate kiss between the male violinist (Trukachevsky) and female pianist (Pozdnyshev's wife) from the Tolstoy novella. This enduring image depicts Prinet's interpretation of the wild and powerful desire

\footnotetext{
${ }^{17}$ Lewis Lockwood, Beethoven: The Music and the Life, p. 144.

${ }^{18}$ The judge, Russell Thayer, ruled that it was also not unlawful to express ideas that 'call in question and argue against any received doctrine of the Christian faith', and respectfully commented that the Tsar of Russia and the United States Postal Service Postmaster were not recognized legal authorities in the United States insofar as literature was concerned. Quotes from: 'Count Tolstoï Not Obscene.; the "Kreutzer Sonata" Cannot Legally be Suppressed.' New York Times, September 25, 1890, available from http://query.nytimes.com/mem/archivefree/pdf?res=9B04E1D9103BE533A25756C2A96F9C94619ED7CF; accessed October 10, 2012.

${ }^{19}$ One film version of the novella which parodies the others is Woody Allen's Love and Death.
} 
that sex creates; a carnal physical desire which is a manifestation of the turmoil and confusion of the first movement of Beethoven's 'Kreutzer' Sonata. The image is a visual representation of the thoughts running through the mind of Pozdnyshev - having mulled over his views of their reading of the 'Kreutzer Sonata', a jealous rage overcomes him, during which he murders his wife after allowing Trukachevsky to flee as it was

ridiculous to pursue in my stockings the lover of my wife, and I did not wish to be grotesque, I wished to be terrible. ${ }^{20}$

The painting also highlights the dialogue which occurs between the two instrumentalists, as they navigate the extensive recurring sequences and semitone units, and the dramatic, grotesque and bizarre motifs and emotions these create. ${ }^{21}$

\section{Overview of the following sections:}

Chapter One will explore Beethoven's original Opus 47 'Kreutzer' Sonata, and the circumstances surrounding its creation. This will include a brief look at Beethoven's Vienna and then a look at the social context of the violin sonata genre around 1800; this will lead in to a section on the events leading to the creation and premiere of the 'Kreutzer' in 1803. My own analysis of Beethoven's 'Kreutzer' Sonata will follow, accompanied by my own reading of the work. This reading draws on the model used by Elisabeth Le Guin in her chapter 'Cello and Bow Thinking' from Boccherini's Body (University of California Press, 2006). The combination of analysis and performative ethnography foregrounds both performative and interactive aspects of the 'Kreutzer'; these are fundamental tools for

${ }^{20}$ Leo Tolstoy, The Kreutzer Sonata and Other Stories, Trans. Benjamin R. Tucker, New York: J. S. Ogilvie, 1890, p. 54.

${ }^{21}$ Richard Leppert points out that these same motifs and emotions are explored in a more literal sense in the Tolstoy novella: the usage of 'broken phrases, interruptions, and rapid and extreme tempo shifts' provides Pozdnyshev with his own agitation, which rapidly results in the irrational fear that Trukhachevsky and his wife are conducting an affair in his absence. Leppert also mentions that the first movement is somehow different and more contradictory than the following two. While this movement certainly was not salon music, and contrary to the traditional premises of the instrumental sonata could be considered to be 'not music of and for women... the feminine is erased from the score', it is not so vastly different from the third movement in terms of those same features as to be the whole trigger for Pozdnyshev. It is more likely that the first movement created the initial fears; watching the effeminate Trukhachevsky's body interacting with that of his wife sent his imagination and personal insecurity into overdrive. In: Richard Leppert, The Sight of Sound, Berkeley: University of California Press, 1995, pp. 172-177. 
developing a proper understanding of the arrangements explored in the later chapters.

In Chapter Two I will look at the string quintet arrangement of Beethoven's 'Kreutzer' Sonata published by Simrock in 1832 . This is a particularly high quality arrangement which was released in the era of quartet scores; as such the first stage of investigation will be the development of the string quartet genre, as there are close ties between the string quartet and quintet settings. This will include some of the changes to the string chamber music genre from Boccherini through to Beethoven; it will also look briefly at the social reception of string chamber music in Beethoven's Vienna. I will then compare the manner in which Beethoven's virtuosic 'Kreutzer' Sonata has been reworked for string quintet, paying particular attention to the manner with which the original gestures and themes have been altered to function idiomatically within the quintet genre - and the demands the arrangement places upon the performer. There will also be a brief exploration about who the arrangement might have been prepared by, and why it was released in 1832.

Chapter Three will deal with the four-hand arrangement by Czerny. The background to this chapter features a discussion about the social and instructional function of four-hand arrangements, and the relationship between these arrangements and the growing popularity of the piano - in particular the markets for which the arrangements were intended. There will also be a description of Czerny as both pedagogue and composer, and an examination of his relationship with Beethoven. The investigation of Czerny's arrangement of Beethoven's 'Kreutzer' Sonata will again look at the manner in which the gestures and idiomatic writing of the original sonata has been altered for the four-hands genre; focussing in particular on the way the partnership between performers changes for the four-hands style. 


\section{Chapter 1: Beethoven's 'Kreutzer'Sonata}

\section{Introduction}

Beethoven's 'Kreutzer' is a transgressive and virtuosic work which taxes the technique of performers, and probably challenged the expectations of Beethoven's audiences. Written on the cusp of what others have described as his 'heroic' period, it was composed with Beethoven himself in mind, in combination with the violin virtuoso Bridgetower. ${ }^{22}$ As such 'Kreutzer' demands a high level of technical proficiency, which was extraordinary for the sonata genre prior to the premiere in $1803 .{ }^{23}$ This chapter will look at the social scene in Vienna within which Beethoven was situated in the early 1800s, and some of the circumstances surrounding both the shifts in the sonata genre and the composition of Beethoven's 'Kreutzer' Sonata. Following this will be my analysis of the 'Kreutzer' which will help to develop an understanding and appreciation for the two arrangements explored in the other chapters. This is accompanied (in footnotes) by a performative ethnography of the 'Kreutzer', which is based on my own experiences as a pianist. The reading serves two purposes: to emphasise the interactions between both thematic motifs and the performers themselves in Beethoven's original sonata; and to provide a form of modern performative arrangement of 'Kreutzer'.

\section{Beethoven's Vienna}

Beethoven came to Vienna after the decline of the Hauskapellen was complete - the traditional viewpoint is that this was likely due to the decline of the monetary fortunes of the aristocracy during the Napoleonic Wars in the late eighteenth century. ${ }^{24}$ An alternative perspective is that the Hauskapellen were a fashion that grew out of the desire to imitate the court fashions (the Hofkapellen, which in turn declined as a result of this social

${ }^{22}$ Michael Broyles, Beethoven: the Emergence and Evolution of Beethoven's Heroic Style, New York: Excelsior Music Publishing Co., 1987, p. 4. Broyles skips 'Kreutzer' in his look at Beethoven's stylistic development, electing to instead move directly to Beethoven's 'Eroica'.

${ }^{23}$ William Drabkin, 'The Introduction to Beethoven's "Kreutzer" Sonata: A Historical Perspective", in Lewis Lockwood and Mark Kroll (eds.), The Beethoven Violin Sonatas: History, Criticism, Performance. Urbana: University of Illinois Press, 2004, p. 83.

${ }^{24}$ F. M. Scherer, Quarter Notes and Bank Notes: The Economics of Music Composition in the Eighteenth and Nineteenth Centurie, Princeton: Princeton University Press, 2004, pp. 39-40. 
downwards spread) and that by the 1790s this fashion had declined as it was "no longer socially useful' ${ }^{25}$ By abandoning this custom yet sustaining the patronage system, it gave rise to a broader participation in musical affairs and allowed the salon to assume an influential role in the direction music in Vienna would take. ${ }^{26}$

Privately hosted concerts spread down the social ladder in the 1780s and 1790s although the cost involved in running them kept their numbers down without the aid of a number of musical acquaintances. ${ }^{27}$ These private concerts often took place in the form of salons, and allowed the preview of both new music and the revival of older - or serious - music, such as J. S. Bach through the efforts of Baron van Swieten. ${ }^{28}$ It was through these forums that Beethoven initially gained traction amongst Viennese patrons. The forums within which these smaller circles of aristocrats and nobles viewed this music allowed the works to be sampled by the musically inclined social elite before performances in more public environments occurred. ${ }^{29}$ As a by-product of this system, musicians became increasingly more professionally oriented; this dramatically increased both the cost of maintaining a list of performers on retainer, and employment of orchestras. ${ }^{30}$

This expense allowed the middle-class a social 'in' with the musicians, as the patronage system began to change such that musicians were generally no longer exclusively owned by any one aristocrat or noble. As such by the time Beethoven reached Vienna, the groundwork which allowed him to break the traditional mould was already being laid. Another consequence of the increasing cost of maintaining an orchestra was the increase in number of public concerts and salon performances.

While the cost of running private concerts was prohibitive, by contrast the public concert took off amongst the upper middle class. Tickets or subscriptions to these concerts were a

\footnotetext{
${ }^{25}$ Julia Moore, 'Beethoven and Musical Economics', PhD diss., University of Illinois, 1987, p. 100.

${ }^{26}$ Tia DeNora, Beethoven and the Construction of Genius: Musical Politics in Vienna, 1792-1803, Berkeley: University of California Press, 1997, p. 44.

${ }^{27}$ Mary Sue Morrow, Concert Life in Haydn's Vienna: Aspects of a Developing Musical and Social Institution, New York: Pendragon Press, 1989, p. 2.

${ }^{28}$ Edward Olleson. 'Swieten, Gottfried Baron van': Grove Music Online. Oxford Music Online, Oxford University Press, available from http://www.oxfordmusiconline.com/subscriber/article/grove/music/27216; accessed January 02, 2013.

${ }^{29}$ DeNora, Beethoven and the Construction of Genius, pp. 28-29.

${ }^{30}$ Ibid., p. 46.
} 
more realistic way of generating a sustainable income and a persistent industry, and initially catered to the tastes and needs of the upper echelons of Viennese society. ${ }^{31}$ This scene typically performed works already trialled in private - amongst circles such as Czerny's regular gatherings with students and professional colleagues - and likely indicated the tastes and 'current trends in the world of the private aristocratic salon'; however the details of salon performances and private programmes are largely poorly documented - if at all. ${ }^{32}$ Typically rising or established composers formed the bulk of the programming; in particular Mozart, Haydn and Beethoven were the most widely performed. $^{33}$

\section{Social Context of the Piano and Violin Sonata: Changing Equality}

As we have seen in the previous section there was an upheaval in the musical scene during the early 1800 s, centred around (and in reaction to) the sociological turmoil surrounding the rise of the bourgeoisie. This was tied directly to the decline of the royal court orchestra, which coincided with the appearance of the smaller chamber music society and concerthall scene - which were both the domain of the more proficient amateur musician in addition to contributing to the lifeblood of the virtuoso. This social shift mirrors both the rise of the amateur musician and the dominance of the virtuoso performer/composer.

The sonata underwent similar changes. From its beginnings as a work for keyboard with another melodic instrument as accompaniment (often in a dispensable manner), over time the dual instrument relationship became characterized by an increasingly melodic and nonoptional solo instrument. ${ }^{34}$ This continued to the point where - when considered as an extension of the solo keyboard sonata already in existence - the solo piano sonata and the sonata for piano and melodic instrument both became staples of the concert hall and small musical soiree. Furthermore, the duo sonata became an increasingly equal partnership, with the technical difficulty of both parts mounting - Beethoven himself described the 'Kreutzer' Sonata as being 'written in a very virtuoso style like a concerto'. ${ }^{35}$ These shifts

\footnotetext{
${ }^{31}$ Ibid., pp. 27-28.

${ }^{32}$ DeNora, Beethoven and the Construction of Genius, p. 29.

${ }^{33}$ Ibid., pp. 34-36.

${ }^{34}$ William S. Newman, The Sonata in the Classic Era, Chapel Hill: University of North Carolina Press, 1963, p. 491.

${ }^{35}$ David D. Boyden, et al. 'Violin.': Grove Music Online. Oxford Music Online, Oxford University
} 
were likely a direct reflection of the changes to society around them, and the increasing availability of the piano and the potential for the instrument to reproduce symphonic works. $^{36}$

These changes to form and context cause Beethoven's maturing style to exhibit itself in contrasting ways. The 'Kreutzer' Sonata displays distinct features of his heroic style and requires virtuosity from both performers: the manner in which Beethoven evades confirming A minor for a substantial portion of the exposition of the first movement and the psychological confusion and turmoil this creates for both performer and listener; the technical facility and surety required for both piano and violin; the challenging opening four solo bars for the violin in the introduction; and the emotionally charged rising semitone that underpins the entire sonata. All of these form part of the ethos of the 'Beethoven Hero' while simultaneously recognising the shift from the home to the concert hall the piano was making. ${ }^{37}$ Scott Burnham believes that this concept revolves around the idea that Beethoven's music is heard as 'speaking to the human condition'; 38 that the 'art of long-term dramatic suspense... [engages] us primarily at a visceral level'. ${ }^{39}$ This concept was evident as early as 1805, when the review in Allgemeine musikalische Zeitung referred to anyone who was capable of forming an understanding of the 'Kreutzer' Sonata as 'eris mihi magnus Apollo', or 'you will be great Apollo'. 40

These same 'heroic' features represent the concertante style Beethoven utilised to further differentiate 'Kreutzer' from his other violin sonatas. The Parisian violin school fronted by Viotti helped to showcase the pre-eminence of the violinist virtuoso-composer, and Beethoven himself could be considered as belonging to the existing keyboard virtuoso-

Press, available from http://www.oxfordmusiconline.com/subscriber/article/grove/music/41161pg1; accessed 14 July 2011.

${ }^{36}$ I will look at this in Chapter 3 when discussing arrangements for four-hand piano.

${ }^{37}$ Scott Burnham , Beethoven Hero, Princeton: Princeton University Press, 1995, pp. 45-51.

${ }^{38}$ Ibid., p. 167.

${ }^{39}$ Ibid., pp. 45-46.

${ }^{40}$ Wayne Senner, Robin Wallace, and William R. Meredith, (eds.), The Critical Reception of Beethoven's Compositions by his German Contemporaries, Vol. 1, Trans. Wayne Senner, Lincoln: University of Nebraska Press, 1999, pp. 224-225. Translation courtesy of Hannah Mason. This comment can also be interpreted as suggesting that Beethoven - for being able to compose a work of this nature - as far as the reviewer was concerned was Apollo, the Greek god of music. From this point I will refer to the Allgemeine musikalische Zeitung by the abbreviation AMZ. 
composer tradition - which was at the time completing the transition to the piano. These virtuosi provided inspiration for a growing middle-class target audience for mass-produced copies of easy printed music and instructional treatises. The 'Kreutzer' Sonata is an example of a sonata written for two virtuosi, and the scritta in uno stile molto concertante on the cover of the original edition underlines this in a dramatic fashion, perhaps even warning amateurs that the piece may be beyond their capabilities.

The two developmental processes of social context and instrumental change were both part of a unified trend towards a wider acceptance of musicians and the musical scene as a legitimate art form, not just a leisure activity for the aristocracy, the operatic scene, accompaniment for religious occasions, or employment in a background music function at the courts. As David Gramit points out it was not just music experiencing this type of growth; the rise of the middle class and the industrial era also displayed an expansion in books and other printed material, combined with increasingly centralised trade and industry. ${ }^{41}$ When considered alongside the burgeoning pianoforte construction trade and continuous developments in instrumental design, the influence of this expansion of capacity for consumption through printed media - and the spread of in-home instruments created an increased demand for more complex works. This demand helped to counterbalance the vast quantity of music produced for amateur musicians, enabled amateurs to become more technically proficient, and widened the potential exposure of popular composers.

This represents two different strands of development, which are not entirely discreet. One strand shows the sonata maintain an amateur audience, as music for the home or for the student/teacher relationship. This provides entertainment for amateur musicians and their families, allowing them to experience music as a personal or social activity. The second responds to a demand for more complex music for professionals and virtuosi, which leads to the creation of hybrids like the 'Kreutzer' Sonata - in this case a mix of both concerto and sonata style and format. These more complicated works form the backbone of the repertoire of the professional musician and were often out of reach technically of the wider amateur music-lover.

${ }^{41}$ David Gramit, "Selling the Serious: The Commodification of Music and Resistance to It in Germany, circa 1800', in William Weber (ed.), Musician as Entrepreneur, 1700-1914: Managers, Charlatans, and Idealists, Bloomington: Indiana University Press, 2004, pp. 84-87. 


\section{Beethoven, Bridgetower, Kreutzer, and 'Kreutzer'}

Suhnne Ahn makes the case that Beethoven's 'Kreutzer' Sonata is in fact partially modelled on or inspired by a work by Kreutzer: his 'Grande Sonata', which was published in Paris in 1799. This was made available in Leipzig in the middle of 1802, and was released in Vienna by Breitkopf and Härtel in January $1803 .{ }^{42}$ The sketches for the three movements of 'Kreutzer' are contained within two sketchbooks. Kessler (movement three) and Wielhorsky (movements one and two) put the respective dates of composition between December 1801 and July 1802 for the third movement, and late 1802 to May 1803 for the first and second movements. ${ }^{43}$ This further supports Ahn's theory.

In the early 1800 s Beethoven was considering a journey to Paris, potentially seeking an appointment in Napoleon's France. ${ }^{44}$ The composition and premiere of the 'Kreutzer' Sonata occurred some five years after Rudolphe Kreutzer had travelled from Paris to visit Vienna, and it is possible that Beethoven may have met with him at this time - although conflicting accounts exist. ${ }^{45}$ Lockwood suggests that Beethoven regarded Napoleon as a

contemporary whose colossal ambition, will to power, and sense of destiny, however differently revealed, seemed to mirror his own. ${ }^{46}$

This regard accompanied feelings which shifted frequently between extremes of admiration and disillusionment with Napoleon. The consideration of a trip to Paris may have been in part due to a desire to try the Parisian musical scene; but also his familiarity with the musical style of Bridgetower - who came from the Parisian violin school ${ }^{47}$ combined with Beethoven's personal identification with the heroism and pride driving the

\footnotetext{
42 Suhnne Ahn, 'Genre, Style, and Compositional Procedure in Beethoven's "Kreutzer" Sonata, Opus 47', PhD diss. Harvard University, 1997, pp. 146-148.

${ }^{43}$ Douglas Johnson, Alan Tyson, Robert Winter. The Beethoven Sketchbooks: History, Reconstruction, Inventory. Berkeley: University of California Press, 1985, pp. 124-136.

${ }^{44}$ Lewis Lockwood, Beethoven: The Music and the Life, p. 239.

${ }^{45}$ Ahn, p.138.; Boris Schwarz, 'Beethoven and the French Violin School', The Musical Quarterly, Vol. 44, No. 4, 1958, p. 439.

${ }^{46}$ Lockwood, Beethoven and the Life, p.183

${ }^{47}$ George Grove, 'Bridgetower, George Polgreen', rev. Simon McVeigh: Grove Music Online. Oxford Music Online, Oxford University Press, available from http://www.oxfordmusiconline.com/subscriber/article/grove/music/03981; accessed October 18,2013 , Also refer to discussion of Bridgetower later in this section.
} 
French Revolution that resonated strongly with his own ideology.

There is at least one other reason why Beethoven would choose to create a sonata in the style of a concerto: he was finally gaining the respect of the Viennese serious music critics. Although preliminary criticism from 1792 was positive following his move to Vienna, the conservative initial publications of the $A M Z$ in 1798 generally considered Beethoven's music to be fundamentally stylistically flawed. ${ }^{48}$ Despite their misgivings, critics also discerned something special and unique in Beethoven's works. ${ }^{49}$ DeNora suggests that this set of critiques shows that some contributors to the $A M Z$ were unwilling to look outside the established set of values for judging contemporary works, instead employing the standing traditions associated with established composers like Haydn to measure the worth of Beethoven's compositions. Others were willing to use the labels of 'original' and 'in a higher style' to legitimize some of Beethoven's experiments. ${ }^{50}$

Over the years following 1799 this changed substantially, not least through Beethoven's efforts to champion his own compositions. The critics at $A M Z$ decided to employ a different standard in evaluating Beethoven's work in order to explain his ability to command learned structures and yet be original at the same time, and as such Beethoven's changing style could still appeal to the educated listener. ${ }^{51}$ This was necessary given that the creations Beethoven produced shifted steadily further away from the style associated with mainstream music. ${ }^{52}$ This was aided by the input of van Swieten: his organisation of Beethoven's pianoforte duel with Wölffl directly helped create a positive change in status for Beethoven, as his distinctly less showmanship-focussed performing style held its own against Wölffl even if no winner was actually determined. ${ }^{53}$ This evolving image may well be the beginning of the persistent Beethoven ethos which gave rise to the concept of Beethoven as an unassailable figure on a pedestal, an overbearing shadow upon German

\footnotetext{
${ }^{48}$ Senner, The Critical Reception of Beethoven's Compositions, pp. 142-146.

49 Ibid.

${ }^{50}$ DeNora, Beethoven and the Construction of Genius, p.179.

51 Ibid., p. 182.

52 Ibid., p. 184.

53 Tia DeNora, 'The Beethoven-Wölffl Piano Duel: Aesthetic Debates and Social Boundaries', in David Wyn Jones (ed.), Music in Eighteenth-Century Austria. Cambridge: Cambridge University Press, 1996, pp. 259-282. See also Senner, The Critical Reception of Beethoven's Compositions, p. 28.
} 
composers during the nineteenth century. ${ }^{54}$ This aside, his efforts to set himself up as a recognised composer required some extra effort on his part to persuade the critics that his music was worth endorsing; he had no such issues with the general aristocracy thanks to his initial championing by van Swieten and Lichnowsky.

The premiere performance of the 'Kreutzer' Sonata was given by Beethoven himself and a Polish-West Indian violinist named George Bridgetower on May $24^{\text {th }} 1803$ during a morning concert in the Augarten, Vienna. No review exists of this concert, but several individual accounts exist - mostly written somewhat after the fact. The most well-known story is that of Bridgetower himself, who talks about two things: his imitation in the repeat of the exposition of the first movement, and the manner with which the second movement was received.

When I accompanied him in this Sonata-concertante at Wien at the repetition of the first part of the Presto, I imitated the flight at the $18^{\text {th }}$ bar of the pianoforte part... he jumped up, embraced me, saying, 'Noch einmal, mein lieber Bursch.' Then he held the open pedal during this flight, the chord of 6 as at the ninth bar. ${ }^{55}$

Beethoven's expression in the Andante was so chaste, which always characterised the performance of all his slow movements, that it was unanimously hailed to be repeated twice. ${ }^{56}$

Bridgetower was a product of the French violin school fronted by an Italian named Giovanni Battista Viotti, who taught students of the calibre of Rudolphe Kreutzer, Pierre Rode, and Pierre Baillot. ${ }^{57}$ Kreutzer travelled to Vienna in 1798, and Rode - who was the recipient of the dedication of Beethoven's Opus 96 violin sonata - came to Vienna in

${ }^{54}$ Lydia Goehr, The Imaginary Museum of Musical Works: An Essay in the Philosophy of Music, Oxford: Clarendon Press, 1992, pp. 207-211.

${ }^{55}$ This translates as 'once again, my dear boy.' This translation is my own; the open pedal referred to is marked in the manuscript.

${ }^{56}$ Both quotes are from F. G. Edwards, 'George P. Bridgetower and the Kreutzer Sonata', Musical Times, Vol. 49, No. 783, 1908, pp. 302-308.

${ }^{57}$ These students would later publish a popular 'official' treatise on the art of violin playing (Méthode de violon) which would standardise string playing in Paris, and provided insight into modern violin technique across Europe. See Boris Schwarz, 'Beethoven and the French Violin School', pp. 432-433. All four of these violinists are strongly associated with the French violin concerto's relationship with the 'heroic' concept, in both their compositions and performance style. See Maiko Kawabata, 'Virtuoso Codes of Violin Performance: Power, Military Heroism and Gender (1789-1830)', 19 ${ }^{\text {th }}$-Century Music, Vol. 28, No. 2, 2004, pp. 98-101. 
1812. ${ }^{58}$ Although Bridgetower likely received his early training on the Eszterhazy estate in Austria, he spent the majority of his career in England from late 1789 and received his later tuition there; his debut performance appears to have been at the Concert Spirituel in Paris in 1789 at the age of eleven. ${ }^{59}$ Additionally the violinist François-Hippolyte Barthélemon was responsible for Bridgetower's continuing violin studies in England, and was himself a French violinist familiar with both traditional French style and that of Viotti. $^{60}$

Bridgetower was the recipient of the original dedication of what was then the autograph of the Opus 47 violin sonata. It read: 'Sonata mulattica Composta per il Mulatto Brischdauer gran pazzo e compositore mulattico' ${ }^{\prime 61}$ ('a mulattic sonata sonata written for the mulatto Brischdauer, a complete loon and mulattic composer') ${ }^{62}$ which Kramer regards as signalling 'sincere intimacy' and an 'outrageously personal dedication'. ${ }^{63}$ This dedication, like the original for Beethoven's Third Symphony 'Eroica', was scratched out in a fit of frustration with Bridgetower - apparently after a disagreement with Bridgetower in which he slighted a woman Beethoven was fond of - and was rededicated to Rudolph Kreutzer. ${ }^{64}$

Ferdinand Ries (the copyist approached by Beethoven to produce the violin part of the first movement prior to the premiere) gave his own account of proceedings leading up to the event. He recounted that Beethoven approached him in the early hours of the morning the day before the premiere to ask him to copy out a part for Bridgetower of the first movement. Beethoven mentioned that there was a beautifully prepared copy of the third movement already prepared (presumably either the copy created for the Opus 30 No. 1 sonata, or a revised version already copied out). Bridgetower would read from the score for the second movement, and the piano part for the first movement was only roughly

\footnotetext{
${ }^{58}$ Boris Schwarz, 'Beethoven and the French Violin School', pp. 439-441.

${ }^{59}$ Josephine Wright, 'George Polgreen Bridgetower: An African Prodigy in England', The Musical Quarterly, Vol. 66, No. 1, 1980, pp. 72-73. Different ages abound, but given the penchant for false advertising when it comes to the ages of child prodigies, the eldest option seems more likely.

${ }^{60}$ Wright, 'George Polgreen Bridgetower: An African Prodigy in England', p. 78.

${ }^{61}$ Grove, rev. McVeigh, 'Bridgetower, George Polgreen'.

${ }^{62}$ Translation by Kramer: Richard Kramer, 'Sonate, que me veux-tu? Opus 30, Opus 31, and the Anxieties of Genre', in Lewis Lockwood and Mark Kroll (eds.), The Beethoven Violin Sonatas: History, Criticism, Performance, Urbana: University of Illinois Press, 2004, p. 60.

${ }^{63}$ Ibid., p. 57.

${ }^{64}$ Grove, rev. McVeigh, 'Bridgetower, George Polgreen'.
} 
sketched out. ${ }^{65}$ This clearly did not detract from Bridgetower's reading of the second movement, considering that they were asked to play an encore reading. ${ }^{66}$

This suggests that the performance in the Augarten was a success, despite the last minute rush to prepare performance copies. Beethoven's ability to extemporize from a hastily prepared sketch for the first movement seems nothing short of phenomenal - even if it was likely well-prepared in his head. In the analysis which follows this examination of the background to the sonata itself, I will examine the published score and investigate the manner in which the two instruments - and performers - interact.

\section{Overview of Beethoven's 'Kreutzer' Sonata}

\section{Movement One:}

Sonata Form

Introduction: Adagio Sostenuto, bars 1-18

Exposition: Presto, bars 19-193

Development: bars 194-343

Recapitulation: bars 344-517

Coda: bars 518-599.

\section{Movement Two:}

Andante and variations

1. Andante con Variazioni, 54 bars

2. Variation I, bars $55-81$

3. Variation II, bars $82-108$

${ }^{65}$ Thayer records this encounter as occurring at 4:30am. Alexander W. Thayer, ed. Elliot Forbes, Thayer's life of Beethoven, Vol. 1, Princeton: Princeton University Press, 1967, p. 332.

${ }^{66}$ Bridgetower notated his cadenza and left this account on a note inside his copy of the sonata. Thayer, Thayer's life of Beethoven, p. 333.

There was a similar occurrence involving Mozart's first performance of his K454 violin sonata with the violinist Regina Strinasacchi. The piano part was not able to be written out in time so Mozart performed from memory in front of Emperor Joseph II. Cliff Eisen and Simon Keefe (eds), The Cambridge Mozart Encyclopedia, Cambridge: Cambridge University Press, 2006, p. 474. 
4. Variation III, Minore, bars 109-135

5. Variation IV, Maggiore, bars 136-235. 100 bars, miniature cadenza prior to coda at bars 190-196

Movement Three:

Sonata Form

Exposition: Presto bars 1-177

Development: bars 178-290

Recapitulation: bars 291-454

Coda: bars 455-539

The 'Kreutzer' Sonata has a numerically balanced three movement structure. ${ }^{67}$ The 'Andante con Variazioni' second movement is the longest movement, as while it has the least bars the slower tempi and extensive repeat markings in Variations I to III - not to mention the final 100-bar extended variation - cause the temporal duration of the second movement to be approximately twice the length of the third movement, and fifty percent longer than the first movement. ${ }^{68}$

The significance of the third movement is not to be underrated: it was composed before the other two movements, initially as the final movement of Beethoven's Opus 30 No. $1 \mathrm{~A}$ major violin sonata, but removed as it was deemed too long and 'brilliant' and thus overbalanced the rest of the sonata. Extensive evidence to support this is presented by Ahn in her dissertation based on first-hand sketchbook research. Ahn shows how the first and second movements of the 'Kreutzer' Sonata were composed both rapidly and reasonably close together. ${ }^{69}$ As such the thematic quirks and material from the third movement were used to create the first two movements. I will conduct my own analysis of Beethoven's

\footnotetext{
${ }^{67}$ By this I mean that by numerical content alone the two outer movements are of very similar length. The performance lengths are likely to be somewhat different, but this is to be expected when the first movement contains an immense 599 bars!

${ }^{68}$ These figures are based on a performance of the sonata by the author in conjunction with Jun $\mathrm{He}$, a DMA candidate in Violin Performance at the New Zealand School of Music. This will be discussed in more detail later in this dissertation.

${ }^{69} \mathrm{Ahn}$, 'Genre, Style, and Compositional Procedure', pp. 3-9.
} 
'Kreutzer' Sonata, as it will aid in illuminating the observations I have made which will be explored in the following chapters: compositional differences between the original sonata and the two transcriptions; idiomatic reworking for the difference setting; and virtuosic and conversational thematic interplay between instruments. Given the convincing evidence in Ahn's dissertation that the third movement forms the kernel from which the rest of the sonata was constructed, I will adopt the model presented therein and examine the third movement first.

One of the predominant features of the 'Kreutzer' Sonata is the level of interplay between the two instruments. The dialogue between the violin and piano is on the level of a true partnership, and the difficulty of the music is such that it is in essence a concerto for two instruments. ${ }^{70}$ Throughout the sonata this takes on different forms, a few of which deserve particular attention: the purposeful slurred rising semitone in the first movement, its reappearance in the third movement and inversion in the second; ${ }^{.1}$ the swapping of themes and motives between the instruments both in answering phrases and within phrases themselves; and the manner with which both these techniques are combined to share the foreground between the two instruments evenly across the sonata.

To this end I will also explore the potential of featuring performative ethnography alongside my analysis, in pursuit of an approach that combines the performer's perspective with that of the analyst; in a more formal manner than - and yet inspired by - the way with which Philip Brett created a synthesis between the two dynamics in his reading of Schubert. ${ }^{72}$ It also draws on the embodied analysis of Le Guin's experiences and technical observations in her reading of a Boccherini cello sonata. ${ }^{73}$ In doing so I will attempt to further highlight both the interplay between the instruments (and by extension the performers) and the manner with which this relates directly to how different themes and motifs both unify and evade the perceptions of the listener. In order to maintain a visual distinction between the two mediums while linking the important passages in the

\footnotetext{
${ }^{70}$ This is evidenced in a literal sense by the subtitle which contains 'Quasi come d'un concerto'.

${ }^{71}$ The relationship between these motifs is explored by Reti, in Rudolph Reti, and Deryck Cooke, Thematic Patterns in Sonatas of Beethoven. New York: Macmillan, 1967, pp. 145-165.

72 Philip Brett, 'Piano Four-Hands: Schubert and the Performance of Gay Male Desire', $19^{\text {th }}$ Century Music, Vol. 21, No. 2, 1997, pp. 149-176.

${ }^{73}$ Elisabeth Le Guin, Boccherini's Body: An Essay in Carnal Musicology, Berkeley: University of California Press, 2005, pp. 14-37.
} 
performative ethnography to the analysis, the performative ethnography will be presented in footnotes. ${ }^{74}$ The reason I have elected to divide the two readings in this manner is simply to keep them discrete; this allows the embodied reading to interact with the analysis in such a way as to call attention to some of the emotive moments while making it clear where one reading ends and the other begins. ${ }^{75}$

While this layout of the analysis has the potential to create confusion due to the irregular order of the movements in the analysis, it is intended to try and strike a balance between conventional analysis and performative perspective so that it is clear where each idea originated, and how they interact. ${ }^{76}$

\footnotetext{
${ }^{74}$ Background details for the Performative Ethnography:

Performers: piano: myself; violin: Jun He (a DMA candidate looking at $18^{\text {th }} / 19^{\text {th }}$ century violin techniques at NZSM performing the 'Kreutzer' Sonata as part of her mid-year recital project involving period bow-use.

Instruments used: Modern Steinway grand piano (model D) and modern violin The ethnography features the performance reading of 'Kreutzer' from June 2012.

${ }^{75}$ Cook discusses pluralism in modern analysis (and the capturing of multiple experiences or types of 'music view' through analysis and performativity amongst other ideas) in Nicholas Cook, 'Analysing Performance and Performing Analysis', in Nicholas Cook and Mark Everist (eds.), Rethinking Music. Oxford: Oxford University Press, 1999, pp. 257-261.

${ }^{76}$ This combines both elements of the 'drastic' and 'gnostic' which Abbate presents as problematic for the performer in their decision-making process. See Carolyn Abbate, 'MusicDrastic or Gnostic?', Critical Inquiry, Vol. 30, No. 3, 2004, pp. 510-415.
} 


\section{Analysis of Beethoven's 'Kreutzer' Sonata}

\section{Third Movement}

The 'Kreutzer', in many ways, conforms to the sonata-form model that was only theorized and described decades after Beethoven's compositions. ${ }^{77}$ This is for a number of reasons, foremost of which is the use of two themes in the opening section: the first (1P, example 1.1) shown by the violin entry in bars $2-9$; the second (1S, example 1.3 ) by the violin in bars 62-69. This second theme is foreshadowed by both instruments (2P, example 1.2) in bars $28-35$, but still in the tonic. The development section transitions immediately away from the tonic (directly following the repeat of the exposition, signposting the transitional border. The recapitulation features standard sonata form treatment of both the primary and secondary theme (both in tonic), and from there a coda.

\section{Example 1.1: Theme 1P}

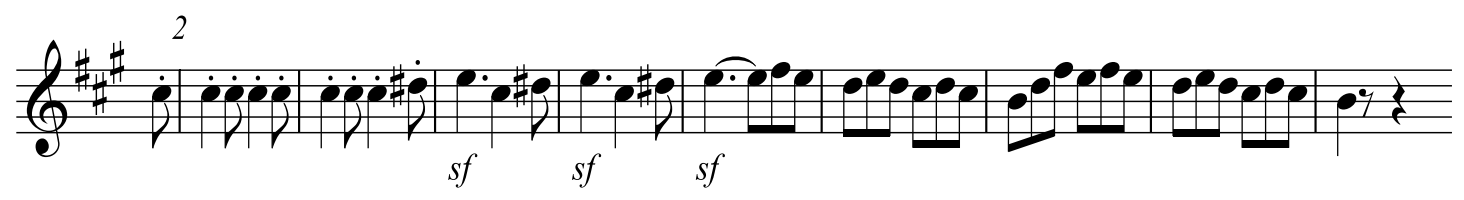

The overriding motivic feature of this movement is the upbeat quaver downbeat crotchet rhythmic unit. This forms the basis of the first theme, and is reversed for the second theme. The polyphonic opening is constructed largely with the use of paired voices, dividing 1P into four phrases as follows: violin with left hand; right hand with violin; both hands of the piano; violin and both hands of the piano. This creates what starts as a reasonably tightly woven texture with a major third between entries in the first and second phrases, spreading to a compound sixth in the shorter third phrase, and ending up with the tightly woven running thirds from the second half of the motif combined with a bass-line for the fourth phrase. These four phrases establish the brillante feeling of the movement, and delay the arrival of the confirming A major perfect authentic cadence (PAC) until bar $28 .^{78}$

This A major tonality is implied by the first doubled octave chord - a major third above the

${ }^{77}$ Charles Rosen, The Classical Style: Haydn, Mozart, Beethoven, New York: Viking, 1971, p.30.

${ }^{78}$ William Caplin, Classical Form: A Theory of Formal Functions for the Instrumental Music of Haydn, Mozart and Beethoven, New York: Oxford University Press, 1998, pp. 253 and 256. 
final chord in the second movement, which in the knowledge that it was actually written afterward implies a conscious decision to brighten the timbre of the third movement and adds to the agitated mood - but not confirmed until the PAC in bar $28 .^{79}$ Instead in the intervening bars it shifts around several keys in sequence - often with a pseudo-stretto entry from the next pair of voices, creating extra ambiguity as to the key. All four phrases begin with the subdominant in one voice and the submediant in the other, although this is less clear in the fourth phrase until it becomes apparent the relative motion of the two notes is inverted to the previous three phrases and using the key from the third phrase as a pivot into the subdominant of the movement, rather than just as a transitory chord before shifting to the dominant minor; the fourth rising chromatically to the sixth instead of falling to the tonic, and the sixth falling first to the third and then finally to the tonic. This sequence features a chromatic alteration in the second half of phrases one, two and four; said alteration forms the beginning of each modulation.

Following this PAC the standard tonic-dominant harmonies expected in the exposition take hold. The secondary motif in the primary tonal area (2P) signals the introduction of material that will form the second theme (1S), and through a modulatory sequence of secondary dominants (bar 42-51) the dominant of the dominant is reached - and confirmed briefly with a V-I cadence of its own - until through an extended repetition of this B major chord (bars 52-60) it becomes apparent that it is a tension-building device, designed to catapult the movement into the dominant (E major).

\footnotetext{
${ }^{79}$ This chord follows on from the peaceful conclusion of the second movement. As such it explodes out of the silence created by the descending $\mathrm{F}$ major arpeggio in the piano - that softens to pianissimo by the bottom - with powerful fortissimo force; this sets up not only the tonal centre of the movement, but also announces the heroic nature of the writing. I really revel in the sheer power available to me with the modern Steinway D with this chord, forcing Jun to wait for the sound to decay before she starts the Presto proper. In rehearsal we practiced a lively yet controlled pace. However, today Jun takes off at a breathless speed, combining pace with a vivacity perhaps triggered by a combination of that massive A major chord and the adrenaline created by the beginning of the final movement in an hour-long recital. Her opening phrase here reveals the rising semitone motif, which by this stage in the recital is familiar to the audience but from our research Jun and I are aware that this was actually the basis for construction of the earlier two movements. In one sense it is a relief to finally get to this motif; in another it signals to us that the end of our performance of this monstrous Sonata is in sight.

Bar 28 confirms the A major tonality, and brings back the heroic nature of the opening chord at the same time. This eight bar section is one of my favourite moments in 'Kreutzer', as it has a bright exuberant tone which matches the colours of A major when played after the first two movements. The arpeggios and broken chords in both parts create challenges of rhythm as we pass them between us, and by bar 52 we have settled on the tempo-a touch slower but with all of the life of the opening pace selected by Jun.
} 


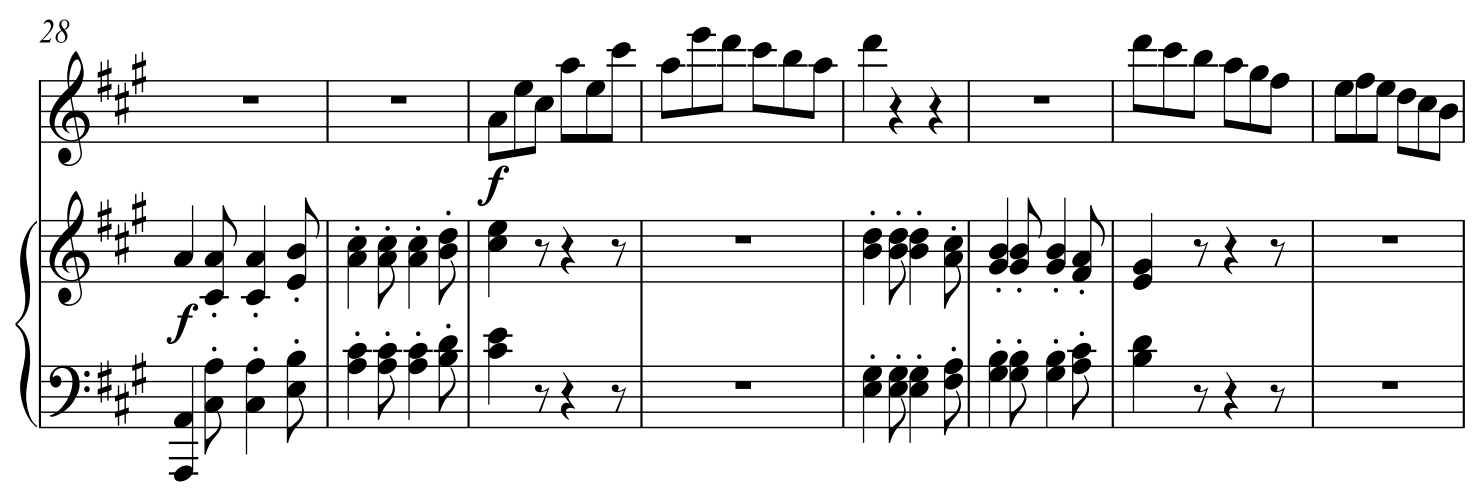

Example 1.3: Theme 1S

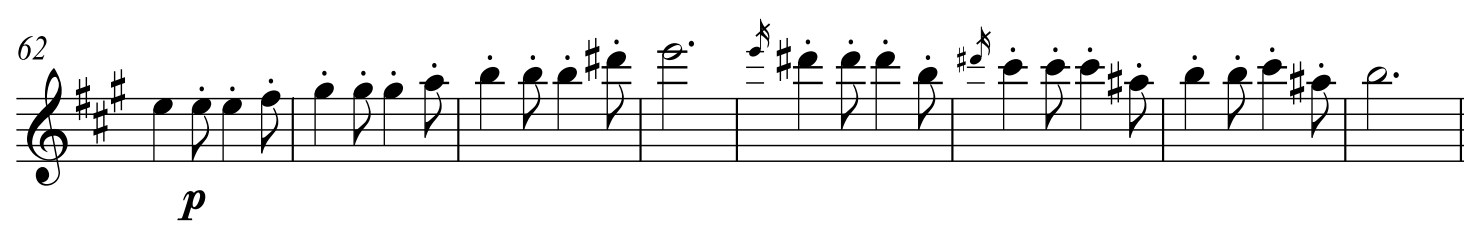

Even here in the secondary tonal area however the constant harmonic shifts continue.

Parallel mode shifts highlight shifts between tonic and dominant (bars 62-70 show an E major tonic move through an E minor chord to their B major dominant chord) and a sudden harmonic shift up a minor third from B major to D major continue to create tension, ensuring that each phrase contains a harmonic crescendo. This pattern continues through to the beginning of a long transition into the closing material for the exposition at the upbeat to bar 100, where the key of E major is firmly re-established, ${ }^{80}$ and aside from some chromatic neighbour and passing notes in sequential runs between bars 108 and $117,{ }^{81}$ these tonic-dominant harmonies are adhered to firmly until the closing material; the D natural at bar 158 heralding the E's shift to the dominant, the pedal alternating octave $\mathrm{E}$ in the right hand of the piano creating the tension to thrust the music into an undulating cyclic pattern which finally resolves into a descending A major scale beginning on the

\footnotetext{
${ }^{80}$ The swirling figure here is quite technically demanding for my left hand at the best of times when it is used in sequence. However, at the tempo Jun is maintaining it creates a panic-filled sense of impossibility and what ends up coming out is the figure in the right-hand with most of the left-hand notes missing. As Jun is playing long, assertive dotted minims with sforzandi to match my downbeats (in a mirror of my double octaves six bars earlier) we set about recreating the heroism from the opening movement, before the section in $2 / 4$ that recalls the figure from the Adagio introduction to the first movement.

${ }^{81}$ This pattern will be looked at in more detail in Chapter Three, as the manner with which Czerny chooses to adapt this for four-hands causes technical problems for the secondo.
} 
subdominant and setting up first the repeat of the exposition and then the development section.

An extra point of interest near the end of the exposition is the slower $2 / 4$ sections in amongst the perpetual motion of the $6 / 8$ quaver crotchet and crotchet quaver rhythmic units, in bars 127-147. These feature the following seven bar progression: E major: vi IV $I^{6}$ ii_V I; with some repetition of the four last bars to augment the second appearance of the phrase. This leads into a dominant chord, four bars in length (bars 148-151) with a pedal trill on the supertonic (F sharp), heralding the closing section of the exposition. ${ }^{82}$ The final segment from bar 166 will be investigated in both of the following chapters; the manner with which the contrary motion scales are adapted for the different settings show an interesting transformation of the conversation which is largely handled between the hands of the piano in the original sonata.

The development section is based on the second theme. It moves through C major, D minor, and E minor in sequence, then in bars 206-213 travels down the circle of fifths to reach $\mathrm{F}$ major - emphasised by a sixteen bar alternating tonic pedal. ${ }^{83}$ Following this brief period of stability, a succession of short one-bar snippets from the head of the second theme rise slowly up in pitch, before inverting their motion and outlining an E major dominant seventh chord in reverse. This gives way to a section which is essentially an extended pedal E from bar 245; while this section which moves through a both major and minor modes and another circle of fifths on the way to the recapitulation, it flirts with an $\mathrm{E}$ pedal until it definitively arrives at bar 267 where it becomes clear that it is now functioning as a dominant pedal. Beethoven has one last surprise in store: the E sharp

\footnotetext{
${ }^{82}$ The end of this section going in to the trill slowly winds down and creates a kind of stasis right before the trill. I take a little extra time getting to this trill, creating a sense of confusion as to what is about to happen. This adds excitement to the revival of pace and life as the second theme returns to finish the exposition. As in the first movement, we play the repeat to balance the structure of the third movement. Jun catches the end of my descending A major scale - the multitude of times we rehearsed this transition paying off in performance.

${ }^{83}$ The links between sequences always feel rather dramatic; this is probably influenced by the spike in technical demands for my fingers here, making sure the articulation is precise and clear to match Jun's crisp bowstrokes. The F major pedal that starts in bar 214 is another of my favourite moments in the sonata, for many of the same reasons as bar 28: the vibrant alternating octave bass underpinning the exciting off-beat chordal sforzandi across both instruments generate an electric heroic feeling that pulsates underneath my fingers and gives them another reserve of energy.
} 
which becomes a chromatic passing note to break the pedal, as he uses chord vi (F sharp minor) to open the recapitulation. ${ }^{84}$

Thus the recapitulation opens with the same evasiveness as the exposition. However, it gradually becomes clear that Beethoven is giving us first the dominant then the tonic $(\mathrm{E}$ then A) while masking it with the use of the submediant and supertonic at the opening of the phrases; this is confirmed by the writing in bars 307-312 which directly mirrors the opening after the textural complexity from having three separate voices functioning in tandem rather than the alternating pairs from bar 2-26. The rest of this section is functionally the same as the exposition but relative to the tonic (rather than having $1 \mathrm{~S}$ in the dominant). ${ }^{85,86}$

The transition to the coda is a mixture of special timbre echoing the opening and bizarre juxtaposition of tempi within the motif itself. Alternating Adagio and Tempo I fragment these phrases, dividing the motif by head and tail: the head taking the Adagio and tail being marked Tempo I. ${ }^{87}$ This section is homophonic, like the opening of the recapitulation instead of the exposition. The closing cadential section from bar 525 onwards uses the head of the motif from the second tonal area to generate the bindings for the end of the sonata, and almost entirely uses the tonic; brief snippets of dominant harmony occur in half-bar bursts at the end of each four bar phrase (bars 528 and 532) and then two bar subphrase (bars 534 and 536) as Beethoven inserts a pseudo-harmonic crescendo to drive towards the end. ${ }^{88}$

\footnotetext{
${ }^{84}$ After the static, circular feeling from the section this rising semitone closes, we try to make sure that the E-sharp is as special as possible - I place it clearly and deliberately, and Jun gives me enough time to do so by matching her C-sharp with it. While we calando we make sure that the feeling of the rising semitones is preserved by playing the upbeat to the recapitulation in time.

${ }^{85}$ Bars 379-398 are extremely technically challenging. While this section was almost manageable in the exposition, now that we are nearing the end of the performance my left hand has almost run out of energy. The frenetic pace that Jun is keeping up means that my left hand is no longer capable of playing the swirling figure in bars 391-394; it manages the first note only before seizing up.

${ }^{86} \mathrm{Ahn}$ talks about a paste-over in the original edition where there is a slight transposition error from what was probably a literal transposition by a copyist that was subsequently altered; this involved the voicing of the left hand in the piano from bars 433-443.

${ }^{87}$ We work hard to make sure that the two halves of this figure flow together, by playing the Adagio at about half the tempo of the surrounding passages so that the surprising mood shifts are surprises but do not mentally jar the listener. This also allows us to launch into the coda at the same breathless pace that Jun opened the movement with.

${ }^{88}$ The nineteen bars of bright dominant-tonic cadential movement in A major (which are
} 


\section{First Movement}

The key relationship between this movement and the third movement is that of parallel mode - A minor first movement, A major third movement. However, this is not immediately obvious as the first four bars of the opening 'Adagio sostenuto' introduction are in the major mode. ${ }^{89}$ The response from the piano in bars 5-8 is in A minor, and ends up on the subtonic (V/bVII bVII in bar 8$).{ }^{90}$ This signals a period of ambiguity with a series of quick shifts through $\mathrm{C}$ major (bar 9) and E major (bars 10-12) then back to $\mathrm{G}$ major (the subtonic). Even here it does not remain stable, shifting between G major and minor; falling to the third in the violin part and rising to the third in the middle voice of the piano. From here the mood darkens further by falling to D minor and oscillating with fairly disjointed chords between dominant and tonic. ${ }^{91}$ What this does not immediately make clear is that the end of the introduction is emphasising what will be the subdominant of the movement itself; the octave As in the right hand of the piano feel like the dominant they are, and as such add unrest and a sense of unresolved tension to the end of the introduction rather than establishing the tonal centre for the movement. However, what this allows Beethoven to do is begin the Presto on the subdominant and create the rising semitone slur on the upbeat in the violin part, which becomes a key motivic feature of the movement. ${ }^{92}$

The first theme in the exposition (1P, example 1.4) occurs right from the outset at the

preceded with an ascending chromatic figure to the dominant) bring back the heroism that recurs throughout the movement. After the emotional turmoil of the sonata this provides performer and listener both with a palpable sense of relief as the piano descends the final $A$ major arpeggio; the final triple-octave $A$ - while it feels like an ending, it also feels like an anticlimactic way to finish such a grotesque and fascinating sonata.

${ }^{89}$ Our anticipation of the opening began offstage. The Adagio features four of the most difficult bars for the violinist - Jun made several attempts backstage before we began. Pulling the third finger across from the $E$ string to $A$ string to create the rising semitone outlining $D$ major when surrounded by shifting and double/triple stopping is extremely awkward.

${ }^{90}$ My answering phrase subverts the tonality and twists it into $D$ minor. In an attempt to sympathise with the violin I create a lot of line and emphasise the falling semitone between $F$ and $\mathrm{E}$ in the bass, $\mathrm{A}$ and $\mathrm{G}$ sharp in the right. (This appears later in the second movement opening).

${ }^{91}$ The disjointed Adagio becomes almost breathless, and I spend much of the time watching Jun's bow and placing my semiquavers precisely with the bite of the hairs, breathing only after each rising octave in the right hand. We decay into my repeated $A$, which feels unfinished - as if we really are in $\mathrm{D}$ minor.

${ }^{92}$ The Adagio will be looked at in detail in both of the following chapters; both transcriptions give this an almost symphonic texture, and the string quintet in particular has a very different set of interactions between performers. 
upbeat to bar 19 in the violin part. As previously mentioned it begins on the subdominant and ends on the relative major. ${ }^{93}$ The answering phrase features the piano playing the theme, and again ends on the relative major, this time with an extensive broken chord. ${ }^{94} \mathrm{~A}$ transitional passage follows which shifts through an F dominant seventh, B minor, E flat minor, and then a diminished triad based on E and a diminished seventh based on G sharp to lead back to A minor and establish it as the tonal centre. This is underpinned by a chromatic ascending bass line from $\mathrm{A}$ through to $\mathrm{C}$, at the same time as the violin ascends chromatically from $\mathrm{E}$ to $\mathrm{A}$ at one pitch per bar in a figure that will become important for the recapitulation; the harmonies then shift through iv ${ }^{6} \mathrm{~V}$ and a PAC occurs to reassert A minor in bar 45 in the second motif for the primary tonal area (2P, example 1.5). This is constructed with the use of an alternating pair of lines, one with the theme and the other harmonizing the octave above on either the tonic (antecedent phrase, bars 45-48) or dominant (consequent phrase, bars 49-52). ${ }^{95}$

Example 1.4: Theme 1P

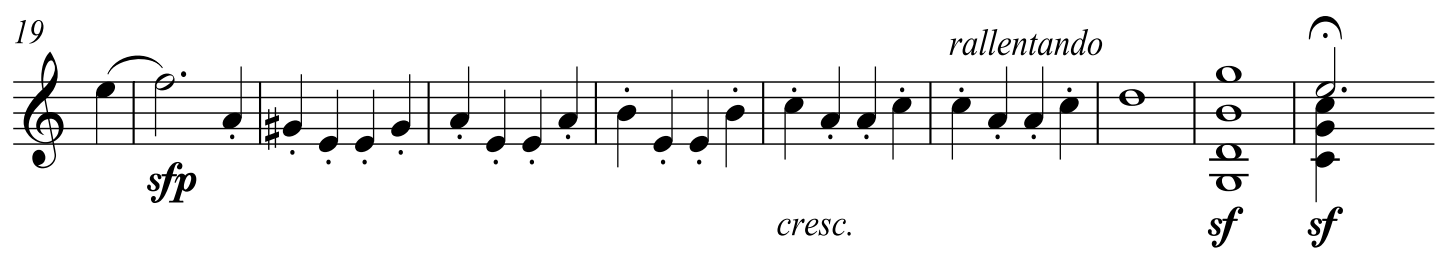

The transition to the secondary tonal area begins in bar 61 . This consists of material adapted from $2 \mathrm{P}$, and shifts first in four bar groups from A minor through relative major $\mathrm{C}$

\footnotetext{
${ }^{93}$ The Presto opens with a sudden D minor chord. However, Jun's rising semitone subverts the tonality immediately and causes it to feel unsettled instead of as if it has arrived somewhere. The staccato crotchets in her part instead demand A minor, and my chords feel as if they are humouring her. I do my best to emulate her attack in my answering phrase, making a big deal out of the rising semitone by placing the downbeat chord slightly.

${ }^{94}$ The miniature cadenza feels like a moment of virtuoso brilliance, and I really play with the rhythm. Her upbeat to an E-F oscillating pattern demands an immediate return to the previous strict tempo, which I attempt to maintain with my constant quavers. This moment will be looked at in more detail in the four-hands chapter.

${ }^{95}$ At bar 45 it finally feels as though we agree on something, with the answering figures and the ability to articulate them in a similar fashion without either of us having to do something extra with them. I feel as though I am really driving the flow at this point, and get a little carried away into the ascending pattern at bar 61 , so have to hold it back when it feels as though it becomes more static upon the appearance of the pedal - Jun has none of this and revives the tempo with her trill by shortening the finishing crotchets.
} 
to E minor, at which point the harmony then begins ascending chromatically towards the dominant of $\mathrm{E}$ minor (B major); it highlights this with a diminished chord with $\mathrm{C}$ in the bass followed by V I [ $\left.\operatorname{dim}^{7}\right] \mathrm{V}$ in $\mathrm{E}$ minor. The move to the dominant minor is underlined by a dominant pedal across bars $81-89$, further emphasised by a pseudo-dynamic crescendo with the sforzandi initially occurring on the second beat in bars 81-85 and then on both beats of bars 86-88. The quintet arrangement of this section will be looked at in more detail in the following chapter.

Example 1.5: Theme 2P
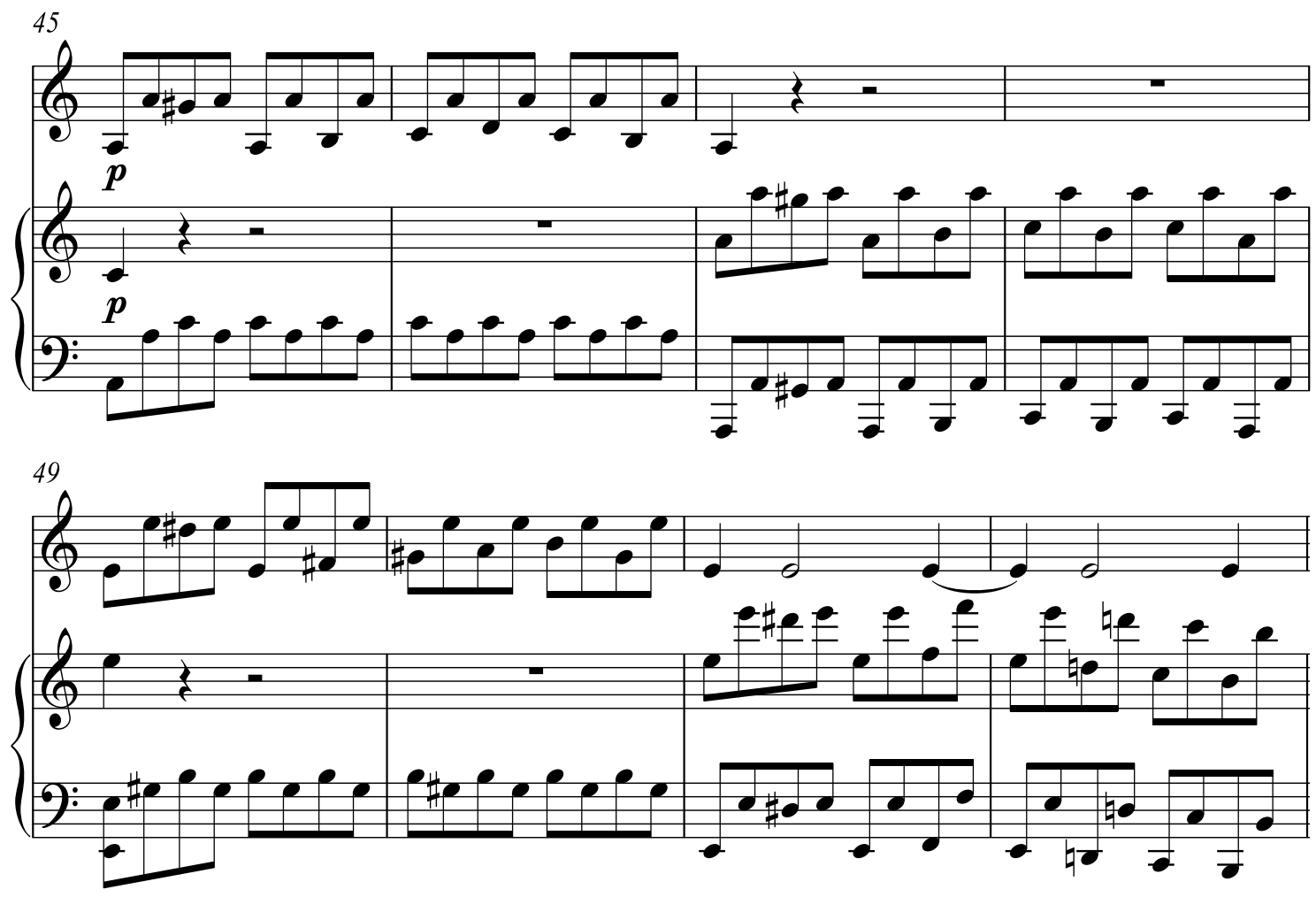

The second tonal area (and its first theme, 1S, example 1.6) appears in bar 91. Again Beethoven chooses to present a slightly ambiguous harmonic structure, although this time it is based upon a mode shift rather than key changes - the initial entry is in E major, while the second entry (bars 107-116) is in the parallel minor. This theme presents a marked contrast to the previous material, with what is essentially a four voice chorale (with one of the piano lines doubled throughout instead of a five voice chorale). ${ }^{96}$ The transitional

\footnotetext{
${ }^{96}$ The second theme always sparks disagreement. I want to play it in a slightly slower tempo and enjoy the reprieve from the agitation of the Presto. Jun does not. She wants to sing her line
} 
material from bar 117 jerks the mood back into the Presto, shifting through the relative major back to $\mathrm{E}$ minor in sequence by bar 121 . The second beats are again emphasised with sforzandi. This section will be investigated in both of the following chapters; each arrangement has an idiomatic way to deal with the chorale which is quite fascinating.

Example 1.6: Theme 1S

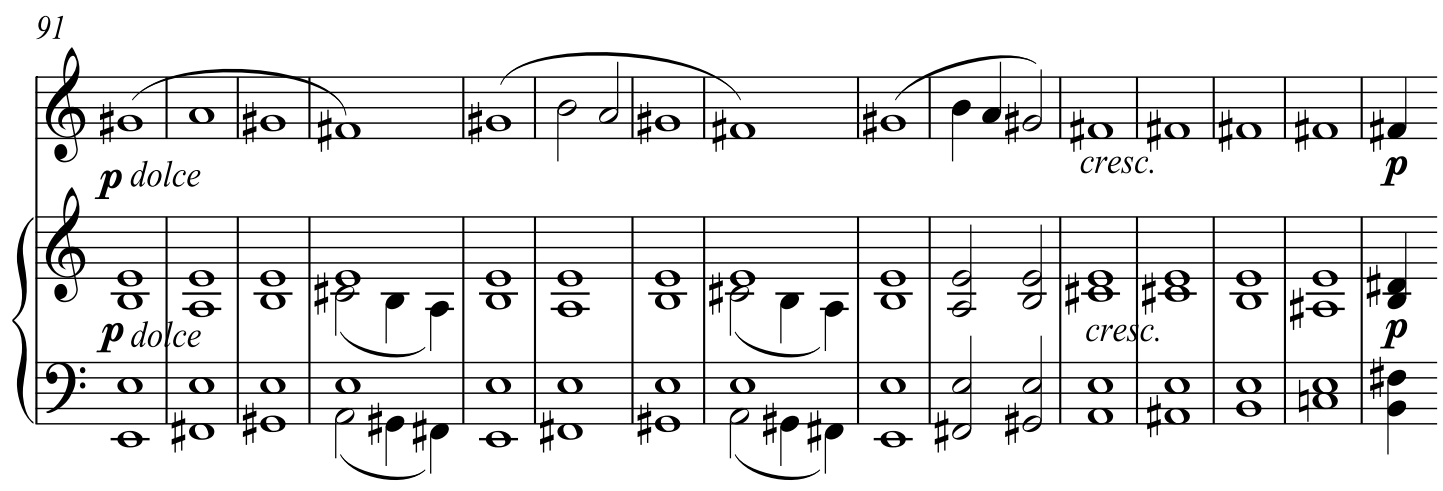

2S (example 1.7), firmly in E minor, arrives in bars 144-156. The rising semitone upbeat motif from 1P forms the basis of this theme, and the first statement occurs in the piano. ${ }^{97}$ The violin repeats the theme in bars 156-167; there is a repeat of the last four bars in bars 168-171, which then repeat again (bars 172-175) but with modified harmonies and figuration (alternating octaves in the piano for just the theme itself without just a bass line instead of fully-realised broken chords) ${ }^{98}$ before the closing section of the exposition begins in bar 176. This closing section $1 \mathrm{~K}$ is based upon $2 \mathrm{P}$, although it is now in $\mathrm{E}$ minor, and features a sforzando on every downbeat from bar 184 to bar 189. Interestingly

through and keep all the momentum from the earlier passage. In an attempt to compromise, I pay extra attention to the voicing of the chords and take time over my interjection bars 105/6; deliberately placing the sforzando in b. 105. This allows me to prepare the parallel minor and change colour for the answering phrase.

${ }^{97} 2 \mathrm{~S}$ - the rising semitone appears first in my right hand. I slur these repeated D-sharp/E pairs with my fingers (1-1 and 4-4) in order to create a stronger link and emphasis their relationship (and also to mimic the execution from a lighter action). At the same time Jun plays a difficult sequence of triple and quadruple-stopped chords pizzicato and forte, in a military manner. When Jun plays these semitone pairs in the same fashion for the answering phrase, I have to articulate the left-hand argumentative offbeat pair with separate fingers (mostly 3-2) in order to match as we play the theme out of line with each other.

${ }^{98}$ This closing sequence is not technically difficult, but the alternating quaver figures that shift between instruments are hard to line up exactly when attempting to pass them between instruments. It marks the first place a carefully measured approach is taken in the performance after settling the tempo directly after the miniature cadenza in bar 37. 
Beethoven ends the exposition on an A minor chord; while this is the tonic, it is also the subdominant of $\mathrm{E}$ minor which has parallels to the harmonic function of the opening chord of the exposition: D minor, which is the subdominant of A minor. ${ }^{99}$

Example 1.7: Theme 2S
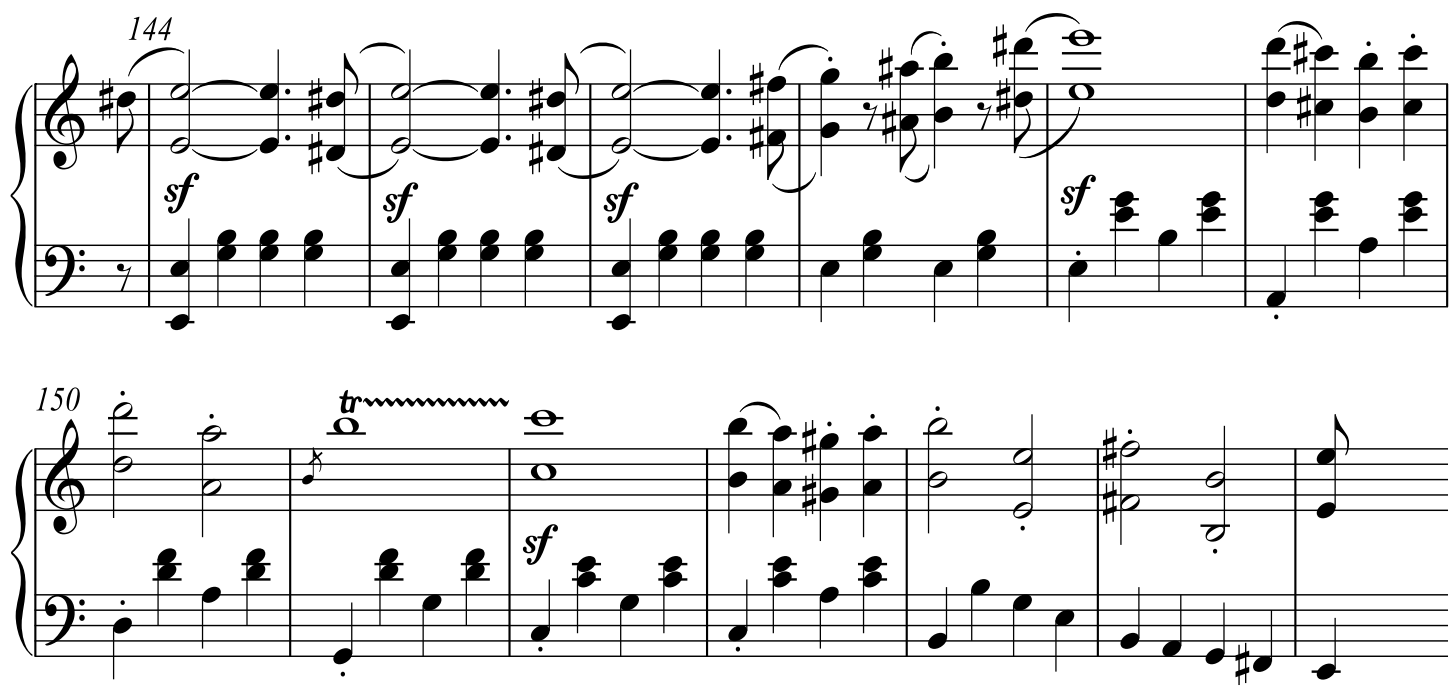

The development opens with a reprisal of $2 \mathrm{~S}$ from the piano, this time in $\mathrm{F}$ major. Being the subdominant of the relative major this immediately turns the tension from the rather forceful cadential section at the end of the exposition into a relaxed mood, foreshadowing the opening theme in the second movement. ${ }^{100}$ This brief respite does not last long; a mere six bars later the E flat at the upper limits of the keyboard followed by the chromatic rising bass line a bar later in bar 200 begins a rapid descent back to the ominous minor mode of the initial $2 \mathrm{~S}$ entry. This time however the theme takes on the darker colours of $\mathrm{G}$ minor at bar 202, and is marked piano in the original - a distinct contrast to the much stronger earlier version which was also littered with sforzandi. The addition of a driving Alberti figure in the right-hand of the piano adds momentum and propels the development into a

\footnotetext{
${ }^{99}$ This A minor chord allows us to choose between repeating the exposition and moving to the development, unlike some of Beethoven's sonatas there is no long first time bar - both first and second time bars are almost exactly the same (the second time bar contains the quaver upbeat for the development). We repeat, and while we are now more comfortable within the performance than when we started, we highlight the dramatic moments a little more for the second time through the exposition.

${ }^{100}$ I relax the pace to show the colour $\mathrm{F}$ major creates in relation to the earlier turmoil - it feels to me like a momentary shelter from the surrounding storm - but then I accelerate using the descending semitone in bar 199 as a springboard, so that when Jun enters with her rising semitone upbeat to bar 202 we are back in tempo.
} 
series of stunning chromatic shifts: E flat major in bars 210-214; and a falling whole tone sequence of secondary dominant/tonicisation two-bar phrases in $\mathrm{D}$ minor, $\mathrm{C}$ minor, $\mathrm{B}$ flat minor, A flat major; then $\mathrm{G}$ minor again into $\mathrm{F}$ minor and then a mixed mode $\mathrm{C}$ functioning as a dominant to begin the next idea. ${ }^{101}$

Still based on 2S, bars 226-257 (example 1.8) feature some of the most taxing piano writing in the entire sonata. The alternating thirds and sixths move between contrary motion (see bars 230-233) and the quaver figure against ascending octave leaps (see bars 234-236). Throughout this section the rising semitone upbeat figure occurs in one of the voices throughout (unless an octave leap is present instead). These bars utilise a falling circle of fifths from F minor through to A flat major in bar 242, at which point a couple of two-bar secondary dominant/tonic shifts occur without breaking the linear motion of the figure. Bars 246-249 emulate this movement, first in B flat minor, then in A flat major. Yet another version of the same alternating figure against $2 \mathrm{~S}$ appears in bars 250-257, which feature A flat major and F minor; the goal however is an appearance of $2 \mathrm{~S}$ in a format rather like the original statement in D flat major. ${ }^{102}$ This section will be investigated in both of the following chapters, as the complexity and difficulties are dealt with in very different ways due to the nature of the new mediums.

Bar 258 bears a similar function to that of the four bars at the beginning of the development in that it serves as a brief respite from the tension and tumult of the surrounding harmonic and textural swirls. A very rigid and homophonic chord and melody

\footnotetext{
${ }^{101}$ This sequence always strikes me as heroic. Double octaves in both hands of the piano (except for leading-note trills in the bass, highlighting the rising semitone) and broken chords with string crossing; Jun plays these deliberately: mostly separate and off the string, the combination of this with the piano conjures images of a purposeful march.

${ }^{102}$ The entire section from bar 226-257 is incredibly difficult, both technically and in terms of coordination between performers. The combination of rising semitone figures and contrary motion quavers between two parts creates the impression of a constant push throughout the section with the arrival of $D$ flat major as the goal. No matter how many times we rehearsed this it never felt comfortable, and the performance was no exception - the challenges presented by simple concepts such as evenness and rhythmic consistency went out the window under extra pressure to the point where it felt as if we were relying on the mechanics of muscle memory and a onein-a-bar pulse to keep us together and make it to the other end. D flat major was a relief.
} 

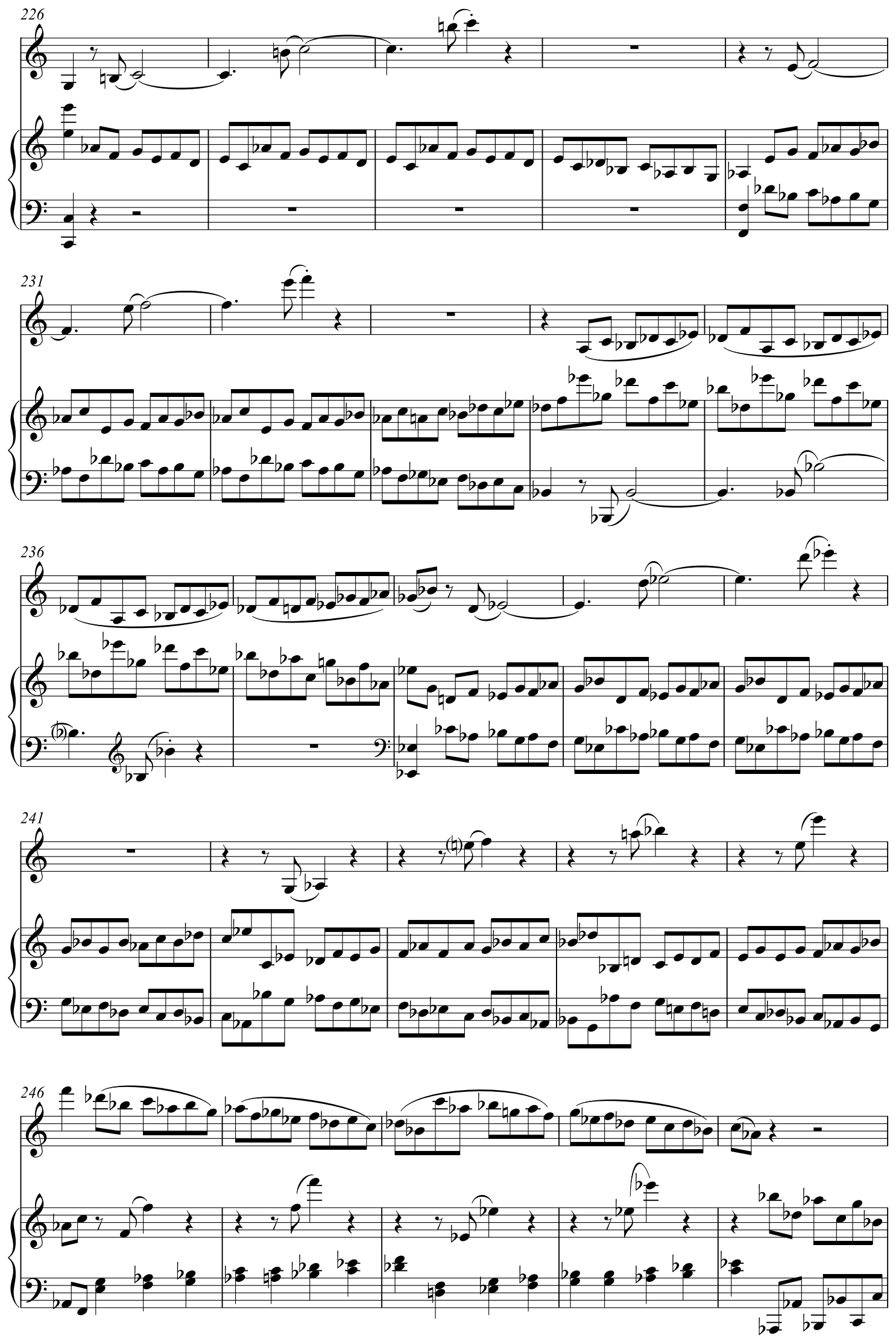

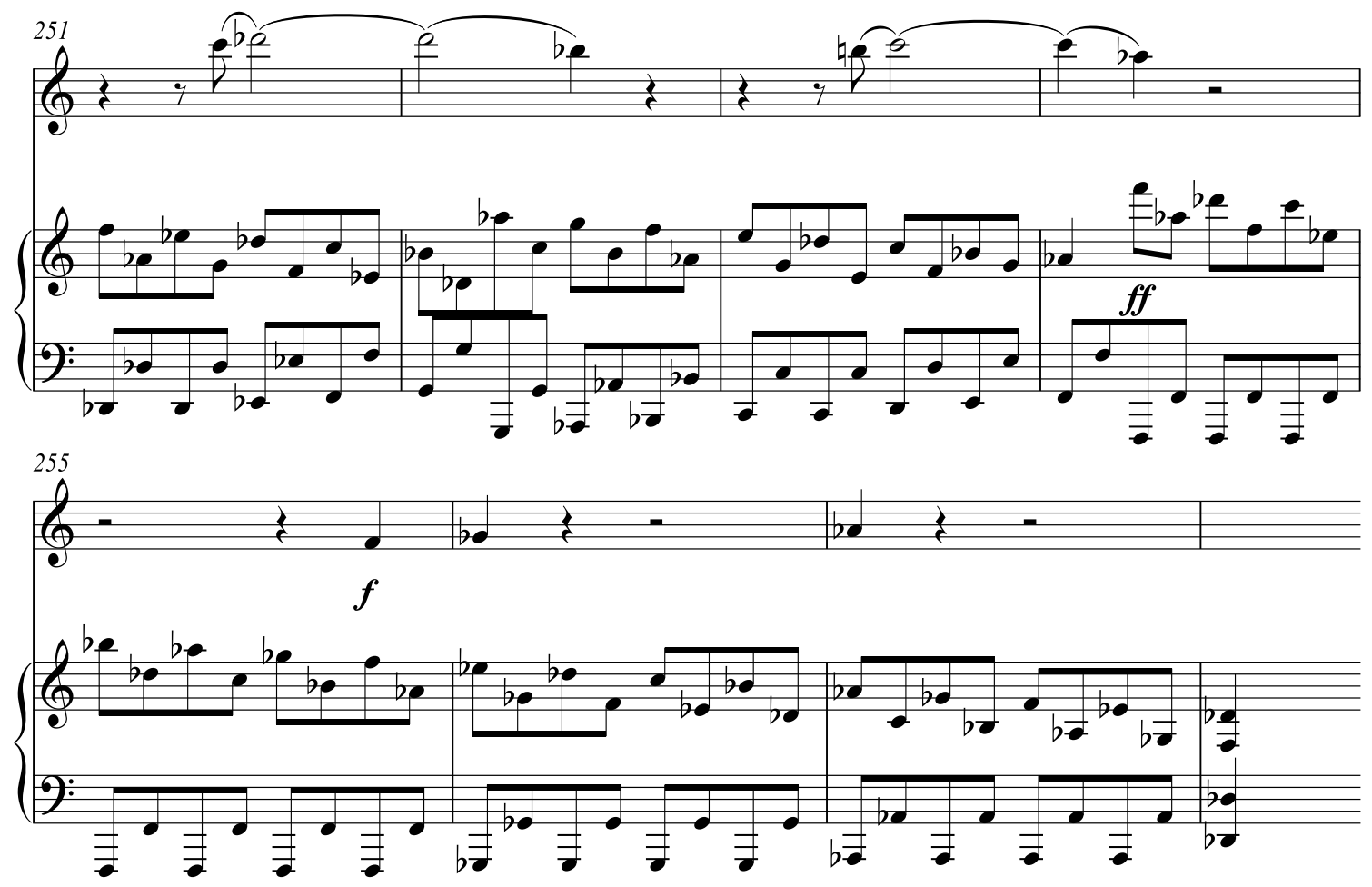

Above - Example 1.8: Bars 226-257

texture allows this island of calm to exist for the first six bars, but by bar 265 an imitative exchange begins between violin and piano with the melody answering in two short fourbar overlapping phrases before a unison third two-bar sub-phrase (bar 268-269) thrusts the music back into chaos.

The section from bar 270-299 adopts a new pattern based upon 2P that features two eightbar antecedent consequent phrases (bars 270-285), two four bar phrases based upon the antecedent (bars 286-293), and then two three bar phrases again in an antecedent consequent patter but with unison alternating octaves as the point of difference. These phrases all follow a gradual harmonic crescendo using an ascending circle of fifths starting in $\mathrm{F}$ minor and ending back in A minor, to begin the transition back to the tonic and the recapitulation. ${ }^{103}$

${ }^{103}$ Bar 270 sees a return of the heroic feeling; structured dominant-tonic alternation with plenty of leading notes in sequence combined with our staccato and sforzandi bring back the purposeful march mentioned earlier in the development. This builds until the extremely assertive triple-octave statement of the motif between both instruments; while this is not particularly technically challenging in comparison to the earlier section, it allows us to make it appear and feel like we are working extremely hard and wrestling with the emotional turmoil 
This transition makes extensive use of the rising semitone; the violin shifts off and onto the dominant with dramatic register skips over auxiliary dominant $6 / 4$ chords in bars 300-304, and then descends chromatically to a G sharp in bar 308: the leading note and also the raised third in the pedal $\mathrm{E}^{7}$ chord the piano uses bars 308-313 to stall the transition and build tension. This sequence of events is then repeated with the instrumental roles reversed, while at the same time using the G sharp as the trigger for the rising semitone to set up an eventual dominant $\mathrm{A}^{7}$ pedal; thus ensuring the recapitulation does not begin in the tonic, but rather with $1 \mathrm{P}$ in the subdominant using $\mathrm{C}$ sharp as the start of the theme as it did in the exposition.

However the recapitulation does not begin in bar 323/4 as the dominant seventh chord in bar 322 suggests. Beethoven inserts yet another evasion of resolution here: 1P appears, but the $\mathrm{G}$ minor tonality of the opening (recall the subdominant nature of the exposition $1 \mathrm{P}$ ) suggests a D minor section rather than the anticipated A minor. ${ }^{104}$ The piano sticks with this key, complete with the rising semitones A-B flat in the right hand and F sharp-G in the left hand, attempting to ground and strengthen the harmonic centre with repeated leading note-tonic and implied V-I movement. However, the re-entry of the violin in bar 337 undermines this with a D-E flat rising figure, warping the piano's figure into a V-I statement of E flat major. The two then shift up a semitone to alternating V-I figures in $\mathrm{F}$ major, with a more decisive V-I root position movement in the bass of the piano complete with both rhythmic and dynamic crescendi (bars 339-343), before an abrupt chromatic alteration to a dominant seventh A chord signals a return to A minor (via the expected subdominant $\mathrm{D}$ minor beginning of $1 \mathrm{P})$.

The actual recapitulation features a few deviations from the "restatement of exposition

being described by the music. This turmoil reaches a somewhat subdued peak in the transitional section, but the semitone - mostly rising, but now appearing also in inversion to underline the harmonic and emotional energy decay - undermines this and we both choose to emphasise this: Jun makes their pitches closer together, and I phrase them more obviously than is perhaps necessary.

${ }^{104}$ I use both una corda and sostenuto to colour bar 324, and wait for the $\mathrm{G}$ minor chord to decay before continuing. The appearance of this chord as the subdominant is completely unexpected and I want to underline this; I also play with what would have been the very bass of Beethoven's instrument by allowing the bass $\mathrm{G}$ to present some menace to what would have otherwise been a very serene chord, rising semitone upbeat notwithstanding. The cadence into $F$ major at bar 334 seems wistful in comparison. 
themes in primary tonal area" model. The first of these is the replacement of the pseudocadenza from bar 35 with an attempted confirmation of $\mathrm{C}$ major - with the use of a PAC which is immediately subverted by shifting the cadence with sequential movement up a third back to a E major chord in bar 360; this same chord is repeated by the piano which flows into the rising semitone figure reappears in a similar manner to that shown in bar 37, this time to solidify the primary tonal area. ${ }^{105}$

The next deviation is the expected alteration to the transitional passage from bar 61. Bar 382 is in A minor, mirroring bar $61 .{ }^{106}$ However, the rising B major broken chord from bar 67 turns instead of continuing upwards and a sequential chromatic pattern happens, moving up through secondary dominant/tonicisation figures and a harmonic crescendo; this continues until the violin inserts an insistent repeated $\mathrm{E}$ octave which eventually leads the piano to the same diminished seventh figure - built on F natural - which gives way to a dominant pedal. Just as it did in the exposition, this pedal (bars 402-410) signals the arrival of the $2 \mathrm{P}$ theme, although this time in the tonic major. ${ }^{107}$ From this point the recapitulation mirrors the exposition right until the transition to the coda begins in bar 510, where secondary dominants-tonic pairs are chained together in sequence until B flat major is reached. ${ }^{108}$

The coda opens with a pedal B flat. This is marked by a sharp drop to piano and a long sustained B flat in the violin, which is joined by quaver octaves in the piano. This new figure also underlines a pedal B flat, as the chords used all revolve around the B flat common denominator. This also recalls the rising semitone motif on a large-scale level, taking the long A minor recapitulation and displacing it over an extended ten bar pedal

\footnotetext{
${ }^{105}$ The sequence that gets us here has that strident heroic nature from earlier; Jun and I pass the cadential figures back and forward with an emphatic urgency which defies the semibreve note lengths and sets up the energy for the following section.

${ }^{106}$ Racing: something that is very easy to do in this rising sequence. However, I have to avoid this if Jun's octaves are to sound heroic and not frantic; I almost manage it.

${ }^{107}$ A brief moment of respite. I had always taken time to enjoy this in rehearsal; for some reason I decide this time to push through the bright major phrase the way Jun always wanted me to, so we create a sense of desperation in the minor second phrase rather than one of nostalgia. This moves in to a repeat of the difficult arpeggiated section; this time I have complete control of the figures instead of the frantic scrambling from the exposition and we drive all the way through to the reoccurrence of the second theme.

${ }^{108}$ Ahn notes that the arrival of the bll chord actually follows a descending chain of thirds which "encapsulates the opening of the piece" by recalling the introduction.
} 
(bars 517-526). ${ }^{109}$ The shift back to A minor is abrupt - a G sharp-A figure in the piano in bar 527 is all the time Beethoven gives the music to re-establish the key - as a dominantsubdominant figure swirls the music into an extended chromatic scale, which alternates between octaves to further disorient the listener. ${ }^{110}$

Bar 547 stabilises the A minor tonality, and could well have been the beginning of the final cadential material, as a falling V-I sequence occurs first in the piano and then in the violin; however, the violin avoids $\mathrm{A}$ in the sequence instead using the rising semitone to move away and continue back to an $\mathrm{E}$ in order to repeat the imitative six bar idea, this time with the instrumental roles reversed. A new pattern emerges, this time outlining an A minor triad. A pedal marking in the piano suggests an echoing effect at the same time as the dynamics decrescendo to pianissimo; the violin with alternating quavers on A-C (bars 559-570) until the piano takes over for another four bars. The reason for this stagnation becomes clear at the appearance of the subdominant major in an eight bar Adagio interlude via a descending third from the C-A alternation in the piano, paired with the rising semitone figure from $1 \mathrm{P}$ in the violin.

Bars 575-582 recall the rising semitone motif yet again. The violin presents a short fourbar melodic snippet that recalls a combination of 1P and (along with the piano) the beginning of the false recapitulation in the relative major (B flat major instead of $\mathrm{G}$ minor). This is followed immediately by an answering phrase in the piano, now in the subdominant minor (D minor). ${ }^{111}$ Tellingly this phrase ends with an A minor pivot chord

\footnotetext{
${ }^{109}$ For some reason no matter how many times we practice this Jun and I tend to lose each other here, and the performance is no exception. I pulse the downbeat like we agreed in rehearsal, but when we reach my cyclic pattern and her alternating octaves before the unison scale, I realise she is half a bar ahead of me! I skip half a beat to line up, but she thinks she is behind and launches straight in to the scale; I catch the end of her scale and after a brief pause on the $F$ to recollect ourselves, we launch into the rest of the unison passage which recalls 1P. Hopefully it seemed intentional.

${ }^{110}$ This entire sequence has the same heroism about it as the earlier passages. With the broken octave chromatic scales building to a peak with sforzandi everywhere - followed by downwards decay to an eerie long A minor chord pedalled over fourteen bars - it seems as if a breathless, frenzied madness has overtaken the music.

${ }^{111}$ These two adagio statements of 1P present two very different emotions. First, Jun plays a calm, backwards-looking motif in $\mathrm{F}$ major. Then I answer with a doloroso $\mathrm{D}$ minor version of the same motif; this second statement directs the tension back towards the coda and as such I place the A minor chord in bar 581 to create a middle ground between the relaxed feeling of Jun's phrase while signalling a contrast between the C-sharp at the start of my phrase and the C-natural in the final chord.
} 
(using the subtonic for the third instead of the raised leading note) which has the effect of erasing the reminiscent mood and replacing it with unease; sure enough the final bars are back at Presto and contain the dominant tonic E-a harmonies which alternate chords and quavers in two bar blocks between piano and violin to rush towards the end of the movement. $^{112}$

\section{Second Movement}

'Andante con variazioni' features the semitone movement as the defining motif. Just as $1 \mathrm{P}$ began with a rising E-F semitone which went on to underpin the thematic construction of the first movement, the second movement's Andante theme opens with a falling F-E semitone. This figure is also slurred across the bar-line in a similar fashion to the first movement, although the falling motion removes the tension added by the rising movement the opening of $1 \mathrm{P}$ contained. When coupled with the immediate dominant pedal in the bass (delaying the confirmation of the tonic) and the chromatic rising link to the second four bars of the theme, this imbues the Andante with a sense of movement and flow that will remain throughout the movement. ${ }^{113}$

Example 1.9: Theme

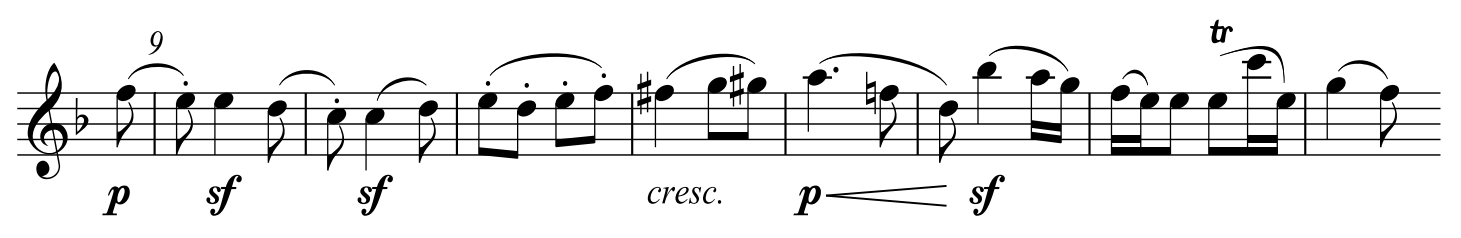

The F major tonality is not confirmed until the cadence into bar eight, due to a partial avoided cadence into bar five; this avoidance utilises rising semitones to both disguise the harmony and create confusion as to which direction the resolution will take. The G-sharp to $\mathrm{A}$ in the right hand recalls the A minor tonality from the previous movement, and the $\mathrm{E}$ -

\footnotetext{
${ }^{112}$ The strident chords in the piano against the staccato violin quavers mix heroic elements with the frantic drive present in different sections of the movement. Jun and I work hard to keep the rhythm even between the two instruments as we pass the quavers back and forward; my pulsating final downwards A minor run paired with Jun's triple-stopped chords (played without a split) stop with a distinct air of finality with a placed V-i cadence with a trebled leading note tonic pair.

${ }^{113}$ I work hard to create this sense of flow with the opening eight bars, before Jun enters to copy my motif in a cantabile fashion. The falling semiquaver followed by sforzando I interpret as being all roughly the same weight - the multitude of markings given point to a flowing continuous line, with miniscule breaks at the end of slurs for a slight placement. Jun's violin does this naturally.
} 
F in the bass implies F major. The other technique used to create tension is the crescendo from piano to piano in bar four, which also where the dominant pedal starts to transition back to F major. The answering phrase with the melody in the violin uses exactly the same format.

The second idea features solo piano with a chorale-like five bar sub-phrase followed by six bars of increasing thematic fragmentation, using bars 20-21 to extend the dominant phrase. This is followed by another version of the opening theme, with the inclusion of the violin. ${ }^{114}$ Beethoven includes the violin in the repetition of the second idea, giving it the upper voice of the piano from the initial statement. ${ }^{115}$ The closing version of the opening theme has the violin and piano both playing the upper melodic line.

This gives us asymmetrical sectional rounded binary form, with rhyming openings and closes to sections. ${ }^{116}$ In addition to following the same format, the first three variations interestingly use repeat marks to define the different sections, whereas the Andante and the fourth variation are written out in full. The first three variations also shift the primary role between instruments around quite deliberately: variation one features the piano in the dominant role; ${ }^{117}$ in variation two the violin takes precedence, while utilising rising semitone slurs onto the notes of the theme extensively to create tension; ${ }^{118}$ the third

\footnotetext{
${ }^{114}$ This chorale is a delight to play after the emotional turmoil of the first movement, even if I do push towards the end in an almost breathless manner. However, the trills in bars 24-26 present a technical challenge, and it is a relief when I pull them off and make them soar effortlessly after having come to grief in rehearsal so many times.

${ }^{115}$ Again Jun's instrument seems to make the technical challenges from my upper line - in this case the trills - seem effortless in comparison. She blends it in with the closing unison phrase delightfully.

${ }^{116}$ Asymmetrical: the second section is longer than the first. Sectional: both sections end with a VI cadence in the tonic. Rounded: the original statement returns in part at the close of the second section. See Douglass M. Green, Form in Tonal Music, New York: Holt, Rinehart and Winston, Inc, 1965, pp. 71-80.

${ }^{117}$ This first variation always feels playful and light. The staccato triplet semiquavers in my left hand combine with the trill on the upbeat falling semitone in the right hand to instantly light up the tone and transport both performers and the listener from the calm serenity of the theme into a lively and joyful place. I attempt to exude a sense of effortlessness with this variation, which is quite a challenge with both hands leaping all over the place! Jun has little regular interjections which seem to converse cheekily with the theme: my right hand says "are you there?" and she says "yes, I'm still here!"

${ }^{118}$ In the second variation Jun has to create a similar effortless feeling, and I help to support it by matching her articulation with a very dry staccatissimmo touch. The playful mood from the first variation carries over into the second, but this time it feels more galant than the previous
} 
variation (Minore) features heavily chromaticised harmony and swaps the theme between the two instruments, however the violin entries are largely doublings of the existing piano line - the exception to this rule is the B phrase where the violin is either harmonizing or answering fragments from the piano. ${ }^{119}$

The fourth variation returns to the partnership presented in the Andante with both instruments taking turns. ${ }^{120}$ This variation combines the elaborate decoration of the first variation with the quick drive of the second to create something of exquisite nature. As mentioned earlier this is the only variation to be scored in full, which allows Beethoven to create direct parallels between it and the Andante with regards to thematic treatment and interplay between instruments. ${ }^{121}$ This variation also includes a coda, which contains both elements of the themes and some dramatic chromatic shifts (none of which stray from $\mathrm{F}$ major for more than a few bars). ${ }^{122}$ Beethoven closes the coda - and the movement - with a rhyming close for the Andante featuring both instruments answering each other, feeding into the contrary motion-answering arpeggios at the final cadence. ${ }^{123}$

\footnotetext{
variation.

${ }^{119}$ The breathlessness that is pervasive in the first two variations becomes all-encompassing in the Minore. Faced with technically challenging chordal harmonies, I make the line flow through the phrases as best I can; Jun does not want the tempo to slacken at all for this dark variation, so we try to make the changes to colour and mood without losing the sense of flow. We rely on the colour from the chromatic harmonies (and the semitones within them) to help with this, placing particularly important ones - like the shift from minor to major in bar nineteen - and I use the pedal extremely carefully so as to not smudge harmonies and still sustain the line where I cannot execute it with fingers alone.

${ }^{120}$ Rehearsing this variation and getting all the articulation clean was a matter of keeping the tempo steady - essentially not pushing in order to recapture and then maintain the effortlessness from the first two variations. The once simple theme has been ornamented to extremes, and the execution becomes much more difficult if either of us rushes our easier passages (as the other person usually has an ornate line at the same time).

${ }^{121}$ As this variation is written out in full, we performed all the repeats marked in the other variations to keep a sense of balance to the movement.

${ }^{122}$ The miniature cadenza (which features both instruments) utilises both a chorale-like figure and an ornate figure in sequence for both gestures. Czerny adds an extensive cadenza for the primo part in the four-hands arrangement; this will be looked at in some detail in Chapter Three.

${ }^{123}$ The conversation between instruments feels like it takes place between us instead as we pass the thematic fragment in the final few bars between each other, after the sheer number of times we have played the idea during the course of the movement.
} 


\section{Conclusion}

Beethoven's 'Kreutzer' is a transgressive, virtuosic work which taxes the technique of performers, and probably challenged the expectations of Beethoven's audiences. Using the combination of analysis and performative ethnography above, I have demonstrated that the thematic and motivic interactions between instruments - and by extension, the performers - extend beyond the notation in the score. In particular: the opening Adagio allows a great amount of freedom to performers, both in tempo and in the interaction between interjections and tendency tones to such an extent that I will look at this section in both arrangements. The section from bar 91 onwards in the first movement allows both performers to agree (or disagree as the case may be) as to how much variation in tempo to use in the answering phrases. The construction of the first variation of the second movement also allows some curious exchanges for the four-hand arrangement, in addition to the interjections Beethoven included as part of the original score. Additionally the performative analysis highlights just how much influence one performer can exert over the other; the opening of the third movement leaves dictation of pace entirely to the violinist. In the case I explore, the circumstances of the performance determined a large portion of this tempo; however, the 'drastic' action as a result of this on the part of the violinist led to an extremely fast-paced tempo which drove right to the end. ${ }^{124}$

In the following two chapters I will investigate the manner with which these interactions and the 'Kreutzer' as a whole - are transformed into new genres. I will also look at the social situations of the two genres (string quintet and four-hand piano) and some of the potential reasons for the creation of such arrangements as those published by Simrock and Czerny.

\footnotetext{
${ }^{124}$ And in truth it had been a long performance for Jun; after a Mozart Concerto and a Paganini caprice she was most definitely looking at the double-bars at the end of the movement as a finish line. When combined with the roar from the piano, this set of circumstances - unlikely to be caused in any other performance - generated this 'drastic' response. See Abbate, 'Drastic or Gnostic?', pp. 510, 532-535.
} 


\section{Chapter 2: The Quintet Transcription}

\section{Introduction}

In the previous chapter Beethoven's original Opus 47 'Kreutzer' Sonata was explored in detail: the manner with which the transgressive sonata functions within the expectations of Viennese society, and the way in which the two instruments and musicians interact with each other. One of the findings was that the 'rising semitone' motif forms one of the fundamental building blocks of the work, and it was also noted that the two parts were written in a highly concertante manner; the work was essentially composed for a pair of virtuoso musicians, Beethoven himself and George Bridgetower.

There are a number of transcriptions that have been made over the years; these include an anonymous string quintet published by Simrock in 1832, a Czerny arrangement for cello and piano, two arrangements for four hands piano (Czerny and Leopold Langer), and two arrangements for piano solo (Leopold Godowsky and Louis Winkler). As mentioned in the introduction to this dissertation, I have selected the anonymous 1832 quintet transcription and the Czerny four-hand arrangement.

In this chapter I will be dealing with the anonymous quintet transcription of Beethoven's "Kreutzer" Sonata, which was released by one of Beethoven's publishers (Simrock) in 1832. I have selected this arrangement in part because of its extremely high quality and idiomatic writing. As there is a close relationship between both the quintet and the quartet, I will look at the social scene for quartets: their target market and the level of proficiency amongst the musicians for whom quartets and quintets were written. I will look at the genres of quatours concertants and quatours brillants and track some of the changes across major composers of quartets and quintets directly prior to Beethoven including Mozart, Haydn and Boccherini in order to get a clearer picture of the instrumental relationships; then I will look at the manner in which the original 'Kreutzer' Sonata has been adapted for the quintet form, paying particular attention to how the relationship between what was originally two performers (and motifs such as the rising semitone) alters in meaning between the two different social and musical dynamics. 


\section{The Quintet in Beethoven's Vienna: streichquartett plus one}

In order to consider the place of the string quintet (and therefore why a transcription of the 'Kreutzer' sonata might be released by Beethoven's publisher) one must look to the intended market and target audience for the dominant surrounding repertoire that shares a similar style of orchestration: the string quartet. John Daverio suggests that the place that Beethoven held for his string chamber music repertoire amongst his output was 'privileged,' and that while he reconfigured works from other mediums into quartets and quintets (Piano Trio op. 1 no. 3 he rearranged as his op. 104 string quintet, as was his op. 103 wind octet (string quintet, op. 4)) he avoided doing the reverse ('Grosse Fuge' fourhands transcription not-withstanding). ${ }^{125}$ These reconfigurations were re-compositions for their new medium rather than a simple transplanting of material. Daverio also references Czerny's School of Practical Composition to support this statement, as he seeks to justify his own inference that the other sizes of string chamber ensembles - ranging from duo to sextet - 'draw on the technical and aesthetic categories associated with the quartet.' 126 While does not mean that the genres are by nature closely interrelated, the addition of a few other elements argument from the work of Beethoven's contemporaries builds a case for this.

Prior to Beethoven's arrival in Vienna, these quartets typically belonged to either the concertant or brillant traditions. ${ }^{127}$ The quatours concertants have their origins in Paris amongst composers such as Giuseppe Cambini (1746 - 1825), Jean Baptiste Davaux (1742 - 1822) and Pierre Vachon (1738 - 1803); their principle features consist of melodic thematic material shared amongst all four movements with some intermingling between instruments, and primarily three-movement formats. ${ }^{128}$ Eisen suggests that these show

\footnotetext{
125 John Daverio, 'Manner, tone, and tendency in Beethoven's chamber music for strings', in Glenn Stanley (ed.). The Cambridge Companion to Beethoven. Cambridge: Cambridge University Press, 2000, p. 147.

${ }^{126}$ Ibid., p. 148.

${ }^{127}$ I do not intend to imply that Beethoven revolutionised the string quartet. Scholars such as Eisen, Daverio, Hunter, Rosen, W. Dean Sutcliffe and David Wyn Jones have demonstrated that it was of sorts a combined effort involving imitation, referencing and emulation between Haydn, Mozart and Beethoven in particular that transformed the string quartet genre over time away from the concertante and brilliant styles; I seek to create an understanding of the traditions around which Beethoven was operating.

${ }^{128}$ Cliff Eisen, 'The String Quartet', in Simon Keefe (ed.), Cambridge History of $18^{\text {th }}$ Century Music. Cambridge: Cambridge University Press, 2009, p. 651.
} 
stronger links to Boccherini than to Haydn in their stylistic and instrumental qualities.

Quatours concertants often featured duet-type passages between the first violin and either the viola or cello, and by 1800 were absorbed by the 'classical' quartet typically ascribed to Mozart and Haydn. ${ }^{129}$ The quatours brillants were music written as virtuosic four-part music for string quartets, typically with more textural variety than the concertant style of quartet. Their main feature (and marked point of difference from the quatours concertants style) was that they featured one instrument over the other three; while the overall effect was virtuosic, the technically challenging material was usually located in one part and sometimes would extend as far as the inclusion of cadenzas (in the style of those found in concertos). ${ }^{130}$ This style of quartet persisted though into the early $1800 \mathrm{~s}$ and was popularised by virtuosi mentioned in Chapter One; Eisen mentions that this style was also 'cultivated' in Vienna by Ignaz Schuppanzigh, Beethoven's friend, a professional violinist with his own string quartet. ${ }^{131}$

Mozart wrote string quintets immediately following the creation of a set of quartets. Rosen suggests that this sequence implies a link between the completion of works for string quartet and a desire to experiment with the "richer medium. ${ }^{132}$ Those quintets favoured the addition of a viola to the makeup of the string quartet, which more than likely was an acknowledgement of Mozart's love of the viola - and probably also a reflection of a personal desire to play with a pre-existing string quartet or a group of friends and make music. $^{133}$

Boccherini composed string quintets which used a second cellist rather than the additional viola - likely a method of providing a stable bass-line foundation when one of the cellists would either cross above the viola to function near the top of the texture, harmonise closely with the first violin, or depart on a virtuosic foray into passagework and

\footnotetext{
${ }^{129}$ Eisen et al. et al., 'String quartet': Grove Music Online. Oxford Music Online. Oxford University Press, available from http://www.oxfordmusiconline.com/subscriber/article/grove/music/40899; accessed December 07, 2012.

${ }^{130}$ Ibid.

${ }^{131}$ Ibid.

${ }^{132}$ Rosen, The Classical Style, p. 264.

${ }^{133} \mathrm{Ibid}$; the supposition about Mozart's personal desire is my own assumption based on a combination of personal experiences with composition students and their compositions combined with Rosen's observation that Mozart 'habitually chose [the viola] when playing string quartets'.
} 
showmanship. ${ }^{134}$ These parts were more than likely written for himself, as he was a virtuoso composer-cellist. The use of virtuosity in Boccherini's chamber music was extensive as he associated with other highly-skilled musicians, and the cello writing frequently made use of the tenor registers and above to fulfil the concertante role usually assumed by the first violist in the string quintet. ${ }^{135}$

Haydn's quartets changed somewhat over the course of his lifetime. His early quartets display reasonably concise material which allow accompaniment and melody to interrelate closely; Eisen uses Rosen to reference their widespread elimination of transitional 'figures and phrases. ${ }^{136}$ Haydn's later string quartets make use of a wide variety of string colours and different harmonic tonalities along with more texturally even writing, giving a different stylistic balance to the four instruments. These quartets are not devoid of virtuosic writing - some of them, such as the op. 71/74 quartets utilise the brillant style - and contain 'richer, more orchestral sonorities... [and] adventurous tonal relationships between movements'. ${ }^{137}$

Beethoven's own compositions for string quartets in general display less of this kind of virtuosity, but instead build on the fuller orchestral-like textures of the Boccherinian quintet, and some of Haydn's later quartets. These exhibit a kind of musical versatility based on the adaptability and homogeneity of four similar voices as a means of generating conversational yet serious music that was playable by advanced amateurs and professionals alike. ${ }^{138}$ Not to imply that other composers or genres did not do this - and Beethoven also produced some concertante string chamber music (Daverio specifically

\footnotetext{
${ }^{134}$ Christian Speck and Stanley Sadie, 'Boccherini, Luigi': Grove Music Online. Oxford Music Online. Oxford University Press, available from http://www.oxfordmusiconline.com/subscriber/article/grove/music/03337; accessed November 17, 2012,

${ }^{135}$ Boccherini was renowned for performing the parts of other musicians during productions of ballets and chamber music when other performers were unwell or unavailable; this included not only cello parts but also violas and violins as well. It is unsurprising that these ranges were utilised in the construction of his own chamber music: if one has the facility required to reproduce these sounds and wish to use them in context, he was well within his rights as a virtuoso composing for other virtuosi to expect them to be able to do the same.

${ }^{136}$ Eisen et al., 'String Quartet': Grove Music Online.

${ }^{137}$ Eisen, 'String Quartet', Cambridge History of $18^{\text {th }}$ Century Music, p. 655.

${ }^{138}$ Mary Hunter, "The Most Interesting Genre of Music": Performance, Sociability and Meaning in the Classical String Quartet, 1800-1830', Nineteenth-Century Music Review, Vol. 9, No. 1, 2012, pp. 53-54.
} 
makes mention of his op. 9 no. 1 String Trio as an example of this $)^{139}$ - but his string quartets and quintets in particular were more along the lines of an amalgamation of the styles of the two-cello Boccherini quintets and Mozart and Haydn's late quartets.

In Vienna the quartet was straddling both the public and private musical scenes. While the classical quartet was preferred by amateur musicians as a method of music making with friends - from the middle class right through to royalty ${ }^{140}$ - it was also making a very determined move into the new concert scene, with the formation of both quartet societies and professional string quartets, such as that of Schuppanzigh. The Schuppanzigh quartet was founded with the express intention of performing publicly. This quartet performed out of a hall which likely could only seat around a hundred people; Beethoven's 'Razumovsky' quartets were written for the ensemble. ${ }^{141}$ Daverio considers these quartets to reflect the disjunction between public and private quartet performances, not only through their references to a multitude of genres ranging from folk-song to the symphony, but also through the manner with which these are combined and cross-pollinated; 'exoteric [topics are] transformed by an esoteric compositional quartet'. ${ }^{142}$ Scores for the late Beethoven quartets were published at the same time as the parts, in order to provide scholars and listeners the opportunity to study the score before/while they listened to the quartets. The early and middle quartets (including the Razumovsky quartets) had their scores published years after the parts were released, which was likely a reaction to the serious music culture developing around the quartet. ${ }^{143}$ As an example: in a direct reflection of the genre's shift towards serious intellectual music, during the 1840s the Beethoven Quartet Society was formed across the Channel in London; they studied and performed Beethoven's late

\footnotetext{
139 Daverio, 'Beethoven's chamber music for strings', p. 148.

140 Prince Rudolphe was an amateur musician, and enjoyed sitting down with musicians and friends to read through string quartets.

${ }^{141}$ Robert Winter, 'Performing the Beethoven Quartets in Their First Century', in Robert Winter and Robert Martin (eds.), The Beethoven Quartet Companion, Berkley: University of California Press, 1994, pp. 35-37.

142 Daverio, 'Beethoven's chamber music for strings', pp. 154-155.

143 Ibid., p. 151. See also Somfai's article 'Clever Orator versus Bold Innovator' on Haydn's quartets - the practice of deliberately releasing the parts by themselves forced the players to listen to each other while reading their own part. This also caused problems for critics who would miss elements of his counterpoint and respond negatively. László Somfai, 'Clever Orator vesus Bold Innovator', in Haydn and the Performance of Rhetoric, Chicago: University of Chicago Press, 2007, pp. 219, 223-224.
} 
quartets in particular. ${ }^{144}$

Schuppanzigh himself was directly involved in Beethoven's compositional development having been introduced to the young violinist through Prince Lichnowsky's morning salon chamber music concerts, Beethoven studied violin with Schuppanzigh as often as three times a week by $1794 .{ }^{145}$ Further to this, Beethoven wrote music which Schuppanzigh and his quartet would read through and offer suggestions and critique; ${ }^{146}$ some of this music was written specifically for this quartet and their performance environment.

\section{The Kreutzer Sonata: duo concertante transformed into}

\section{chamber music for five musicians}

Whilst the author of the transcription is unknown, the craftsmanship involved in the creation of the quintet version of the 'Kreutzer' demonstrates an understanding of the construction involved in the original sonata on an intimate level. Far from being a straight violin (or cello) plus quartet arrangement, the quintet spreads both instrumental parts from the original 'Kreutzer' both across and between all five instruments. This ensures that while the parts are playable, they all require a high level of technical competency and skill from each individual musician in order to execute figures originally designed for the piano. While some of these figures are rewritten and re-voiced slightly to be more idiomatic in a quintet setting, the piano part has been spread across the different parts to highlight the voice-leading and chromatic shifts: in particular the rising semitone figure emphasised in the first chapter. ${ }^{147}$ The use of a second cello instead of a second viola allows the arranger to divide the bass-line between two instruments with the same timbre. It also allows them to create variety in voicing, which utilises this closeness of sound to provide different

\footnotetext{
${ }^{144}$ Daverio, 'Beethoven's chamber music for strings', pp. 53-54.

${ }^{145}$ DeNora, Beethoven and the Construction of Genius, pp. 117-118.

${ }^{146}$ Ibid., p. 118.

147 In order to compare the manner in which the quintet arrangement (Simrock, 1832) differs from Beethoven's original 'Kreutzer' sonata, it will be necessary to investigate the ways in which the elements identified above - changes in figures for execution purposes, alterations or additions to texture and chords, and the manner in which the violin part shifts between instruments - exhibit themselves in the transcription. It will also be important to consider the effects (if any) they have on the music, and to understand why these decisions have been made. As there are a few anomalies in the second and third movements, I will make specific mention of these; however the majority of the investigation will be in the Adagio and the exposition and development of the first movement.
} 
effects ranging from pedals and octave-displacing escape notes to doublings for volume both in unison and at the octave - in rhythmic units ranging from entire bars to Presto quavers. This lends both a depth and weight to the setting unavailable to the Mozartean double viola quintet model, and provides the first cellist with occasional breaks from the often awkward passagework.

While the arranger has used these different effects to recreate the piano half of the duo within the quintet setting, he has also embedded Beethoven's solo violin part within the transcription. As previously mentioned, the first violin could have been chosen to carry the violin part from the original (and therefore require a considerably more skilled (essentially virtuoso) violinist soloist to perform the part. This would have represented the concertante style of quintet writing Rosen - unfairly - calls

'a lazy extension ... of treating the string quartet superficially as an accompanied solo for the first violin. ${ }^{148}$

Given the manner in which some of the passagework is spread out, the first violinist is able to provide moments of differentiation and special colour to the more lyrical passages, and carries the traditional upper-ranges of the part writing, whilst not being required in order to be able to execute all the technical challenges of the original. ${ }^{149}$

${ }^{148}$ Rosen, The Classical Style, p. 264. I use the word 'unfair' as Rosen implies there are no skilfully constructed concertante quintet works, thus framing the entire genre in very negative terms.

${ }^{149}$ As the techniques described above have been used throughout the entire transcription, I will consider some sections - particularly those with major alterations - in depth and then bypass others with either less important or recycled techniques for the sake of brevity. However, I will additionally comment on sections which are direct transcriptions - where the arranger makes use of the concertante style of quintet composition - as they are not the norm and they often serve to highlight changes in theme, or recreate a particular soundscape that embedding the violin line amongst the rest of the quintet could potentially mask. While these concertante sections are not quite true to their literal definition as there are two celli rather than the traditional string quartet formation, the effect is the same. 


\section{Comparison between the quintet arrangement and Beethoven's original 'Kreutzer'}

\section{First Movement:}

The 'Adagio Sostenuto' demonstrates right from the outset that the first violin does not reproduce the violin part from Beethoven's original 'Kreutzer' Sonata. ${ }^{150}$ The opening four bars spread the line between violin II, viola and cello I - the opening quadruple-stop is turned into a doubled chord (minus the top A, which is likely emphasised by a standard spread $2+1+1$ bow stroke), ${ }^{151}$ and then the remainder of the idea is presented in a choralelike manner with one voice to a line. This reflects the duet-like nature of the violin and viola lines Rosen refers to as being Mozart's style of quintet writing. ${ }^{152}$ This has the added effect of doubling the rising C-sharp to D semitone, although the resolution itself is not doubled.

The answering figure in the following four bars replicates the same doubling (this time in violin I and II), and the chorale-like part writing features a duet between violin I and cello I - utilising the difference in timbre between the two instruments to create a conversational duet. At the same time, the second cello demonstrates the use of doubling at the octave - in this case, a literal representation of the original piano left hand.

This is the first glimpse of the quintet functioning as a whole; through its stark contrast between expansiveness and confined space, it displays the breadth of power and intimacy available to the musicians within the second phrase alone. ${ }^{153}$ Where the first allows the inner trio of players to make their opening statement, the second adds the outside pair to demonstrate an almost exaggerated array of emotion. In particular the descending fifth to a

\footnotetext{
${ }^{150}$ For this paragraph and the following pages (up to the Presto) refer to figure 2.1. I will consider the Adagio introductory passage in full, as it serves to set up techniques and motifs Beethoven uses throughout the first movement - and the rest of the Sonata - within these eighteen bars; it also demonstrates a number of the techniques already mentioned available to arranger and composer for string quintets alike. The Adagio also calls attention to some differences in both articulation (both in phrasing and in note length) and definition in voice-leading between the two different styles. At the same time, I will consider the effects that this has on the relationship between performers and the manner with which this differs from that of the original sonata.

${ }^{151}$ Robin Stowell, Violin Technique and Performance Practice in the Late Eighteenth and Early Nineteenth Centuries, Cambridge: Cambridge University Press, 1985, pp. 152-153.

${ }^{152}$ Rosen, The Classical Style, p. 264.

${ }^{153}$ Bars 5-8
} 
pianissimo bottom $\mathrm{D}$ from the second cello adds a gravity and depth missing from the opening statement, and emphasises the shift to the minor tonality with both motion and sound in a way the piano cannot due to the natural resonance of the C-string.

The following passage, which features chromatic and evasive tonal shifts, also demonstrates another technique available to the string quintet that the piano cannot innately reproduce - the articulated slur. While it is possible for a pianist to create the effect of an articulated slur, the effect can be generated by a string player with a simple shift of arm weight within one bow stroke. ${ }^{154}$ The nature of stringed instrumental tuning and the extra nuances available to the performers make it possible to colour the different chromatic resolutions to a greater extent than the original, as both halves of the answering phrases can provide smaller, brighter descending semitones to the third of the chord (resolution of 4-3 suspension in the violin lines). ${ }^{155}$ The part writing here shows the flexibility available to the string quintet, as it transplants the upper line of the piano into the second violin part; this allows it to match the tone and articulation of this articulated slur precisely, in addition to having the sound of each gesture blend together between bars eight and nine with the first gesture ending on the same note as the answering statement begins. This happens again in bars ten and eleven (although the first violin starts the answering gesture an octave below the second violin's G sharp).

\footnotetext{
${ }^{154}$ While the technique involved in recreating the effect with a piano is similar, both the execution and effect are arguably more cohesive when produced by a stringed instrument.

${ }^{155}$ When I refer to tuning, I imply that a string quintet musician needs to base their fine-tuning of pitch on a common denominator - whereas for the violinist in a duo with a pianist, there is only one fixed set of frequencies to tune to. If the dominant part in the quintet is constantly changing, the other musicians will have to alter their pitching of tendency tones slightly for the personal tuning tastes of the dominant part at anyone moment in time. Without a defined 'leader' the default is to tune from the bass up.
} 
Example 2.1: Adagio
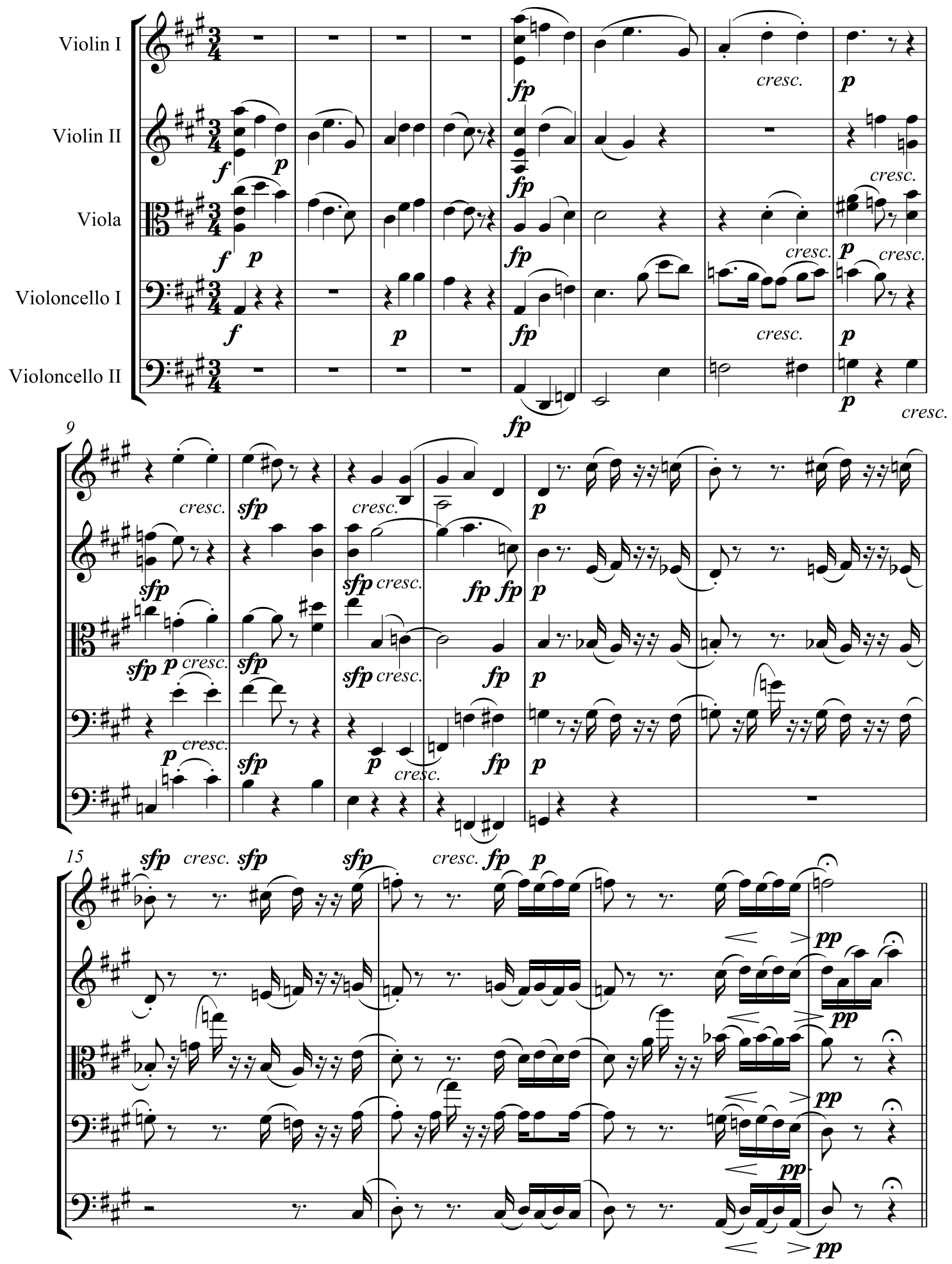

The additional subtleties in colour available to the string quintet continue through the remaining bars of the Adagio introduction. This allows the closeness between the chromatically shifting chords to rise to the forefront and enables the quintet to breath 
additional life into the swirling harmonies. At this point, we see the first violin take over the violin melody for the first time, and it carries it through to the end of the introduction. This is the closest that the transcription has come to a straight representation of the original sonata in its violin plus piano format. There is some rearrangement and re-voicing of parts - largely the interjection from the octave leap, which alternates between cello I and viola before finishing in the second violin. This has the additional effect of overlapping the two violin parts so that the first violin blends into the final moments of the Adagio with the $F$ natural that forms the third of the opening chord of the Presto (which will eventually reveal itself as the subdominant). The use of the first violin to round out the introductory section serves two purposes: the first of which is the obvious transliteration of the upper line from the combined chord structure to the first violin line; the second however is to take the colour of the first violin's A-string and interweave it with the similar motion sixths and contrary motion octaves that appear throughout the closing segment of the introduction, and as such to transform the upper parts of the end of the introduction from a true duet between two musicians that mirrors the original sonata into one that grows to involves the entire quintet.

The transition to the Presto demonstrates again that the transcription is not an accompanied violin soloist but rather a musical creation for five skilled musicians. The cello I part introduces the first theme rather than the giving it to the first violin - presenting it down an octave allows the deeper natural resonance and register of the cello to give it a different character to the answering phrase. The first violin takes the role of the piano in this answering phrase and gives the second statement of the theme; however it takes the format of the opening violin statement from the original sonata to mirror the cello as the rest of the quintet is there to fill out the remainder of the piano's part. The bravura cadenza-like figure from the piano in bar thirty-six is not given to the violin; the first cello is given a modified version of the arpeggiated broken chord, which serves to preserve the feeling but simplify the execution somewhat to better suit the range of the cello.

The first violin takes over the violin part from the original sonata for the chromatic transitional shift to $2 \mathrm{P}$. This demonstrates the same tone qualities used to highlight the chromatic colours in the final passage of the introduction. At the same time, some of the other qualities mentioned earlier are used to construct the supporting instrumental lines: conversational alternating octaves between cello one and two, with the viola providing 
syncopation a compound sixth below the first violin. This carries on into $2 \mathrm{P}$, with the conversation between violin and piano from the original sonata shifting around the quintet: the piano moves around the quintet as a whole (with the right hand of the piano swapping around the upper strings, and the bass of the left simplified down to crotchets to alternate between both cello parts), while the original violin part shifting in two-bar units between one of the upper strings that does not already contain the complex piano right-hand line pattern. This demonstrates again that whilst there are moments where the first violin is used to herald changes in section or particular colour shifts, the quintet as a whole is far from a straight-forward transcription of the original sonata.

The use of available forces bears some resemblance to the original, but transforms the soundscape so that the conversations occur between ever-changing pairs of instruments. The rapid quaver movement of the very next section from bar 61 (example 2.2) serves as an example of this: initially the second violin and first cello hold the complex piano line, before passing them to the first violin and second cello. These take the form of the two-bar snippets used in the previous section (2P).The second cello continues the ascending quaver sequence, but the viola takes over from the first violin. The quavers return to the initial second violin and first cello pairing as the four-bar phrases break down into a quickly ascending sequence - the viola and second cello take over the rhythmic crescendo while the violins present triple octaves between them (there is an additional lower E during bars 69-71 when compared to the original violin part).

This rapidly becomes a conversation between viola and both violins: as the original violin part reaches bar 81 (example 2.3) it gets split between all three of these parts, with the E-D sharp semitone upper line in each figure given to the first violin and the other descending parts alternating between second violin and viola. This creates an odd rippling effect, when contrasted with the first cello (who carries the entire left-hand of the piano over the four bars that this interaction amongst upper strings lasts. 
Example 2.2: Bars 61-67

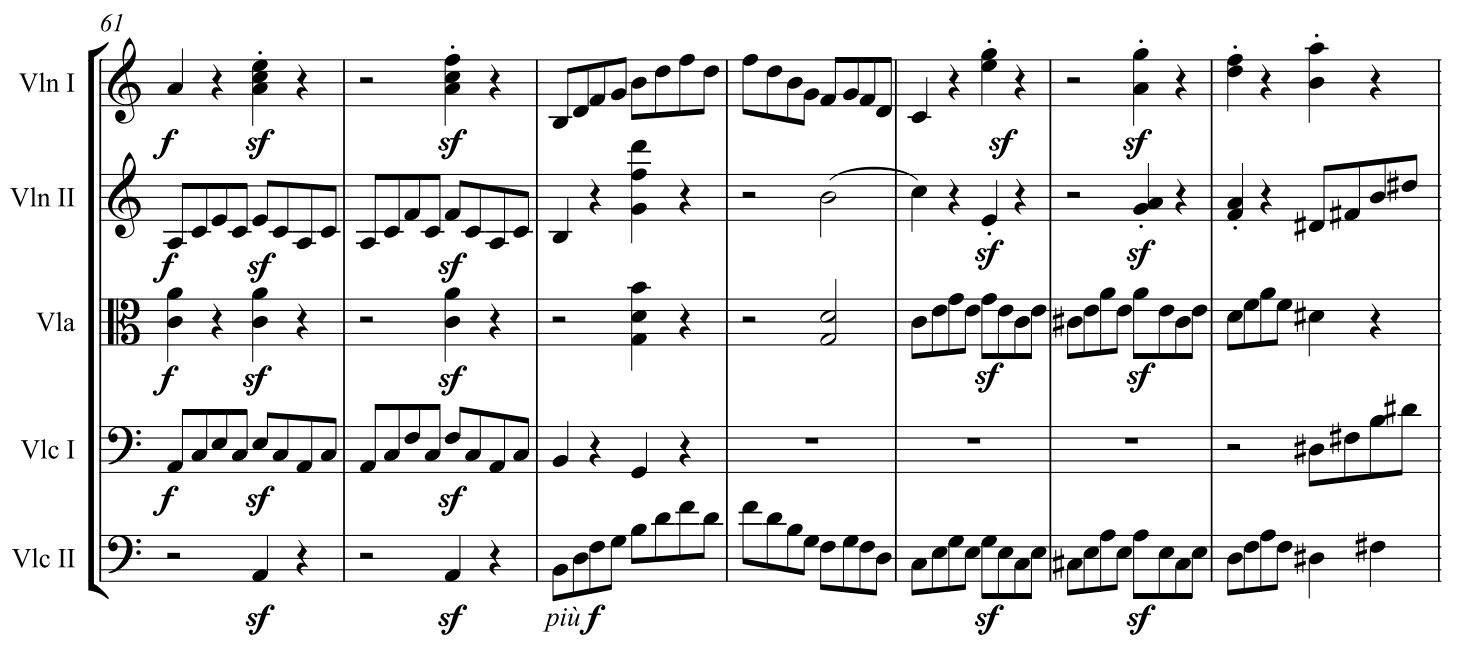

Example 2.3: Bars 81-84

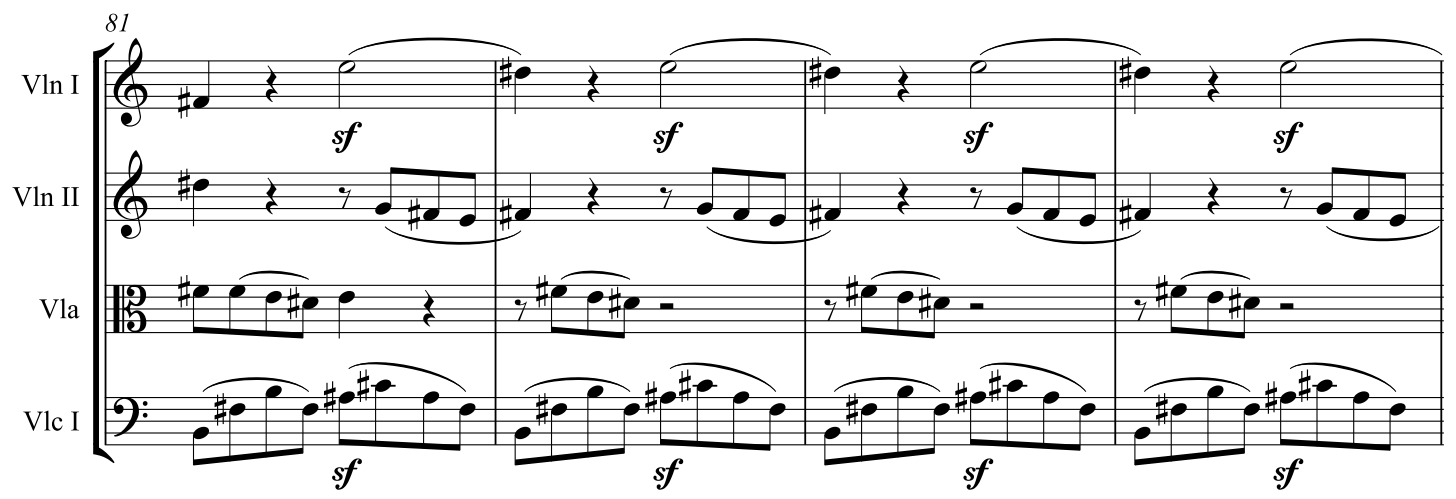

The second subject (bar 91, example 2.4) features the full array of string players in chorale style. These twenty-four bars provide an example of almost a complete transcription from the original part-writing; the differences between transcription and original amount to the re-voicing of the second violin and viola parts in order to swap the two lines and transition smoothly from the preceding section - this is necessitated by the location of the original violin line in the viola part leading in to the second subject. The first violin carries the original violin line throughout this section - the one difference being the eight-bar bow stroke for the opening statement of the second theme. A few technical differences affect the soundscape - the shift from piano to strings allows the supporting voices to present an even legato sound, yet still include both line and nuance (variations in arm weight and variety of vibrato) both within and between the long notes in a way that a pianist would need to work much harder to emulate. The other main difference is the complexity of tuning between five stringed instruments where one pair is playing in octaves and the other 
plays largely in thirds; this is vastly more difficult than the original, yet provides more opportunity to add additional colour through altering the size and brightness of intervals.

Example 2.4: Bars 91-105

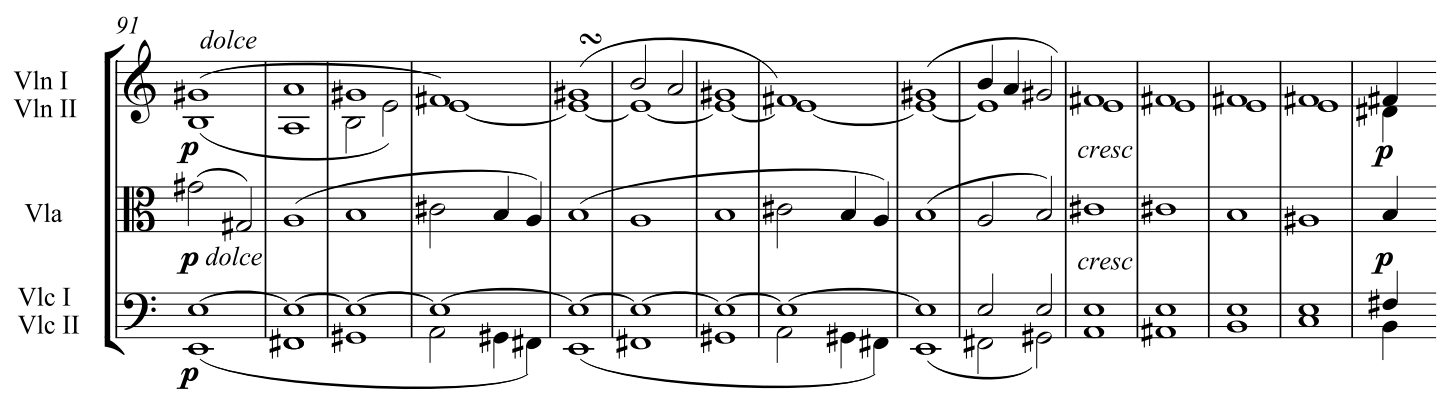

The end of the exposition features an interesting passage for the second violinist between bars 149 and 155: they reproduce the original violin part, complete with quadruple stops within the surrounds of the rest of the quintet. The other musicians produce a texture that features the second cello producing a downbeat only bass line, with the first cello and viola filling in the other three beats from the left hand of the original piano part. The first violinist acquires the upper half of the octaves from the right hand. The triple- and quadruple stops allow the second violinist a moment of overt virtuosity, while overshadowing them with the power and range of the writing given to the first violin. These roles break down in the final moments of the exposition - the upper strings are all given strident double, triple and quadruple stops, while the two cellists play either in unison or with one acting as a pedal for the other. From bar 184 through to 187 both cellists play fast quavers taken directly from the original violin line to produce both power and definition through doubling; the first cello continues with the violin part right up to the double bar, but combines the G sharp and A from the bass with this in a virtuoso touch. The second cello adds a pedal effect in bar 188 and bars 190 - 193 to underpin the lively first cello line.

The most technically challenging section of the development from the original sonata presents the quintet members with a dynamic conversation between all five instruments. From bar 226 where the second violin enters with the falling sequence of thirds motif that combines with the rising semitone that opened the development (referencing the opening of the Presto), the quintet arrangement shuffles all of these motifs around to create a stretto effect. All five parts have a version of both of these ideas, while the falling sixths from the piano's right hand part are split between two of the upper strings and turned into repeated 
quavers make the figures more idiomatic and maintain rhythmic drive. ${ }^{156}$ This allows the effect of the small interjections bouncing around the quintet to do so both visually and sonically. This includes having the interjections bounce between cello (both first and second) and first violin; it also occurs between viola and second violin, highlighting the differences between outer and inner pairs of instruments. The use of pairing similar instruments for sound contrasts - at times directly - with these figures: the pairings of thirds and octaves between both cellists from bar 246 onwards (which meshes with the octaves between second violin and viola) provides a stark juxtaposition to the tumultuous writing in the twenty bars immediately prior. This allows the group to build directly to a climactic fortissimo point in bar 254 where the original violin line actually gets absorbed into the repetitive quavers in the octaves of the cello parts.

Example 2.5: Quintet Transcription -

including the omission of the violin figure in bar 258;

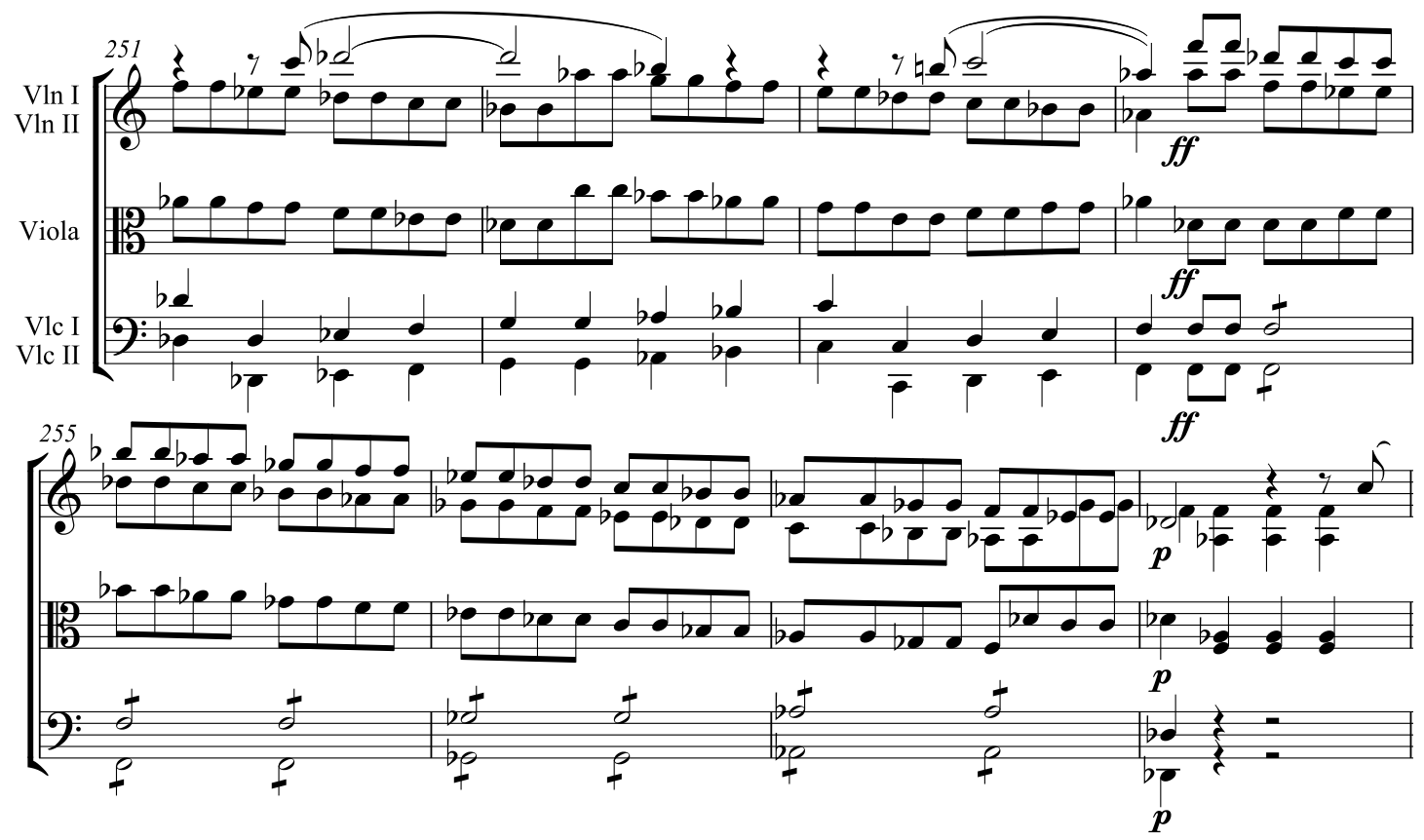

${ }^{156}$ While not impossible, trying to co-ordinate alternating notes between two players at that pace would be rather difficult. The repeated quavers are most likely chosen to echo the violin line from bars 295 -299; while these bars serve a different purpose, the technique and result are the same when compared to the piano writing within the same bars. 
Example 2.6: the original sonata bars 251-258 for comparison

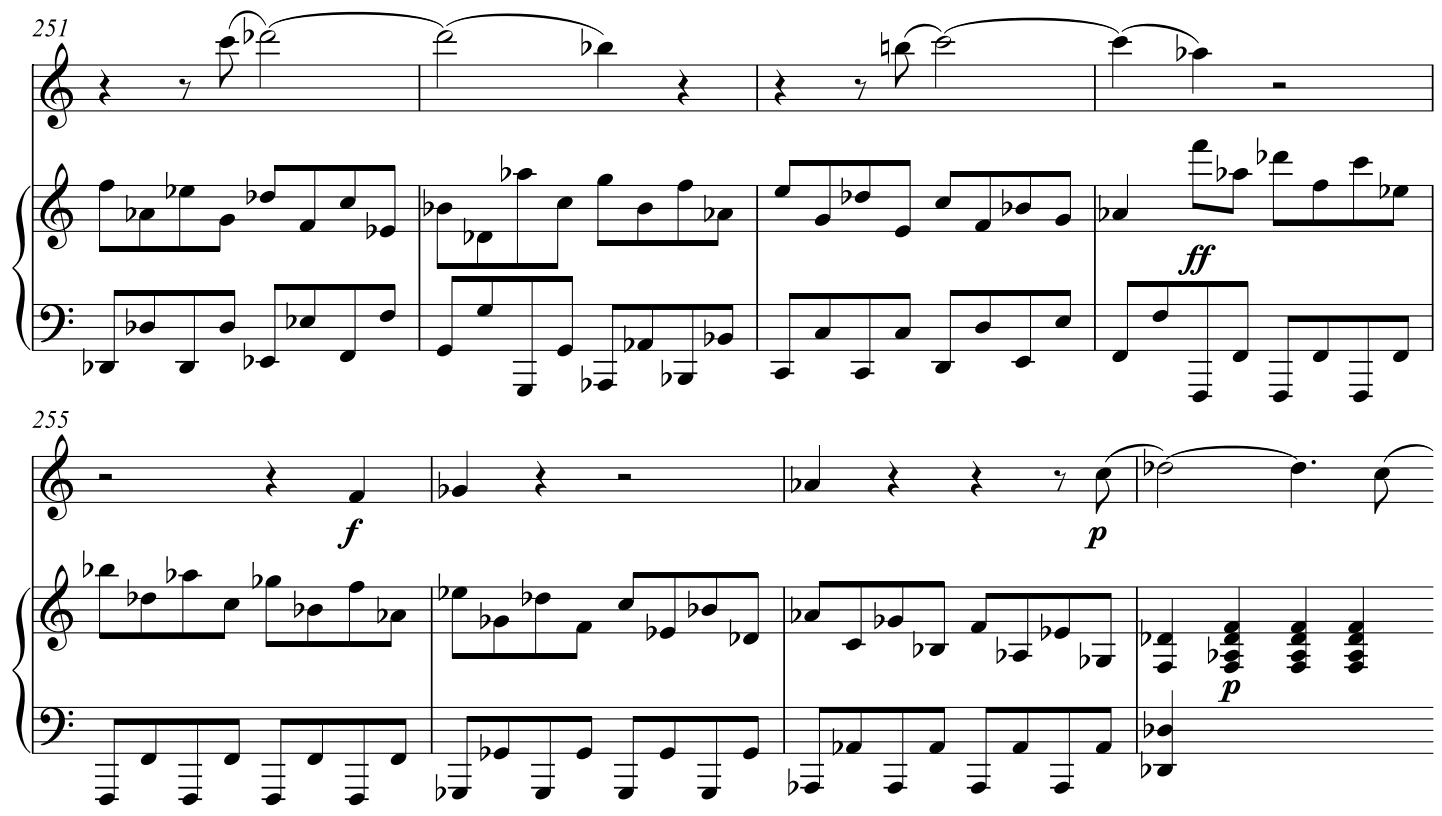

The quintet has a major point of difference from the original sonata directly after this climax: there is an entire bar of the violin line missing from bar 258 (see figure 2.6). This has the effect of reducing a triple statement entry to a double entry, which reduces the rhetorical significance of the D flat major tonal shift. ${ }^{157}$ This is probably a result of the awkwardness of transitioning between the downwards scale and the upwards semitone gesture a sixth above it; it also avoids having the first violin halt a downwards descent a tone before arriving at the $\mathrm{D}$ flat major chord. This is not a problem in the original sonata as the downwards scale is handled entirely by the piano and the violin is free to make the entry to match the opening of the development.

Another difference in figuration occurs in bars 294 - 299 (example 2.7). The violin from the original is given initially to both cellists and repeated quavers are combined into crotchets; this line then passes to the second violin and first cello and returns to repeated quavers. The piano line is refigured so that the alternating octaves are turned into a moving line oscillating with a stationary pedal for the upper strings in bars 294/5; the first violin then presents a descending scale in alternating octaves, while the viola and second cello revoice their octaves into repeated quavers. This kind of re-voicing is presumably to remove

${ }^{157}$ An example of a triple statement occurs at the beginning of the development in the first violin - which (tonal centre aside) displays what would have been an otherwise identical statement. 
some of the complications of rapid string crossing in octaves for all bar the first violinist and also to remove the problems with trying to tune unison alternating octaves (string crossing included) across multiple members of the chamber ensemble. A similar device is used across the remainder of the development: the arpeggios are passed between instruments across the quintet, from second cello to first violin. ${ }^{158}$ Both statements present the gesture to the first violinist who completes the downwards balancing figure to close the end of the development section and heralds the false recapitulation. ${ }^{159}$

\section{Example 2.7: Bars 294-299}

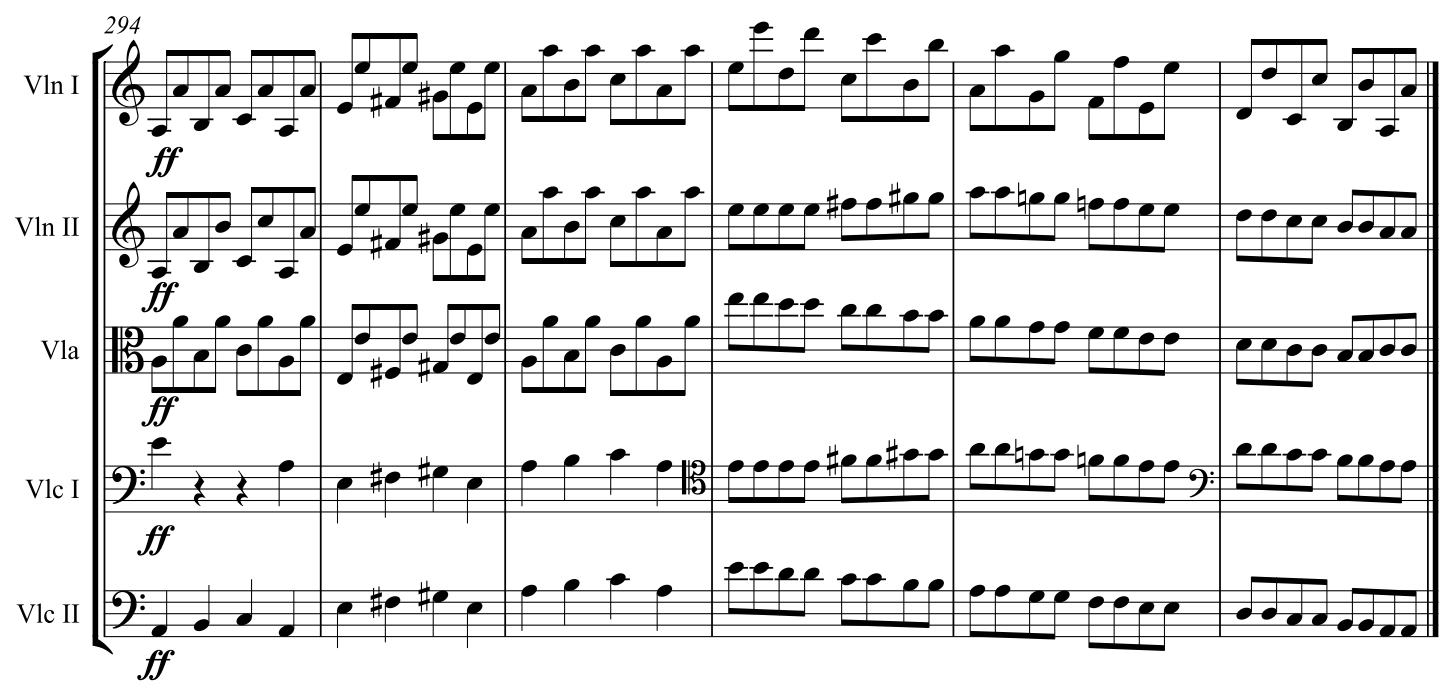

\section{Second Movement}

The Andante theme demonstrates similar chorale writing, with the opening statement of the first violin being the original violin part. However, the main point of difference in this variation is that the repetition of the BA' section is handled with repeat markings instead of altering the part with melodic emphasis (trills) in what would have been beat four of bar 36 and bar 54 .

The second variation also contains an anomaly - being written in a brillant style, the original violin part is given entirely to the first violin throughout the variation, and the

\footnotetext{
${ }^{158}$ The first cello is skipped the first time, and the second cello and viola are both omitted from the second statement of this idea; this means that no matter which order the cellists are seated in, the motion will be largely contiguous and in a single direction.

${ }^{159}$ As mentioned at bar 343.4 in the analysis in Chapter 1.
} 
piano is spread between the remainder of the quintet. The other strings (with the exception of the cellos in the second half) are given the specific direction '1te mal col'arco, 2te reprise pizzicato': first time bowed, the repeat plucked. This is a major point of difference from the original; while the piano is capable of producing different types of staccato, there is something rather different (almost magical) about a string quintet pizzicato sound when compared to a detache bow-stroke that the detache and staccato of a pianist would find difficult to emulate. ${ }^{160}$

The Minore variation once again has the first violinist performing the entirety of the original violin part. This allows the quintet to make changes to their overall tuning (and allows the first violinist to alter both rising and falling semitones for extra colour) without requiring them to constantly change the focal point of their tuning.

The final variation is again written in a brillant style; the difference here is that while the first violin opens with the original violin part to answer the second violin's statement (taken from the piano's right hand), and carries the original violin part through most of the transitions, it also takes over the dominant melody from the second violin during the ornate second piano-dominated section (bars $19-29$ ) until swapping back to the violin part. For the majority of the rest of the variation the first violin plays the original violin part or the corresponding upper texture from the right hand of the piano where the violin has rests; the exceptions to this are in the miniature cadenza where the first cello and viola play all the virtuoso material, and in the closing cadential moments where the first violin swaps to the right hand of the piano for several bars to stay at the top of the texture. The rest of the quintet manages the conversational piano lines between them.

\section{Third Movement}

The third movement makes much use of the rising semitone, as shown in the first chapter. This allows the violinists in particular to highlight the closeness between the D sharp- E and $\mathrm{G}$ sharp-A pairings (particularly in the opening section); it also allows the quintet as a whole to produce rich, resonant sounds which are characteristic of the quintet texture. The two violinists carry much of the conversational aspect of the relationship between the

\footnotetext{
${ }^{160}$ This is entirely my own opinion.
} 
original violin and right-hand piano parts; this is demonstrated particularly in bars 62100. Bars 95-121 demonstrate the conversational nature spread across the quintet as a whole, utilising relationships between both upper and lower strings, using the viola as a bridging instrument. Example 2.8 shows the opening of this section.

Example 2.8: Bars 92-100

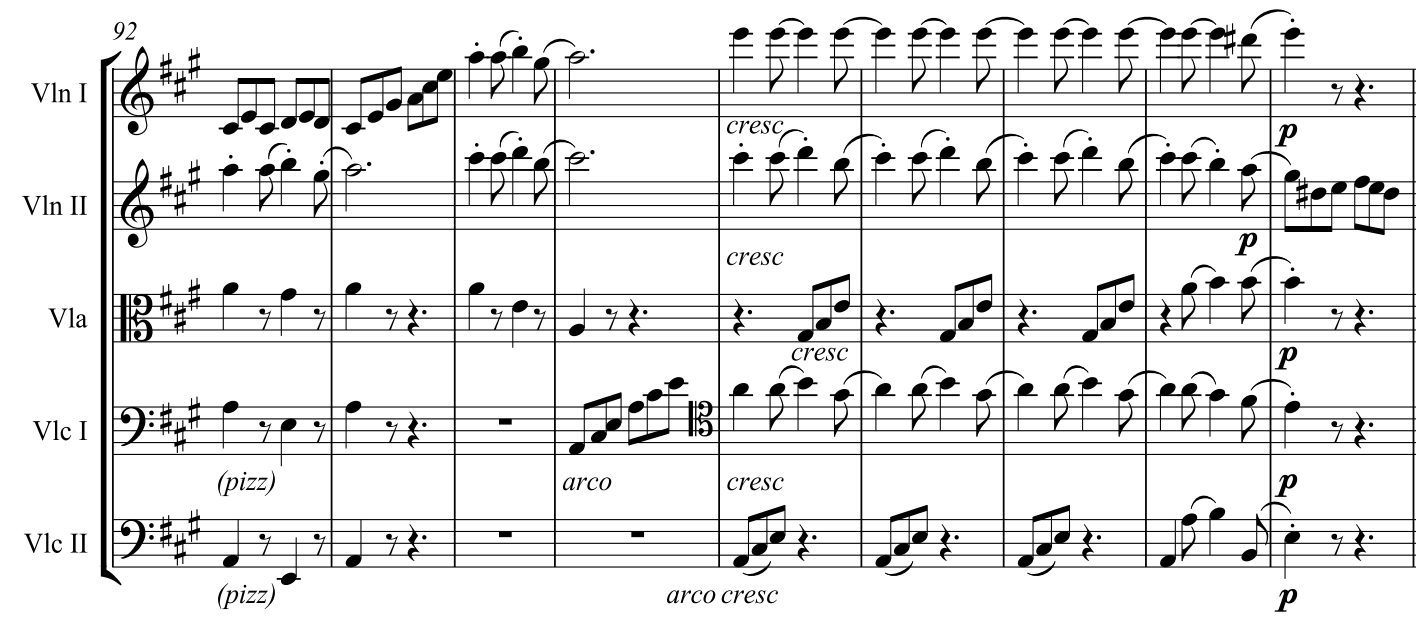

This is also extremely evident in bars 166 through to the first time bar at bar 177 (example 2.9). Due to the nature of the part-writing in the original sonata, the figurations in this movement are all readily transferred to the quintet setting, and the brillant style grants much of the virtuoso violin part to the first (and as mentioned above, in places to the second) violin; yet the dynamic and virtuoso writing for both left and right hand of the original piano line means that the rest of the quintet also receive vibrant virtuosic parts requiring skilled musicians. This allows the quintet demonstrates the shift in emphasis between voices in a very direct and visual manner consumed entirely by the original piano. ${ }^{161}$ I feel that this reproduces what originated as very symphonic piano writing in a highly effective manner - even more so than the two preceding movements.

\footnotetext{
${ }^{161}$ This provides a display for the audience that would otherwise be confined in a large part to the keyboard of the piano and (depending on venue) be hidden from at least half the audience; the passing of motives (rising semitone in particular) and rapid triplet sections between musicians allows for a visually more vibrant display showing the relationships between voices and ideas in a very different manner to the original sonata.
} 
Example 2.9: Bars 166-177
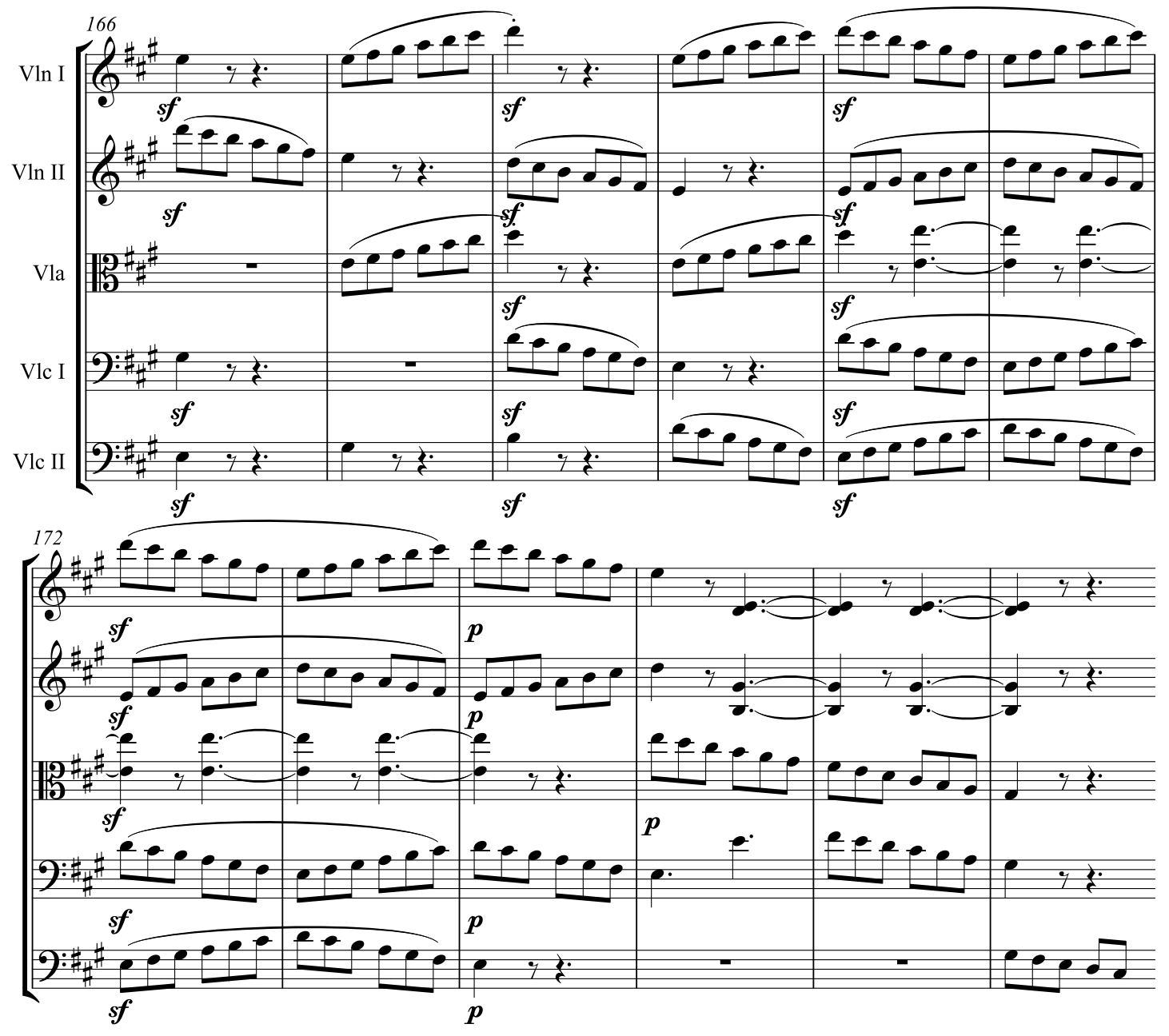


\section{Conclusion}

The quintet transcription of Beethoven's 'Kreutzer' Sonata creates a very different set of interactions between musicians from the original work. While it preserves almost all of the original figurations and technical issues that accompany them, the manner with which the violin part is initially interwoven with the entire quintet, and reduced mainly to the two violins for the remainder of the work creates an interesting mixture of brillant and more texturally adventurous styles of writing. This allows the quintet to explore both virtuosity and conversational writing within short spaces of time; it also demonstrates the bridge between accompaniment/soloist relationships and the effects that the duo concertante original can create when the same material is spread across five instruments.

The visual aspect of the quintet also provides a point of difference between the two, as it not only splits contrapuntal voices but allows them to be witnessed by the listener without the use of a score. As a trade-off, the quintet makes a slight concession as far as competitiveness between voices when compared to Beethoven's original sonata, as by giving them to five string instruments it evens out the impact of the juxtaposition of piano and violin timbres; The impact of this is lessened by the register differences between instruments and the aforementioned visual impact of the five musicians.

The transcription contains a level of difficulty that preserves the virtuosic nature of the original and as such would still require at the least skilled amateur musicians to manage the part-writing; however given the date of publication (1832) it is probably marketed at the growing number of professional musicians and musical societies dedicated to the study and performance of 'serious' intellectual music. Given the direction Beethoven's chamber music for strings was heading, it may have been drafted by either him or one of his students; however, lacking any concrete evidence to support that theory (and the date of publication) it seems more likely that it was created and released by Simrock to take advantage of the growth in the chamber music market and to stay ahead of changes in the concept of copyright before an opportunity to release a version of a polarising work such as the 'Kreutzer' disappeared.

In the 1830s Prussia was solidifying its version of the concept of 'copyright', and the general trend was towards recognizing music (specifically, that which is published by the 
composer) as an 'intellectual work' which influences performers. The result was an act which protected the rights of the composer after their death for a period of 'ten years after the author's death if unpublished insofar as arrangements were concerned'. ${ }^{162}$ This would have created potential copyright infringement issues for Simrock should they have waited much longer to publish the transcription, as arrangements were included under the 1837 Prussian Copyright Act; Simrock was one of the major publishers to recognise the inherent 'property right' of a melody as early as 1830; as such Simrock presumably realised that given that in Britain copyright had already extended to the content of entire books decades earlier, greater change would not be far behind. ${ }^{163}$

This also has roots in the developing 'work concept'. Even by the time Beethoven composed the original 'Kreutzer' Sonata, composers in Vienna were beginning to request that publishers print scores exactly as they received them. At one stage Beethoven requested that the date be printed exactly as he had written in his score; by 1826 he asked that they include his tempo markings (often precise metronome markings). ${ }^{164}$ The arrangement industry was also impacted; as composers took greater control over the perceived value of their published works, arrangements came to be understood as a different version of a work. ${ }^{165}$ As such, borrowing sections of works without permission became viewed as theft - which fortunately does not apply to either of the arrangements in this study, as neither of them purport to be anything other than an arrangement. However, Goehr also states that this type of composition became viewed as derivative or unoriginal, which implies a lack of worth. ${ }^{166}$ Both of the arrangements in this study are far from 'worthless', and through the analyses we can see that they contain rather creative ways of solving problems and recreating Beethoven's work in different new medium. In the following chapter, I will look at the four-hand piano arrangement by Czerny and show how Beethoven's 'Kreutzer' has been arranged for very different social dynamic to either the quintet transcription or original sonata.

\footnotetext{
${ }^{162}$ Friedemann Kawohl, 'Music Copyright and the Prussian Copyright Act of 1837', in J. Samson and B. Zon (eds.), $19^{\text {th }}$ Century Music Studies, London: Ashgate, 2002, pp. 283, 294-5.

163 Ibid., p. 282.

164 Lydia Goehr, The Imaginary Museum of Musical Works: An Essay in the Philosophy of Music, Oxford: Clarendon Press, 1992, pp. 224-225.

165 Ibid., pp. 222-223.

166 Ibid., pp. 221-223.
} 


\section{Chapter 3: Czerny and 'Kreutzer'; a quatre mains}

\section{Introduction}

In this chapter I will be examining a second contemporary transcription of Beethoven's 'Kreutzer' Sonata: Grand Duo Brilliant pour le Pianoforte à quatre mains, arrange d'apres la Sonate de L van Beethoven Oeuv 47. ${ }^{167}$ This transcription for the popular fourhand piano market was completed by Carl Czerny and released by Anton Diabelli's publishing firm in 1827 - the year of Beethoven's death.

In order to properly investigate the transformation of Beethoven's 'Kreutzer' Sonata from duo concertante to à quatre mains some ground work is necessary. First I will examine the market for duet (four-hand) transcriptions in early to mid-nineteenth-century Vienna, and the types of music involved in catering to this market; I will then look at the link between the dominance of the piano and Czerny's role as a teacher. Having shown the need for reasonably rapid publication rates amongst the amateur-influenced publishing industry, I will briefly examine Czerny: both his numerous contributions to composition - with an emphasis on his four-hand piano repertoire - and his relationship to Beethoven. Finally I will look at the transcription itself and the manner with which the duo concertante relationship between violin and piano is reconfigured to be played by two performers at the same piano.

\section{Writing (or re-writing) for four-hand pianoforte}

During the early nineteenth century, the public concert was on the rise. However, personal finances aside, this was only really true if 'one lived near a major metropolitan center'. ${ }^{168}$ Therefore in order to reach the majority of consumers - amateur musicians, music teachers and music-lovers - that either could not afford to attend concerts regularly or did not live near a concert hall or similar performance venue, an additional method of distributing musical works such as string quartets and symphonies to the wider middle class needed to

\footnotetext{
167 Translation: Grand duo brilliant for the pianoforte with four hands; an arrangement of the Sonata Opus 47 by L van Beethoven. This translation is my own.

${ }^{168}$ Thomas Christensen, 'Four-Hand Piano Transcription and Geographies of Nineteenth-Century Musical Reception', Journal of the American Musicological Society, Vol. 52, No. 2, 1999, p. 259.
} 
be found. This has deep ties to both the rise of the bourgeoisie and spread of the piano (as both the dominant keyboard instrument and as a domestic instrument); the ownership of pianos in homes continued to grow throughout the nineteenth century. ${ }^{169}$

The most common method of making music written the concert hall available to domestic consumers was the arrangement. While the string quartet primarily the domain of the male amateur and professional musician, the piano was the primary instrument of choice for women making music in the home. ${ }^{170}$ This meant that aside from rearranging works for chamber music groups such as quartets and quintets, the other market for arrangements of concert hall works was the piano-playing middle class and aristocracy. ${ }^{171}$ This covered both solo arrangements (such as the two-hand Winkler and Godowsky versions of the 'Kreutzer' Sonata); but also four-hand transcriptions such as the version prepared by Czerny to be looked at by this study. ${ }^{172}$ Bashford mentions that four-hand transcriptions of the quartets destined for a male audience 'were a means by which women could get some hands-on experience of this repertoire. ${ }^{173}$

Christensen points out that one of the major advantages for creating arrangements for piano - be it for two or four hands - is a simple and easy manner of packaging complex works for consumption in the pre-recording industry era. ${ }^{174} \mathrm{He}$ is correct to state that it is logistically far easier to gather two musicians to read through a composition than it is to put together a string quartet. The four-hand versions of works - regardless of source -

\footnotetext{
${ }^{169}$ Cyril Ehrlich, The Piano: A History, Oxford: Clarendon Press, 1990, pg. 222. This assumes worldwide production figures bear at least a linear relationship to worldwide increases in piano ownership. Leon Botstein also made a similar statement (from a different angle) in his 1985 dissertation about the growing ownership of the piano in most Viennese middle-class homes. Leon Botstein, 'Music and Its Public: Habits of Listening and the Crisis of Musical Modernism in Vienna, 1870-1914', PhD diss., Harvard University, 1985. p. 70.

${ }^{170}$ Christina Bashford, 'Historiography and Invisible Musics: Domestic Chamber Music in Nineteenth-Century Britain', Journal of the American Musicological Society, Vol. 63, No. 2, 2010, p. 307. Bashford also mentions that this remained the case in Britain until at least the 1870 s.

${ }^{171}$ Christensen, 'Four-Hand Piano Transcription', pp. 259-262.

${ }^{172}$ The Winkler is likely from the late 1800s; the Godowsky appears to have been published in the U.S. in 1915. While these dates are much later than the scope of study, they are still examples of works of a similar nature to those available during the mid-nineteenth century. Being transcriptions of the 'Kreutzer' Sonata they are related to the content of this study, and are readily available on IMSLP.org.

${ }^{173}$ Bashford, 'Historiography and Invisible Musics', p. 309.

${ }^{174}$ Christensen, 'Four-Hand Piano Transcription', p. 260.
} 
offered every musical amateur the opportunity to get to know some orchestral or chamber music as well as - and perhaps better than - any seasoned concert subscriber. ${ }^{175}$

The benefit of the four-hand transcriptions was manifold: composers (and publishers) were able to market their works to an ever-growing domestic scene. These transcriptions would allow not only the amateur to get to experience the material being consumed by the public concert audiences from the comfort of their own home, but also to play through the music whenever they wanted instead of being forced to wait for their local concert hall to put on a performance of a particular symphony or piece of chamber music. ${ }^{176}$

There were additional reasons for the existence of some of the four-hand versions of larger works: use as trial performances of symphonies prior to their appearance in an orchestral concert; critical reviews of newly composed works; and for the purposes of composition or piano instruction. ${ }^{177}$ The creation of a four-hand transcription (for example, a four-hand symphonic reduction - or draft reduction) could fulfil potential uses for at all stages of the preparation of a symphony; these same editions could then be used by the critic to compile a review of the work in a setting where it was considered possible to 'comprehend' the work as a whole without the necessity of a full orchestra; later on those same editions could be used by the pedagogue to teach skills ranging from counterpoint to coordination and sight-reading.

Some composers created their own editions: Brahms in particular created a lot of reductions or transcriptions of his own work; ${ }^{178}$ others did some of their own works Mozart sometimes preferred to do his own reductions of large-scale works. ${ }^{179}$ Another

\footnotetext{
175 Ibid.

${ }^{176}$ This is in addition to being available as an alternative to said performances, in order to increase both profit and exposure.

${ }^{177}$ Christensen, 'Four-Hand Piano Transcription', pp. 263-267. He mentions specifically that it was: 'common in the Parisian salons of the mid-nineteenth century to test orchestral works with fourhand (and sometimes eight-hand) versions before actual concert performances took place' ${ }^{178}$ Ibid., pp. 267-268

${ }^{179}$ There is a famous anecdote which describes Mozart's desire to produce a reduction of his 'Entführung aus dem Serail'; urged by his father to create a piano reduction before anyone else can, he eventually begins an extensive re-composition process to mould it in a pianistic form. However he only makes it as far as the second act before someone else releases a reduction. In a letter to Nannerl on 16 Demeber 1785: Leopold writes: 'Now it has come to pass exactly as I
} 
style of composer was the pianist-virtuoso who created two-hand transcriptions of works in the virtuoso style for their own use (Franz Liszt is probably the foremost historical example). But there was a class of composer who specialised in transcribing the works of others for the growing four-hand market: Czerny belongs to this category, with a long list of reductions ranging from chamber music to symphonies to his name. ${ }^{180}$ Hummel also belongs under the specialist arranger category. The majority of his arrangements were for piano, violin, flute, and cello (he had an extensive collection of settings of Mozart's works in particular); ${ }^{181}$ he also created piano reductions of Beethoven Symphonies 2-7. ${ }^{182}$

\section{The Rise of the Pianoforte; or the Pedagogue in the Home}

As a direct result of the rise of the middle class and domestic status of the piano, demand for teachers of the piano grew accordingly. ${ }^{183}$ The virtuoso pianists - who were fast becoming the dominant force on the stage - were gradually displacing the market share of the virtuoso violinist, and parents were beginning to wonder if their child could be the next Mozart. The one on one master-apprentice lessons were viewed as the essential method of acquiring proficiency, and this allowed pedagogues of the likes of Czerny, Hummel, and Clementi to command a not insubstantial fee for their services. ${ }^{184}$

Basic tuition was generally handled by a regular music-master. There are many notable pianists who were initially taught by their father - Mozart, Beethoven, Czerny and Liszt are a few from the names already mentioned in this study. ${ }^{185}$ However, if one either saw

foretold to my son ... he has lost his time, and Torricella ... his profits.' Otto Jahn, Life of Mozart, Trans. Pauline Townsend, London: Novello, Ewer \& Co., 1891, p. 215.

${ }^{180}$ Fuchs, 'Beethoven's Ambassador Posthumous', pp. 91-95.

${ }^{181}$ Mark Kroll, Johann Nepomuk Hummel: A Musician's Life and World, Lanham: Scarecrow Press, 2007, p. 21.

${ }^{182}$ Mark-André Roberge, 'From Orchestra to Piano: Major Composers as Authors of Piano Reductions of Other Composers' Works', Notes, Second Series, Vol. 49, No. 3, 1993, p. 927.

${ }^{183}$ James Deaville, 'A Star is Born: Czerny, Liszt, and the Pedagogy of Virtuosity', in David Gramit (ed.), Beyond the Art of Finger Dexterity: Reassessing Carl Czerny, Rochester: University of Rochester Press, 2008, p. 53.

${ }^{184}$ Stephan D. Lindeman and George Barth, 'Czerny, Carl': Grove Music Online. Oxford Music Online, Oxford University Press, available from http://www.oxfordmusiconline.com/subscriber/article/grove/music/07030; accessed October 27, 2012.

${ }^{185}$ Alan Walker, et al., 'Liszt, Franz': Grove Music Online. Oxford Music Online, Oxford University Press, available from http://www.oxfordmusiconline.com/subscriber/article/grove/music/48265pg1; accessed 
the potential for natural proficiency in a student or wished to attempt to push a child into superstardom, they were inevitably sent to either an accomplished teacher (Liszt was sent to Czerny for fourteen months) ${ }^{186}$ or to a renowned performer/composer (Czerny was tutored by Beethoven for three years; ${ }^{187}$ Hummel was taught by Mozart). ${ }^{188}$ Those more advanced teachers taught both performance and composition at the same time; Czerny is said to have 'lamented' the fact that 'Liszt [began] his performing too early, without the proper training in composition. ${ }^{189}$

Czerny's teaching style an amalgamation of the tuition he had received at the hands of his father, Beethoven, and his association with Clementi. He began teaching at the age of 15 , and by 1815 Czerny was reportedly giving one-on-one lessons for twelve hours a day; one of his students was Beethoven's nephew, Carl. ${ }^{190}$ This provided him with a circle of students with which to hold a musical salon (at which, amongst other things, his students performed works by Beethoven); not only this, but it also provided him with an impetus to compose pedagogical works - studies, exercises, and instructional methods are amongst his output. ${ }^{191}$ However, there is one major source of his output that forms both a teaching tool and potentially marketable option: the transcriptions for piano, both for piano solo and four-hands.

November 23, 2012. Their parents were all professional musicians; I do not mean to imply that family members in general were responsible for initial tuition.

${ }^{186}$ Ibid.

${ }^{187}$ Lindeman and Barth, 'Czerny, Carl'.

${ }^{188}$ Kroll, Johann Nepomuk Hummel, pp. 11-18.

${ }^{189}$ Lindeman and Barth, 'Czerny, Carl'.

${ }^{190}$ Alice M. Hanson, 'Czerny's Vienna', in David Gramit (ed.), Beyond the Art of Finger Dexterity: Reassessing Carl Czerny, Rochester: University of Rochester Press, 2008, p. 26. Also see Fuchs, 'Beethoven's Ambassador Posthumous', pp. 83.

${ }^{191}$ See the Index of Works located in David Gramit (ed.), Beyond the Art of Finger Dexterity, Reassessing Carl Czerny, Rochester: University of Rochester Press, 2008, pp. 275-277. 


\section{Czerny: the collected works}

Czerny was a prolific arranger of musical works. Initially he copied out Beethoven Symphonies from parts to create scores; but he soon began composing his own works. These (and his arrangements) were initially so successful that his publishers let him publish as much as he wanted. ${ }^{192}$ The true extent of his transcriptions and arrangements is unknown; however there are at least 300 published transcriptions. His total output transcriptions and original compositions alike - number 861 individually published works with opus numbers; a similarly high number of unpublished works and transcriptions without opus number by Czerny also exist. ${ }^{193}$

Czerny's compositional output catered to both the amateur and professional pianist alike, although not usually at the same time. As there was a divide between the expectations of professionals and dilettantes, composers generally focussed on developing works for both markets separately. For most composers their most regular income source would have been the amateur market, which consumed new material at a voracious pace. ${ }^{194}$ Composers like Mozart, Clementi, Haydn and Pleyel published a large number of works for both their students and amateur players alike; ${ }^{195}$ Haydn's keyboard music was as consumer-driven as it was ambitious, and prior to his travels to London and experiences with their concert hall scene it was intended to appeal to both professional and amateur alike. ${ }^{196}$ Mozart's output included works for amateurs (including his students, several of whom received dedications), which were separate to those he composed for himself and his more advanced students (including his concerti, some fantasies and variation sets). His publishers would often create their own versions of this more difficult material in order to market them to the amateur musicians. ${ }^{197}$

Czerny's name is largely associated with his studies and technical exercises by modern

${ }^{192}$ Lindeman and Barth, 'Czerny, Carl.' Grove Music Online.

${ }^{193}$ Anton Kuerti, 'Carl Czerny, Composer', in David Gramit (ed.), Beyond the Art of Finger Dexterity: Reassessing Carl Czerny, Rochester: University of Rochester Press, 2008, p. 139.

${ }^{194}$ K. Komlós, Fortepianos and their Music: Germany, Austria, and England, 1760-1800, Oxford: Clarendon Press, 1995, pp. 109-110.

${ }^{195}$ Ibid., pp. 110-114.

${ }^{196}$ Ibid., pp. 111-112.

197 Ibid., pp. 113-114. Examples given by Komlós include simplified editions of the variation sets K. 179, K. 264 and K. 573. 
scholarship, however his output covers a range of genres and technical proficiencies; there are compositions for the beginner pianist right through to the virtuosi. His composing was not limited to etudes and technical exercises; there are quartets, masses, requiems and symphonies; there are hundreds of arrangements of other composers works for piano (both two and four-hands), included amongst these are Beethoven's complete symphonies and overtures; there are also a large number of works which use themes from popular operas. ${ }^{198}$ Many of those works with opus numbers contain more than one composition. He made a distinction between 'serious music' and brilliant concert pieces, ${ }^{199}$ somewhat unfortunately for Czerny his crowning achievement in the current narrative is his Art of Finger Dexterity, as his 'serious music' is largely unknown and mostly unavailable to the majority of pianists. Czerny had a bit of a reputation as a composer of studies, arrangements and concert pieces. He was aware of this reputation, and wished to make amends for it with more 'serious music'; however appeared unable to resist the call of his publishers - and his last recorded statement of this desire was 33 years after the first, ten days before his death. ${ }^{200}$

The list of published works displays no fewer than 80 compositions for four-hand piano; this includes sonatas, variation sets, a 'Grand Polonaise Brillante' and a concerto for fourhand piano and orchestra. This list includes works utilising themes from operas and other composer's works; however it does not include any of his transcriptions of works for fourhands such as the Beethoven Symphonies and overtures already mentioned. Czerny also made four-hand arrangements of Beethoven's Op. 20 Septet (1824); the Op. 50 Romance for violin and orchestra, which Czerny gave an Opus number (Op. 44); 'Adelaide'; and an arrangement of the second movement of the 'Kreutzer' Sonata (as 'Variations brillantes' in $1822 / 23)^{201}$

\footnotetext{
${ }^{198}$ Anton Kuerti, 'Carl Czerny: In the Shadow of Beethoven', Queen's Quarterly, Vol. 104, No. 3, 1997, pp. 487-492.

${ }^{199}$ Kuerti, 'Carl Czerny, Composer', pp. 139-140.

${ }^{200}$ Kuerti, Anton. 'Carl Czerny: in the shadow of Beethoven.' See Pazdírek, Franz, The Universal handbook of musical literature. Practical and complete guide to all musical publications Vol. 5 Vienna: Pazdírek \& Co., 1904. pp.660-689, available at http://archive.org/details/universalhandboo05pazd for the list of Czerny's catalogued works. ${ }^{201}$ Fuchs, 'Beethoven's Ambassador Posthumous', p. 95.
} 


\section{Czerny: Master and Apprentice}

The first contact between Czerny and his lifelong mentor Beethoven occurred at a young age, when Czerny was already able to demonstrate a command of the piano. Initially taught by his father, he was taken to be introduced to Beethoven around 1800; after hearing Czerny perform the first movement of Mozart's Piano Concerto in C (K:503), Beethoven's own 'Pathetique' Sonata and 'Adelaide' (with the young musician's father as the singer), Beethoven agreed to teach Czerny. ${ }^{202}$ While Czerny only received formal lessons for a few years, the relationship that was forged between the two lasted for the rest of Beethoven's life - and Czerny continued to act as an ambassador for Beethoven for the remainder of his own. ${ }^{203}$

The high esteem in which Beethoven held Czerny is well documented; Beethoven was not fond of making reductions of his own work, and regularly entrusted this task to Czerny. In 1805, Beethoven had Czerny prepare the piano reduction of Fidelio. ${ }^{204}$ In 1825 Beethoven wrote to the Wiener Zeitschrift für Kunst, Liteartur, Theater und Mode to inform the readership that the versions of his Op. 124 Overture (an orchestral work) for both two- and four- piano that Czerny was working to complete would be published in the near future, and were 'completely faithful' whereas the already available four-hand score - already published by one Carl Wilhelm Henning - was 'totally inappropriate ... deviates from the original score. ${ }^{205}$ This was in addition to Czerny having been employed by Beethoven to aid in making corrections to his published works, and in notating Beethoven's extemporisations; both of these were methods by which Czerny developed his compositional and arranging skills. ${ }^{206}$

Czerny's other major legacy from his friendship with Beethoven was his intimate knowledge of Beethoven's entire keyboard repertoire. As early as the age of 13 he had memorised the currently existing keyboard works of Beethoven, and had been employed

\footnotetext{
202 Lindeman and Barth, 'Czerny, Carl'.

${ }^{203}$ Fuchs, 'Beethoven's Ambassador Posthumous', pp. 99-100.

204 Lindeman and Barth, 'Czerny, Carl'.

${ }^{205}$ Fuchs, 'Beethoven's Ambassador Posthumous', pp. 94,105.

${ }^{206}$ Fuchs presents as an example the passage from Czerny's "Anecdotes and Notes on Beethoven" whereupon Beethoven performs a piano version of Gluck's Iphigenie en Tauride from the score, after which Czerny borrowed the score and transcribed the arrangement as he remembered Beethoven having played it.
} 
by Lichnowsky to perform that repertoire for him on a weekly basis. ${ }^{207}$ This familiarity was passed on to Czerny's own students; in his weekly musical salon in which Czerny's pupils performed for family and friends, the works of Beethoven featured frequently on the programme. Beethoven's students would also appear there; Baroness Ertmann Beethoven's pupil and the recipient of the dedication to his Op. 101 Sonata - who performed the work at one of these gatherings. That event also garnered Czerny a personalised 'presentation copy' with the dedication to Czerny in Beethoven's own handwriting. ${ }^{208}$

As already mentioned, one of the uses of the four-hand transcriptions of works was for instructional purposes; Czerny's arrangements of Beethoven's symphonies and overtures were almost certainly played by his students at his musical salons, at which Beethoven was often present in addition to the normal audience of aristocrats, upper middle-class and other noteworthy musicians. ${ }^{209}$ When this publicity was combined with Beethoven himself occasionally performing or extemporising, the salons no doubt led to both the further spread of Beethoven's music amongst the amateur four-hand piano-playing population, and the further popularity of Czerny's other transcriptions and arrangements. ${ }^{210}$

\section{à quatre mains: the four-hand transcription of Beethoven's 'Kreutzer' Sonata}

The four-hand transcription of Beethoven's 'Kreutzer' Sonata has some very distinctive features that mark it as amongst some of the most difficult repertoire that require a grasp of piano technique unlikely to be found amongst the regular four-hand amateur market; some of the manner in which the original sonata has been reconfigured implies the intention for this sonata to be played by either aspiring virtuosos or exceptionally skilled amateurs. First and foremost amongst these passages is the manner in which the most technically challenging elements of the development section in the original piano part have been split between the two parts, requiring strong left-hand technique from the primo and right-hand from the secondo whilst simultaneously removing the element of contrary motion which would give a pianist playing the original part something to balance the gestures each hand

${ }^{207}$ Kuerti, 'Carl Czerny: in the shadow of Beethoven', pp. 487-491.

${ }^{208}$ Fuchs, 'Beethoven's Ambassador Posthumous', p. 85.

209 Ibid.

${ }^{210}$ Fuchs, 'Beethoven's Ambassador Posthumous', p. 85. 
makes in the execution of the passage.

The arrangement also features writing similar to Czerny's symphonic reductions, which flesh out chords or create additional doubling for strength and power. Amongst the changes are some passages where the two players physically cross over arms or immediately seize upon space vacated by the other. The resulting arrangement provides the listener with an experience not dissimilar to the original sonata; however, it provides the pianists with a thoroughly different experience that transforms the communicative and musical elements from that of a distinctive partnership with two voices into one with a very different medium. A number of the alternating or arpeggiated figures are refigured in some manner, in order to accommodate for either their physical location on the keyboard relative to the other players (such as bars 443-448 in the first movement, as we shall see), or to allow them to flow from one gesture into another. One of the common methods Czerny uses to generate extra strength is to have alternating quavers (octaves or with one moving line) in the right hand together with crochets in the left hand to form consecutive triple octaves.

In this analysis I will examine the manner with which Czerny has altered the context within which the 'Kreutzer' functions, lending the power inherent in a texture reminiscent of his four-hand symphonic reductions to the violin and piano sonata. Czerny also takes some artistic licence with both ornamentation and extemporisation in a couple of places; I will highlight moments where these have significance. I will also discuss the way in which this creates a different experience for the pianist to the performance of the original sonata. Page numbers refer to the four-hand score; bar numbers refer to the corresponding passage in the original sonata as the four-hand score has none, but the passages all line up. As with the analysis of the quintet, the majority of the four-hand analysis will focus on the exposition and development of the first movement, and the second movement; most of the techniques and idioms represented within these sections are utilised throughout the remainder of the arrangement. 


\section{First Movement}

Right from the outset Czerny demonstrates that this arrangement is to be a partnership between the two players in more than just setting; Beethoven's difficult opening violin statement is shared between the two parts in such a way that it grows to encompass an extra octave to the original in the final chord. The answering statement similarly contains far more expansive writing than the original; while the right hand of the primo is only one octave above the initial piano part's right hand (which it closely reflects) the textural density is doubled. Czerny preserves the conversational aspect of the interjections in the highly chromatic section during bars 13-18, although the top of the texture and interjections themselves are doubled. This also doubles the rising semitone; also the falling b-natural/b flat sequence in bars 13-15. Example 3.1 shows how the pianists interact during the entire Adagio introduction.

The next opportunities Czerny takes to strengthen the texture are the block chords at the end of each phrase in $1 \mathrm{P}^{211}$ This continues into the cadenza; instead of belonging to one part, the cadenza is instead played by both primo and secondo a tenth apart. This is also extended somewhat; the range extends right up to the $\mathrm{E}$ above that presented in the original sonata, and spends four repetitions of the arpeggio gesture up at that extreme of the piano before terminating with a four-octave arpeggio instead of the three-octave arpeggio from the original. ${ }^{212}$ Accompanied with a separate 'Prestissimo' marking, this is simultaneously more exhilarating and more challenging to execute than the original cadenza as it involves co-ordinating with another pianist. Example 3.2 shows the notation of this double cadenza.

Doubling - characteristic of symphonic orchestration - is again employed to emphasise the rising semitone in the 'a Tempo' transition to $2 \mathrm{P}^{213}$ The piano quavers which drive this section split are between both players throughout pages 4-7; this causes the first example of the left hand of the primo being asked to play figurations initially intended for both hands to execute simultaneously from bar 61 . The chorale section which follows (1S) involves more doubling - here it is contained initially within the secondo in the first

\footnotetext{
${ }^{211}$ These are in bars 25-27 and 34-35 (the phrase into the cadenza).

212 This top E was not present on any of Beethoven's 1803 pianos (see introduction).

${ }^{213}$ Adler, Samuel. The Study of Orchestration. $3^{\text {rd }}$ ed. New York: Norton, 2002, pp. 569-583.
} 
Example 3.1: the Adagio

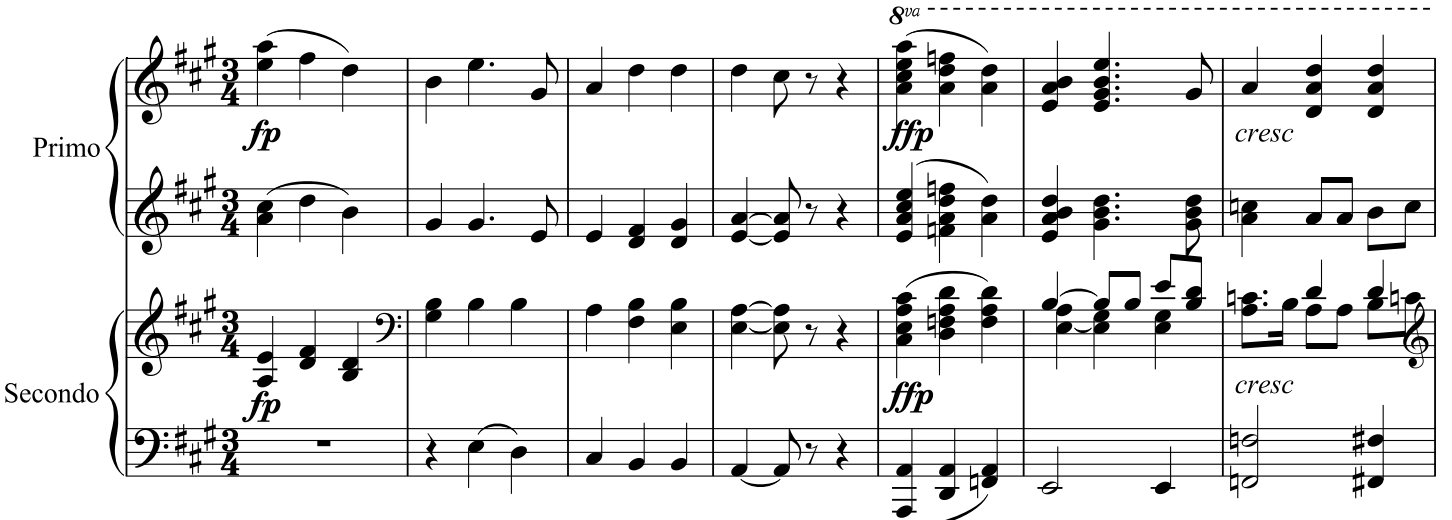

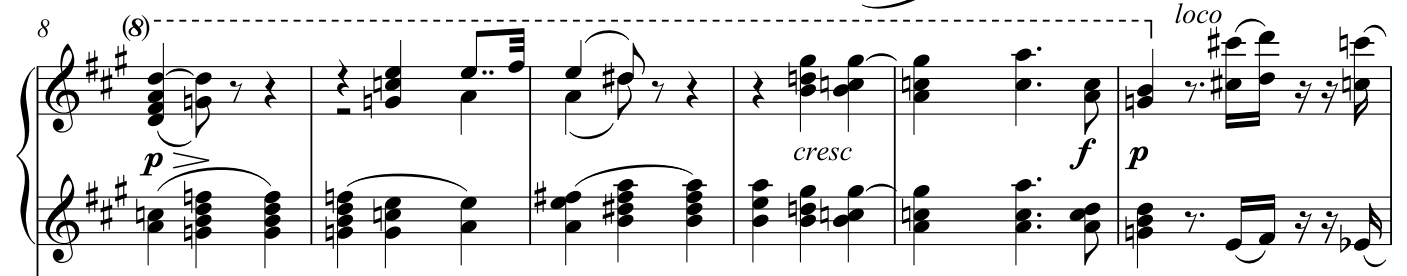

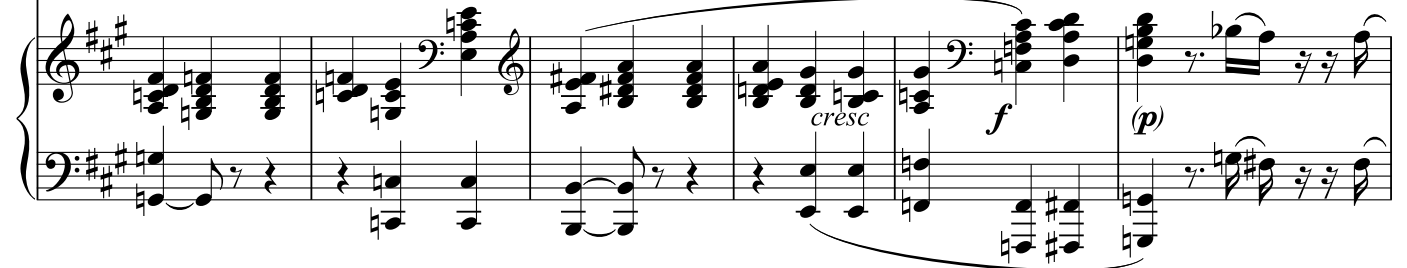

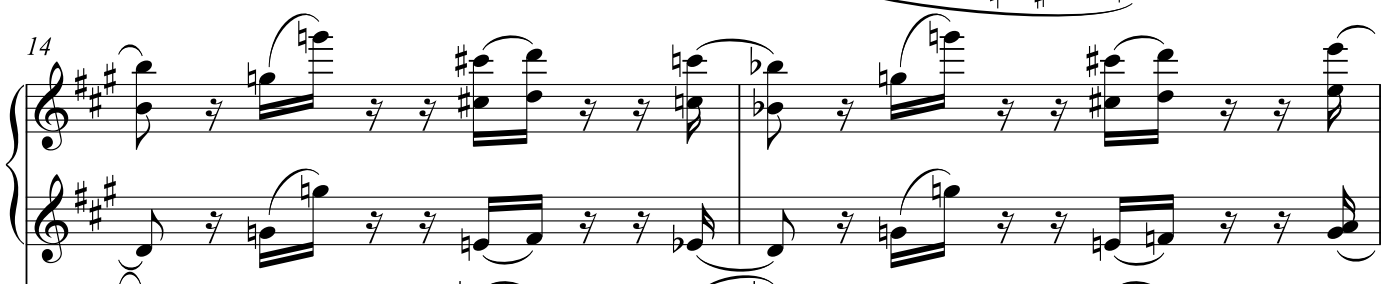

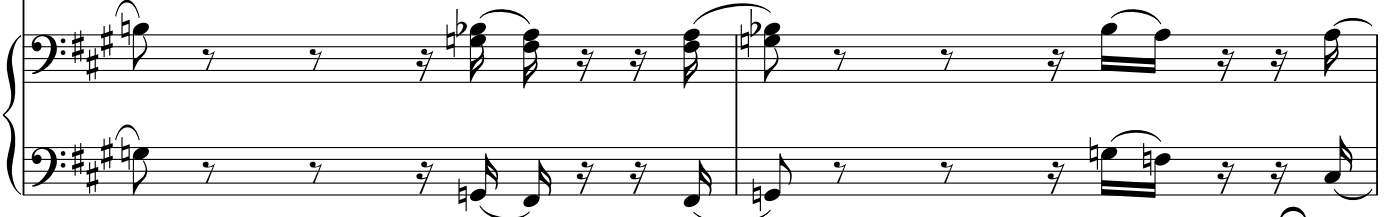

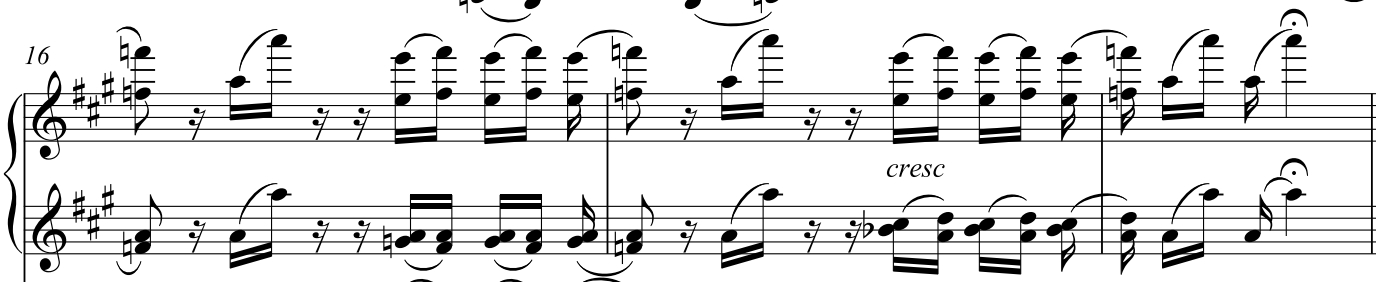

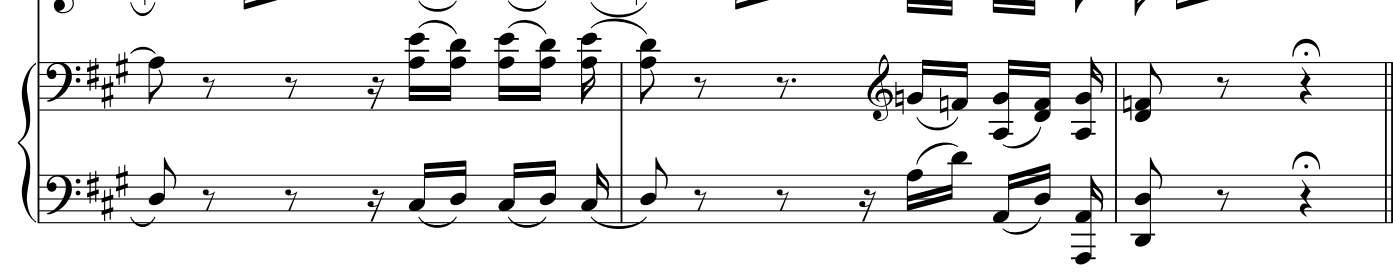


Example 3.2: the Cadenza

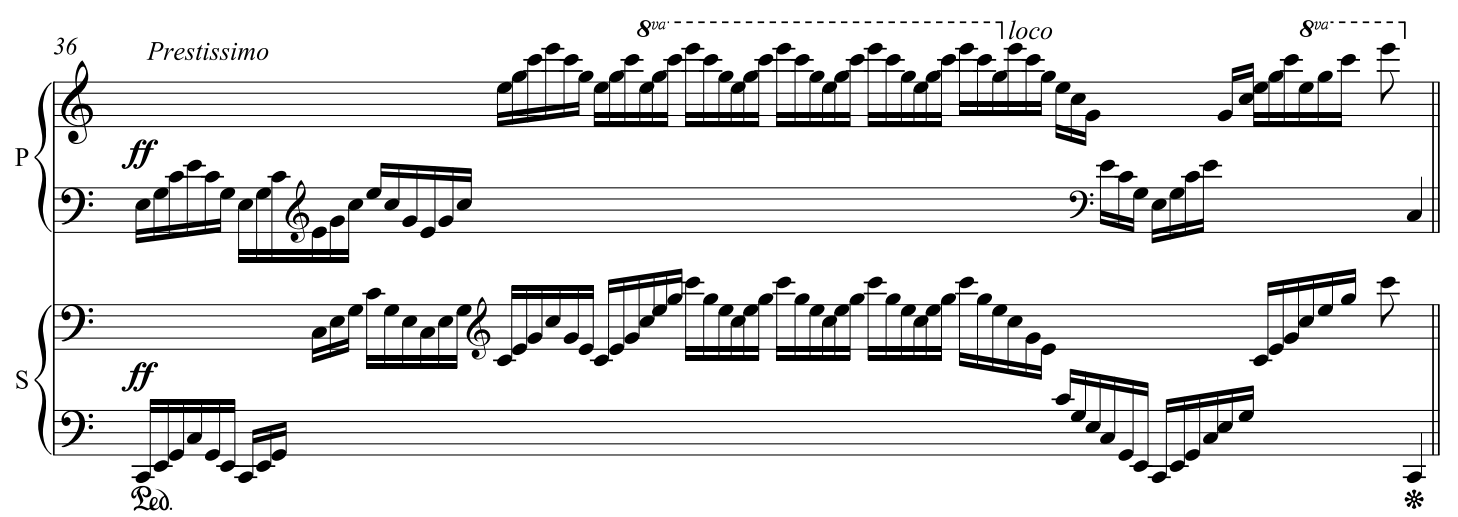

phrase, as it includes the original violin line as well as the primo; the second phrase contains more extensive doubling in both parts, and also features the addition of a turn (into an added octave) and trill to the violin part. ${ }^{214}$ The primo is also written an octave above the original violin part for the second phrase; this is in order to provide clearance over the thickened texture of the secondo. As a result of the extra doubling between parts, both players are required to work together for the initial statement of 1S (example 3.3), instead of allowing one to set the tone for the other to emulate or change in their answering phrase. ${ }^{215}$ A similar effect is taken advantage of in the build-up to the end exposition on pages 8-11: these climatic passages allow Czerny to display the raw power the piano with up to three pairs of double-octaves plus an almost continuous swirling undercurrent of quavers. $^{216}$

In the development section, Czerny takes advantage of both the extremities of the piano and the individual performers to emphasise the conversational elements of the 'Kreutzer'. The very first phrase is split between both parts - Czerny choosing to double the entirety of the melodic line, which initially featured doubling only in the first three

\footnotetext{
${ }^{214}$ The turn from the original piano part has been omitted.

${ }^{215}$ While it is still possible for the secondo to make interpretive changes in the second statement of this phrase, it removes the expressive individuality of the first phrase.

${ }^{216}$ This also holds some differences in configuration from the original; in particular the final bars into the closing material of the exposition (bars 172-177) contain alternating octave quavers in three hands (one additional pair compared to the original, as the violin part has been refigured into a more pianistic pattern). In addition, the changes to the right-hand of the secondo to treble rather than double the melodic line function to not only provide strength to match the additional power of the surrounding texture, but in combination with the use of extreme registers they also create additional excitement for both players through the high-powered growth pushing forward into the following section.
} 


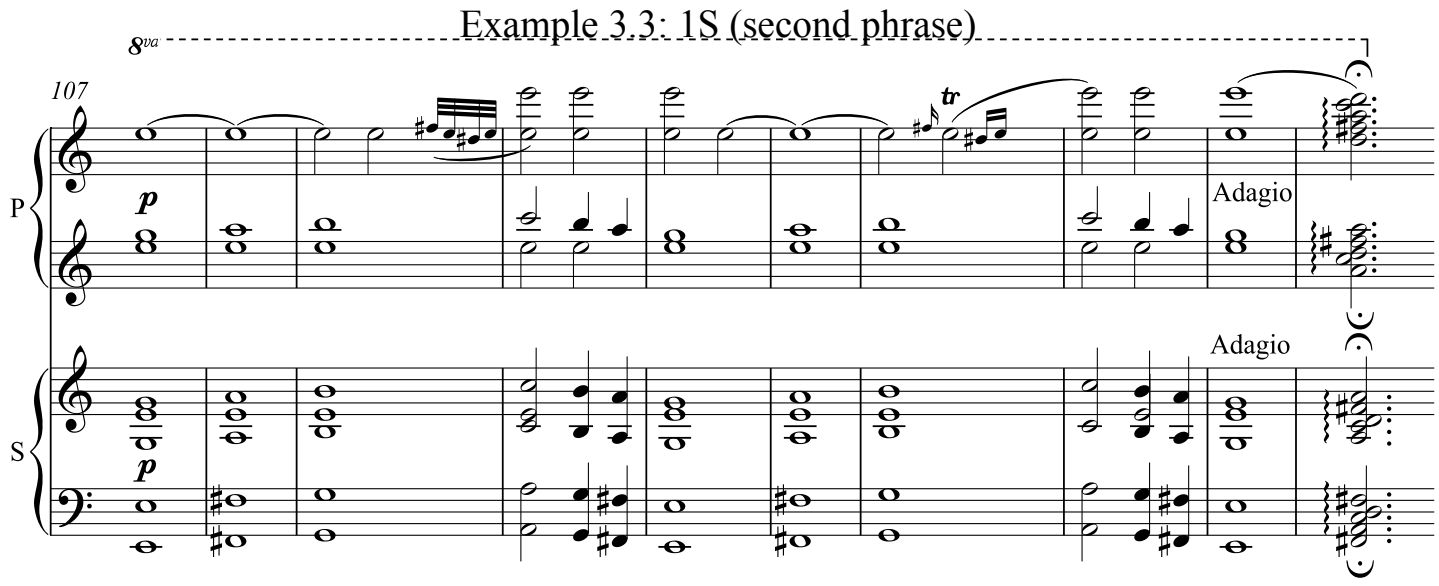

bars. ${ }^{217}$ The second phrase creates a conversation which did not exist in the original sonata by adding an extra F\#-G response to the primo in the right-hand of the secondo (bars 202$204) ;{ }^{218}$ the secondo then echoes the movement of the primo two octaves below. This has the additional conversational effect of constant swapping between registers; the conversation is elaborated upon in much the same way as Beethoven's original piano part during bars 214-226, but with the left hand in the secondo; and right-hand given to the primo and displaced up an octave. The following technically challenging section (from bar 226 - this begins on pages twelve and thirteen on the bottom system) splits Beethoven's piano figures between parts; the original right hand figures predominantly in the primo left hand, while the original left hand figures predominantly in the secondo right hand. This has the complicated effect for the players of removing the balancing gesture that a pianist playing the original sonata receives; all the original alternating-third gestures were either given to the right hand alone or balanced by a contrary motion set of alternating thirds in the left hand beginning a second below those of the right hand. ${ }^{219}$ While this increases the level of direct interaction between players, it also complicates matters somewhat as it gives rapid complex figures intended for one musician to a pair of musicians - and inverts the hand they are asked to perform them with.

This continues in some manner all the way through to the D-flat major section; while the

${ }^{217}$ Interestingly, Czerny decides to omit the quadrupling in bar 201 in favour of using the secondo to add a lower sixth and create a strong $V$-i root movement into the following phrase (instead of the implied version of the original).

${ }^{218}$ This prefaces the actual conversation from Beethoven's original sonata in bars 210-213; this however only occurs between hands of the piano.

${ }^{219}$ These were either major or augmented seconds; hence the use of the more general 'second'. 
secondo receives the entire piano part from bar 250 to round out the section (albeit with most of the right hand transposed down an octave to accommodate the primo, minus a few minor re-figurations), the primo plays the violin part in their right hand and the right-hand part of the original piano with their left. The little interjections which occur throughout this section (and alternate between violin and piano in the original) swap between the bass and treble registers in the Czerny - Czerny even requires both players to cross their own hands over while executing them, while matching their rapid quaver gestures with the other player. This is substantially different to the interactions between the quintet - while their moments overlap and intersect, they do not achieve this with the same intimate physicality that the two pianists must. Refer to example 3.4 for a closer look.

Czerny chooses to double the entire melodic line during bars 300-313; this creates twice the emotive content of the semitone movements relative to the original as the secondo reproduces the accompanying texture almost exactly. The descending quaver figure(bars 308-311 and 318-321) is played both times by primo; this allows Czerny to keep the accompanying figure in the bass register, reminiscent of Beethoven's use of piano block chords in both places for the original sonata. This has the interesting effect of reducing the interplay between the two parts, as it allows the primo to dictate the amount of ritardando in both phrases as it has the moving part. This has the potential to make any variation between the two seem less conversational than Beethoven's setting.

Pages 22 and 23 feature several exciting additions to Beethoven's original sonata. The first of these is the doubling of the bass in the secondo bb. $402-405$; and then subsequent refiguring of the left hand to stabilise the bass moving in to the reappearance of $2 \mathrm{~S}$. The next is the refiguring of the violin part for the primo across the same bars; this is embellished with a rapid ascending scale to the actual entry of the original violin part (displaced up an octave). The other addition is again in the primo: the violin part has been displaced up an octave for the second phrase (bars 428-437) and adorned with a trill that runs right though to a terminating figure during the second half of bar 436 . 
Example_3_4: Bars 234-258 (continues_over_page)
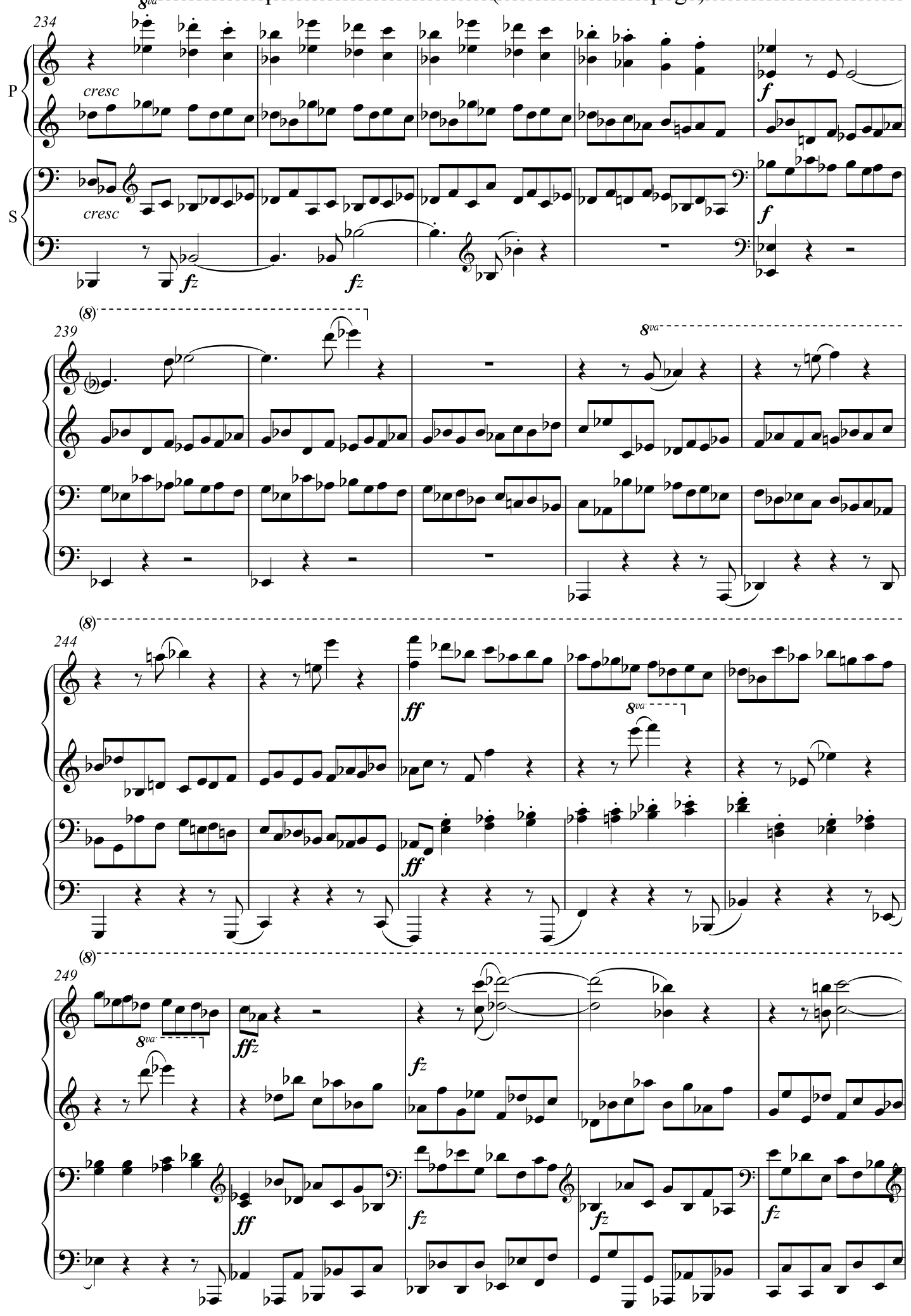


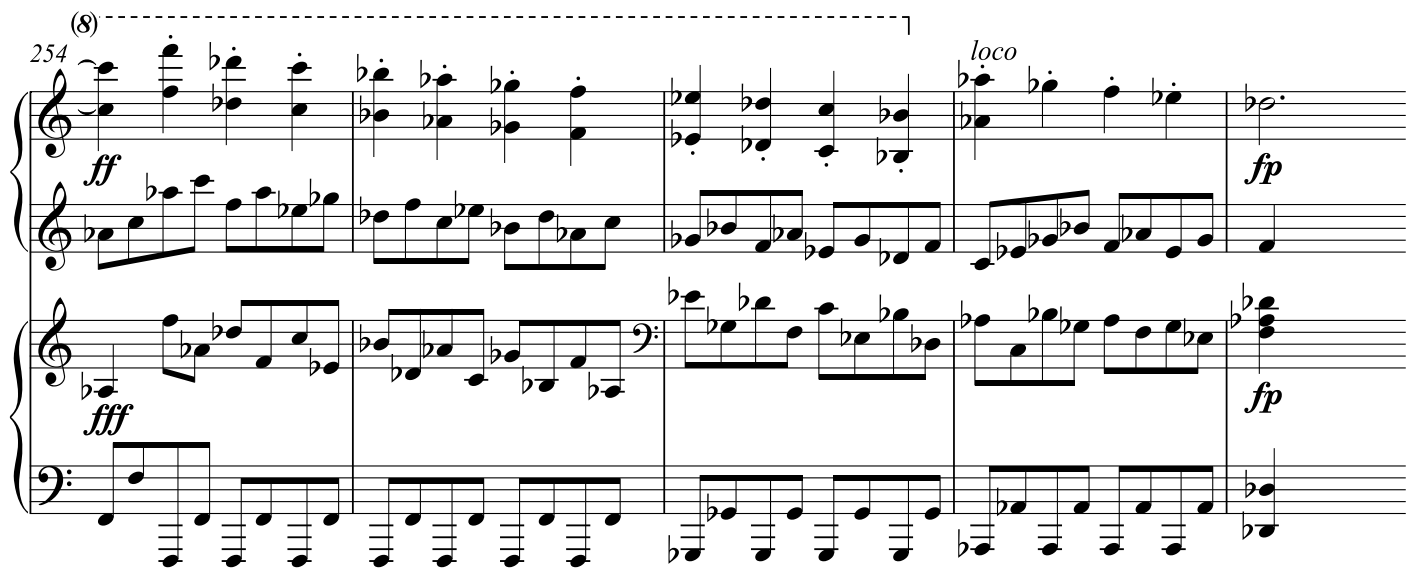

Two other moments in the first movement demonstrate some of the differences Czerny needed to make to the four-hand arrangement to avoid issues created by placing the original parts onto one piano. One is an example of re-figuration to avoid the other player and their own hands: on page 25 (bars 443-448), primo executes the right hand of the original piano with a couple of small alterations: the right hand is displaced up an octave; and the bottom d" $-\mathrm{c}$ " in the arpeggio is altered to e" $-\mathrm{c}$ " in order to avoid the left hand, which is tracing the original violin part (combined into staccato crotchets) in order to avoid contacting with the secondo. The second moment occurs on pages 28 and 29, where the four-hand arrangement allows Czerny to utilise the doubled double-octaves in the decay from the climax into the ghost-like long open pedal. ${ }^{220}$

\section{Second Movement}

The second movement contains a number of moments of artistic licence; it also contains many of the elements of the original sonata in a directly recognisable form - such as a distinct division of the original piano and violin parts between the primo and secondo parts.

The Andante theme contains the original piano part within the secondo in its entirety: there are a few differences near the end of the theme, but these are either due to the notes having been included in the primo or a filling-out of the texture at the cadences. The primo begins as a doubled violin line, but develops into a symphonic extension of the secondo from bar

${ }^{220}$ Czerny includes this pedal marking in full; it is the only pedal marking in this movement. 
45 ; by the end of the theme it has thickened to the point that it is removing the upper notes from the secondo at the cadence.

In the first variation, the secondo consists entirely of the original piano part. Czerny has made a number of additions in the primo: while it contains the original violin part, it also includes an additional bass part which requires the player to reach across the secondo performer and produce bottom Cs; they are then required to use their left hand to play in between the two hands of the secondo player on two different occasions. Just as in the development of the first movement, this space is vastly more intimate than the other settings of 'Kreutzer'. Beethoven's original features the violin interjections on top of the texture, whereas the quintet arrangement has the musicians intertwine slightly more - but mostly because there are five of them to split the parts between. The four-hand arrangement asks each of the pianists to physically intrude upon the other musician's space. $^{221}$

Example 3.5: Bars 55-62 (second variation, bars 1-8)
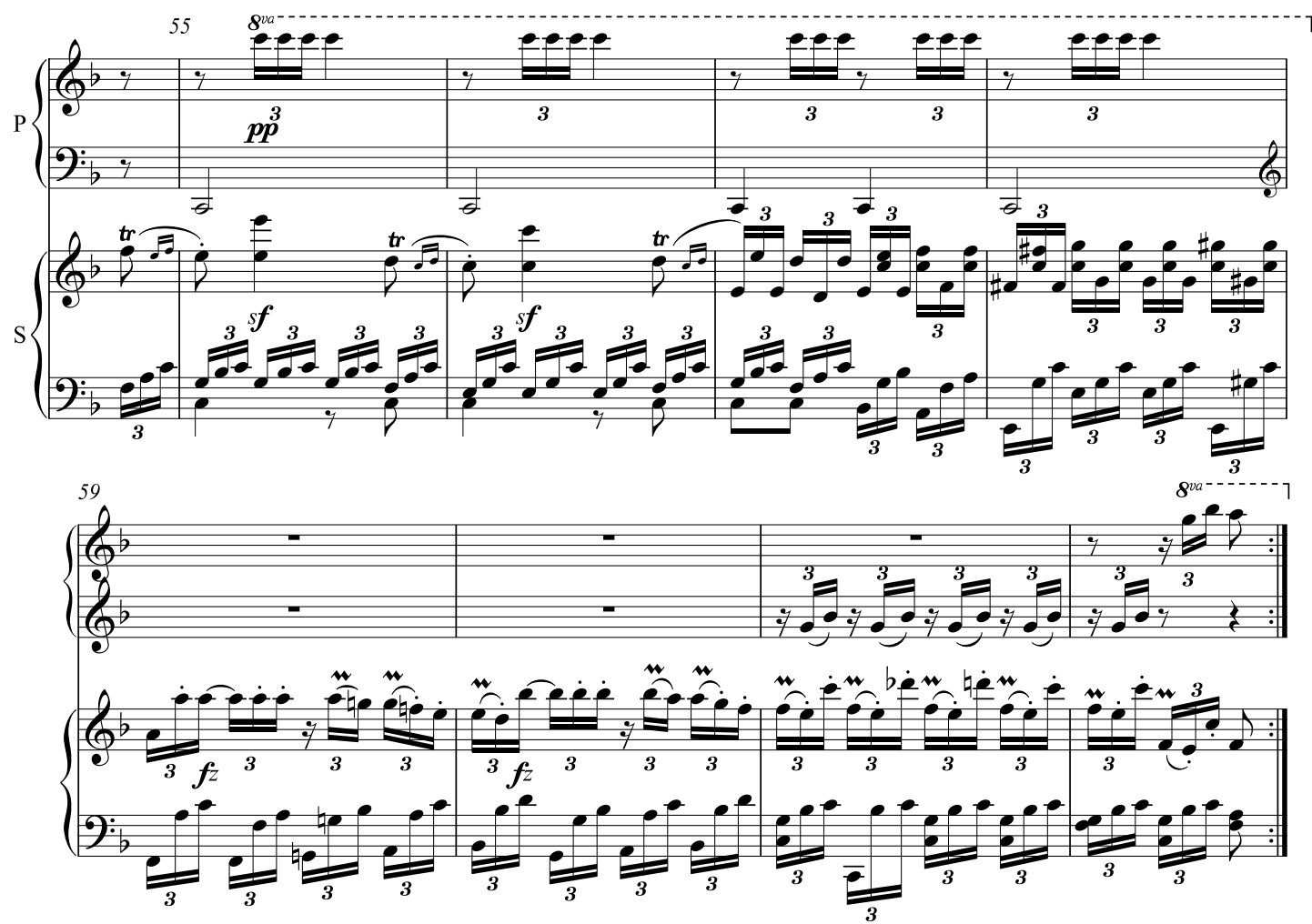

The second variation has the same part division as the first, minus the additional bass

${ }^{221}$ Philip Brett talks about the potential implications and embarrassments of this kind of situation (and that explored in 'Example 3.4') in his article 'Piano Four-Hands: Schubert and the Performance of Gay Male Desire'. 
notes. Czerny adds a few additional ornaments to the final statement of the theme in the primo. The third variation is similar to theme in its construction; however, more of the symphonic writing occurs in the primo part than in the Andante, reflecting the darker and more expansive colours of the Minore variation.

The fourth variation changes roles around: primo opens with the original piano line, and then swaps to the violin at its thematic second phrase entry in the original - in much the same way that the first violin in the string quintet does. ${ }^{222}$ Czerny adds an element of levity with the secondo: he invents an offbeat dominant pedal bass line for the first four bars, and then threads the secondo right hand into the space between the primo player's hands from bar five for a couple of bars in an adaptation of Beethoven's original violin entry (prior to its acquisition of the theme).

Although there is a concentration of the brilliant writing in the primo part during the second movement, Czerny goes to some length to preserve Beethoven's conversational aspects between players. An example of this is the manner with which the call and response ornamentation between players on pages 44 and 45 (bars 16-18) remains from the original; ${ }^{223}$ the same thing occurs during the echoing passage on pages 46 and 47 . From this point Czerny starts to add and remove ornaments - mostly adding new ornaments. ${ }^{224}$ Czerny essentially orchestrates the remainder of the movement up to the cadenzas on pages 48 and 49, adding additional notes and doublings to both parts. The initial cadenza - given to the secondo - is the same as the cadenza during bars 57-58 in the original piano part; primo gets a massive additional 'Presto' cadenza that deviates substantially from the original, after producing a long segment of doubled ornamented melodic line in the build-up to the two cadenzas. Page 53 features another example of writing in the left hand of the primo part (bars 84-87) which disappears in order to make

${ }^{222}$ Czerny also moves the right-hand up an octave from bar five in order to avoid his creation in the secondo, and inserts an extra half-octave into the brilliant chromatic run in bar eight.

${ }^{223}$ For some reason, Czerny decides to remove the trill from the right hand of the piano at this point, opting to replace it with a held G.

${ }^{224}$ This directly contradicts Beethoven's reprimand of Czerny's additional ornaments and Czerny's declaration later in life mentioned in the introduction to this dissertation. This is not an isolated incident during this general time period, either: George Barth describes several similar cases where Czerny makes alterations to the works of other composers that he arranged for publication in his essay 'Carl Czerny and Musical Authority', in David Gramit (ed.), Beyond the Art of Finger Dexterity: Reassessing Carl Czerny, Rochester: University of Rochester Press, 2008, pp. 125-136. 
way for the arpeggios in the secondo; it also features a triple trill for the primo part - a combination of original piano and violin parts.

Example 3.6: Czerny's augmented cadenza
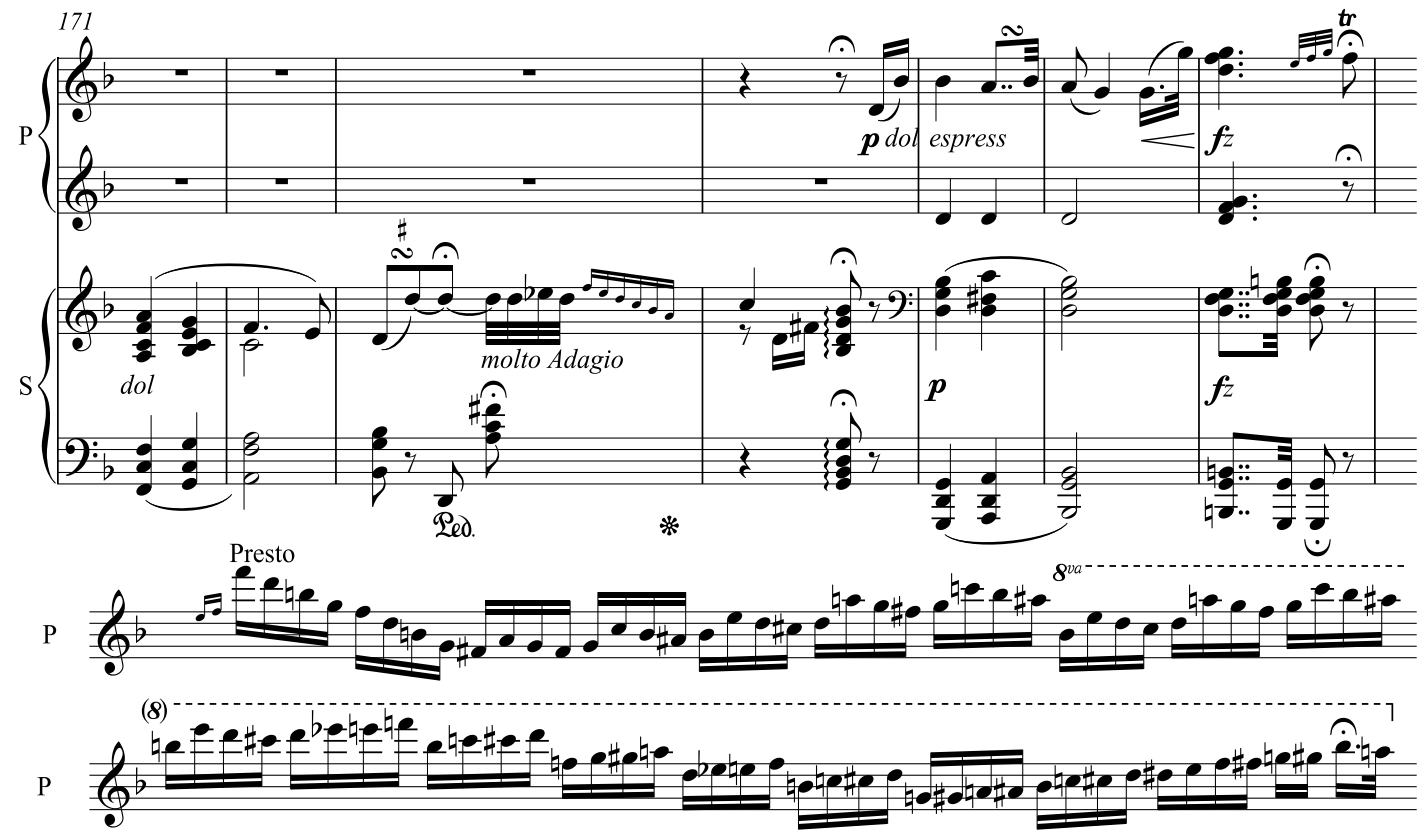

\section{Third Movement}

The third movement contains many examples of symphonic doubling; this can be seen particularly in arppeggiated figures which were largely only found in a single voice in the original, some examples of which can be located on pages 54 and 55, the opening page in each part. The movement makes use of a very wide range of space on the piano: this is demonstrated again on the opening pages, first with the initial chord which spans five octaves, and later with the discontinuity between conversational phrases during bars 28-41 as the secondo utilises the bass of the instrument and the primo stays in the upper reaches.

Czerny has created several difficulties for the performers through this orchestration. As an example, in the secondo on page 58, he writes thirds in the right hand instead of spreading these between both hands as Beethoven did in the original sonata; instead the left hand doubles the lower voice down the octave. At the same time, the primo doubles the upper voice with their left hand (a figure originally performed by the left hand while being balanced by a similar motion gesture in the right hand) and provides the melodic contour 
of the original violin part with their right hand. This requires the performers to not only be technically sound but also synchronised across multiple, rapid quaver-containing voices in a manner with which Beethoven only expected two voices to be at a time. ${ }^{225}$

Another place which presents the pianists with potential synchronisation difficulties gets created near the repeat marking across bars 166 through 176. Czerny preserves the call and response nature of the scales between players; however, he requires both players to present contrary-motion scales in this fashion. These scales alternate registers, before becoming synchronised in bar 170; however Czerny uses bars 173 and 174 to create an abrupt reversal and makes them doubled contrary motion scales (with the contrary motion occurring between the players).

Example 3.7: Bars 114-126
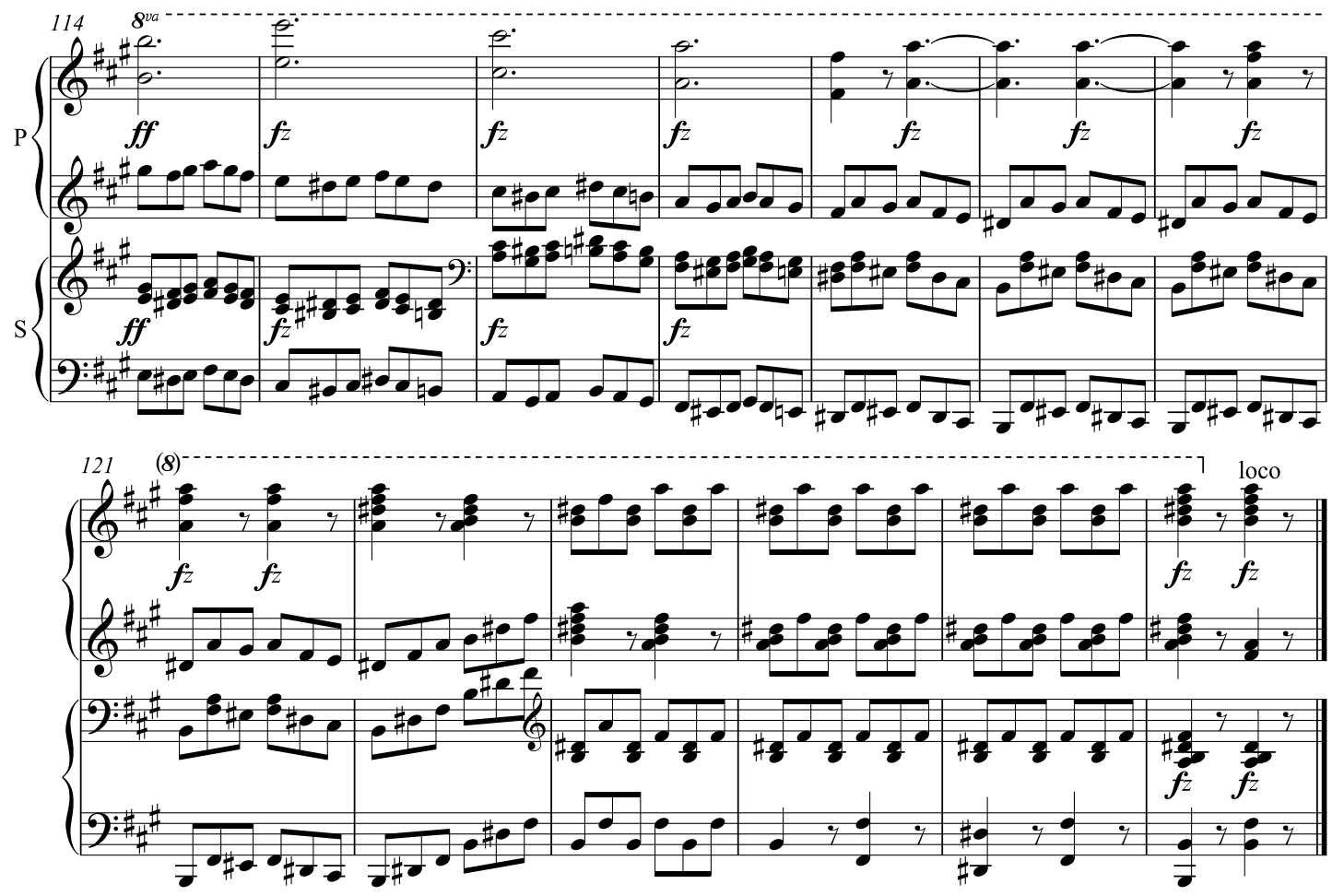

${ }^{225}$ This shows the influences of Clementi and Hummel on Czerny's piano style compared to that of Beethoven. 
Example 3.8: Bars 166-177
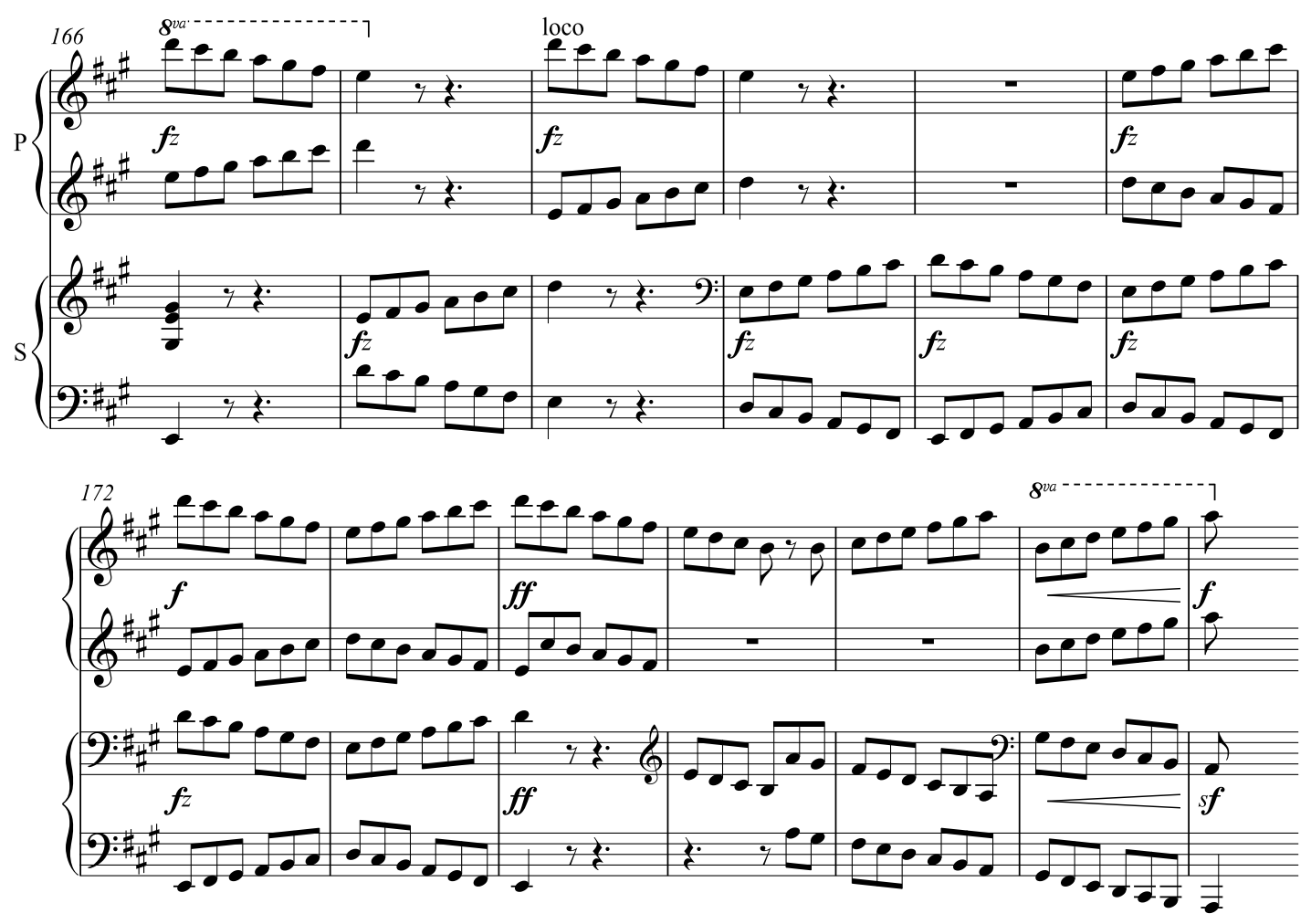

For a pedagogue, Czerny includes very little fingering in this arrangement. The only occurrence of fingering occurs on page 77 (bars 505-508) in the left hand of the primo, in a fast figure that has occurred many times throughout the third movement. 


\section{Conclusion:}

Czerny's four-hand arrangement of Beethoven's 'Kreutzer' Sonata presents a mixture of familiar and vastly altered textures to the performer. As much as it preserves the original arrangement of parts within some of the second movement - and retains the conversational and concertante aspects of the original - it presents a very different challenge to the pianist from the piano writing in the original. The rapid violin figures are reworked to fit under the hands of the pianist (with the notable exception of the second variation of the second movement) yet the most difficult passages of the original piano part are broken up between primo and secondo parts - often with the hands which receive the difficult writing reversed. This removes the balancing gestures available to both muscles and mind, and requires a very different approach. ${ }^{226}$ This also takes the visual interaction between two distinct instruments and combines it: a very different view is available to the audience, and the interplay between performers is either confined to their own section of the keyboard or intruding visually on that of the other performer.

The arrangement itself is of a difficulty level such that it would not have been aimed at the amateur market; it would have taken a very skilled amateur to cope with the difficulties contained within the score. It preserves - indeed, heightens and modernises - the virtuosic nature of the original sonata, and demands this level of skill from both pianists - in particular, the primo player requires a very independent left hand. Czerny very likely created it for his more proficient students, so that they could experience one of Beethoven's most transgressive chamber works for themselves without needing to find a sufficiently skilled violinist; it is possible that Czerny himself might have read it with them, in a classic master-apprentice scenario.

\footnotetext{
${ }^{226}$ Indeed, having performed the original 'Kreutzer' sonata I found it initially very challenging to separate the actions which had been so secure in my muscle-memory and associate just one of them - in the wrong hand, no less - with a new set of actions.
} 


\section{Conclusion: One 'Kreutzer', Three Ways}

Beethoven's 'Kreutzer' Sonata is a virtuosic composition which transgressed the expectations of the Viennese musical society in the early 1800s. As scholars such as Ahn and Drabkin have suggested, the virtuoso level of technical difficulty and concertante style was extraordinary within the context of the sonata genre when Beethoven and Bridgetower gave the premiere performance in 1803 . The 'Kreutzer' Sonata has a conversational quality that permeates the textural construction of the work, while simultaneously undercutting the harmonic foundations and playing with the expectations of his audience in the first movement. This combination of extreme difficulty and emphasis on the musical relationship between performers and thematic interplay has captured the minds of listener and critic alike.

The earliest recorded review suggests from the outset that 'Kreutzer' challenged expectations and befuddled listeners, simultaneously praising Beethoven's 'great genius... glowing fantasy... deeper harmonic art' and suggesting that it would require two virtuosi to 'come together and study the work' in order to allow listeners to enjoy the 'grotesque' work. $^{227}$ To some extent this is true - the 'Kreutzer' Sonata is too difficult for the amateur musician to simply sit down and read through. As such it falls outside the typical target market of the sonata, and belongs to the public performance art of both the violinist and pianist-virtuoso traditions.

The emotions that Beethoven's 'Kreutzer' provokes in the listener led to the creation of Tolstoy's novella of the same name (which inspired Janacek's string quartet of the same name); these works have been the inspiration for Prinet's artwork and numerous works for cinema and the stage. However, Beethoven's sonata also inspired arrangements from his contemporaries; Beethoven's publisher Simrock released an arrangement for string quintet in 1832, and his student and friend Czerny created a four-hand arrangement for piano.

Far from being a simple transcription featuring a violin soloist accompanied by a string quartet, the quintet arrangement takes Beethoven's original violin part and spreads it across the quintet. While special moments and important transitions are reserved for the first

${ }^{227}$ Senner, The Critical Reception of Beethoven's Compositions, pp. 224-225. 
violinist, the majority of the writing moves the original violin part between instruments creating a different style of conversation to that of Beethoven's sonata. This conversational medium in itself is a different forum from the dual partnership created by Beethoven; it involves small fragments of ideas dispersed between multiple parts rather than the sharing of entire thematic ideas. The piano part is rewritten with more idiomatic string writing, but the arranger still demands a high level of technical proficiency from each player. As such it is designed to be playable by the amateur musician, yet simultaneously fully compatible with the public concert scene for which Beethoven's original sonata was intended. The arrangement draws particular attention to the different tonal shifts and individual lines within the texture in a visual manner which Beethoven's original sonata cannot readily emulate.

Czerny's four-hand arrangement demands a proficient technique. Considering that the arrangement splits figures written for both hands of a single pianist between the two performers requiring extremely independent hands, the target market likely consisted of his own students. Czerny also took a number of liberties with the score, turning the arrangement into a work similar in texture and style to his symphonic reductions for fourhands. Doublings at the octave, use of the upper octave, added embellishments and cadenzas - all techniques he professed to later in life as things not to be done to the work of another composer, particularly that of his mentor Beethoven. That being said, the arrangement preserves the conversational and thematic aspects in a manner much closer to Beethoven's original than the quintet transcription; and while it is in a medium recognised for its usefulness for the study and wider transmission of concert hall works it is difficult enough that the virtuosic concertante aspect of Beethoven's original sonata is maintained. The reworking of the two original parts for one instrument also transforms the visual aspects into a very intimate setting, which requires each performer to both respect and invade each other's space; as such they interact through the music on a very different social level to Beethoven's original setting of the sonata.

These currently little-known arrangements capture the essence of Beethoven's 'Kreutzer' Sonata and rework them for their new mediums. As I have shown, the string quintet and four-hand piano arrangements both rewrite passages to behave idiomatically for the new instruments. At the same time, they retain similar levels of technical demand upon performers. The quintet has moments of virtuosity for each player rather than throughout 
the entire work - with slightly greater emphasis on the first cello and violin parts, the first violin in particular. The four-hand arrangement splits the most demanding passages between players, but requires a highly independent left hand from the primo; both players receive virtuosic passages. Given that both these nineteenth-century arrangements allow concert hall performances and study readings from the way in which they disperse Beethoven's original parts - yet lose none of the captivating effects from the myriad of interactions between motivic devices and players - the arrangements and Beethoven's 'Kreutzer' Sonata are truly one piece written three different ways. 


\section{Works cited}

Abbate, Carolyn. 'Music-Drastic or Gnostic?'. Critical Inquiry, Vol. 30, No. 3, 2004, pp. 505-536.

Adler, Samuel. The Study of Orchestration. $3^{\text {rd }}$ ed. New York: Norton, 2002.

Ahn, Suhnne. 'Genre, Style, and Compositional Procedure in Beethoven's "Kreutzer" Sonata, Opus 47’. PhD diss. Harvard University, 1997.

Barth, George. 'Carl Czerny and Musical Authority', in David Gramit (ed.). Beyond the Art of Finger Dexterity: Reassessing Carl Czerny. Rochester: University of Rochester Press, 2008, pp. 125-138.

Bashford, Christina. 'Historiography and Invisible Musics: Domestic Chamber Music in Nineteenth-Century Britain'. Journal of the American Musicological Society, Vol. 63, No. 2, 2010, pp. 291-360

Botstein, Leon. 'Music and its Public: Habits of Listening and the Crisis of Musical Modernism in Vienna, 1870-1914'. PhD diss. Harvard University, 1985.

Boyd, Malcolm. 'Arrangement': Grove Music Online. Oxford Music Online. Oxford University Press, available from http://www.oxfordmusiconline.com/subscriber/article/grove/music/01332; accessed January 4, 2013.

Boyden, David D. et al. 'Violin': Grove Music Online. Oxford Music Online. Oxford University Press, available from http://www.oxfordmusiconline.com/subscriber/article/grove/music/41161pg1; accessed July 14, 2011.

Brett, Philip. 'Piano Four-Hands: Schubert and the Performance of Gay Male Desire'. $19^{\text {th }}$ Century Music, Vol. 21, No. 2, 1997, pp. 149-176.

Broyles, Michael. Beethoven: the Emergence and Evolution of Beethoven's Heroic Style. New York: Excelsior Music Publishing Co., 1987.

Burnham, Scott. Beethoven Hero. Princeton: Princeton University Press, 1995.

Busoni, Ferruccio. 'Sketch of a New Esthetic of Music', in Three Classics in the Aesthetic of Music. Trans. Dr. Th. Baker. New York: Dover Publications Inc., 1962.

Caplin, William. Classical Form: A Theory of Formal Functions for the Instrumental Music of Haydn, Mozart and Beethoven. New York: Oxford University Press, 1998. 
Christensen, Thomas. 'Four-Hand Piano Transcription and Geographies of NineteenthCentury Musical Reception.' Journal of the American Musicological Society, Vol. 52, No. 2, 1999, pp. 255-298.

Cook, Nicholas. 'Analysing Performance and Performing Analysis', in Nicholas Cook and Mark Everist (eds.). Rethinking Music. Oxford: Oxford University Press, 1999, pp. 239-261.

'Count Tolstoï Not Obscene.; the “Kreutzer Sonata” Cannot Legally be Suppressed.' New York Times, September 25, 1890, available from http://query.nytimes.com/mem/archivefree/pdf?res=9B04E1D9103BE533A25756C2A96F9C94619ED7CF; accessed October 10, 2012

Daverio, John. 'Manner, tone, and tendency in Beethoven's chamber music for strings', in Glenn Stanley (ed.). The Cambridge Companion to Beethoven. Cambridge: Cambridge University Press, 2000, pp. 147-64.

Deaville, James. 'A Star is Born: Czerny, Liszt, and the Pedagogy of Virtuosity', in David Gramit (ed.). Beyond the Art of Finger Dexterity: Reassessing Carl Czerny. Rochester: University of Rochester Press, 2008, pp. 52-66.

DeNora, Tia. 'The Beethoven-Wölffl Piano Duel: Aesthetic Debates and Social Boundaries', in David Wyn Jones (ed.). Music in Eighteenth-Century Austria. Cambridge: Cambridge University Press, 1996, pp. 259-282.

DeNora, Tia. Beethoven and the Construction of Genius: Musical Politics in Vienna, $1792-$ 1803. Berkeley: University of California Press, 1997.

Drabkin, William. 'The Introduction to Beethoven's “Kreutzer” Sonata: A Historical Perspective', in Lewis Lockwood and Mark Kroll (eds.). The Beethoven Violin Sonatas: History, Criticism, Performance. Urbana: University of Illinois Press, 2004, pp. 83-109.

Edwards, F. G. 'George P. Bridgetower and the Kreutzer Sonata'. Musical Times, Vol. 49, No. 783, 1908, pp. 302-308.

Ehrlich, Cyril. The Piano: A History. Oxford: Clarendon Press, 1990.

Eisen, Cliff. 'The String Quartet', in Simon Keefe (ed.). Cambridge History of $18^{\text {th }}$ Century Music. Cambridge: Cambridge University Press, 2009, pp. 648-660. and Keefe, Simon P. (eds.). The Cambridge Mozart Encyclopedia. Cambridge: Cambridge University Press, 2006. 
et al. 'String quartet': Grove Music Online. Oxford Music Online. Oxford University Press, available from http://www.oxfordmusiconline.com/subscriber/article/grove/music/40899; accessed December 07, 2012.

Ellingson, Ter. 'Transcription (i)': Grove Music Online. Oxford Music Online. Oxford University Press, available from http://www.oxfordmusiconline.com/subscriber/article/grove/music/28268; accessed January 2, 2013.

Fuchs, Ingrid. 'Beethoven's Ambassador Posthumous', in David Gramit (ed.). Beyond the Art of Finger Dexterity: Reassessing Carl Czerny. Rochester: University of Rochester Press, 2008, pp. 82-107.

Gramit, David. 'Selling the Serious: The Commodification of Music and Resistance to It in Germany, circa 1800', in William Weber (ed.). Musician as Entrepreneur, 17001914: Managers, Charlatans, and Idealists. Bloomington: Indiana University Press, 2004, pp. 81-104.

Green, Douglass M. Form in Tonal Music; An Introduction to Analysis. New York: Holt, Rinehart and Winston, Inc., 1965.

Grove, George. ‘Bridgetower, George Polgreen', rev. McVeigh, Simon. Grove Music Online. Oxford Music Online. Oxford University Press, available from http://www.oxfordmusiconline.com/subscriber/article/grove/music/03981; accessed October 18, 2013.

Goehr, Lydia. The Imaginary Museum of Musical Works: An Essay in the Philosophy of Music. Oxford: Clarendon Press, 1992.

Good, Edwin M. Giraffes, Black Dragons, and Other Pianos, Pianos: A Technological History from Cristofori to the Modern Concert Grand. Stanford: Stanford University Press, 1982.

Hanson, Alice M. 'Czerny's Vienna', in David Gramit (ed.). Beyond the Art of Finger Dexterity: Reassessing Carl Czerny. Rochester: University of Rochester Press, 2008, pp. 23-33.

Hunter, Mary. "“The Most Interesting Genre of Music": Performance, Sociability and Meaning in the Classical String Quartet, 1800-1830'. Nineteenth-Century Music Review, Vol. 9, No. 1, 2012, pp. 53-74. 
Jahn, Otto. Life of Mozart. Trans. Pauline Townsend. London: Novello, Ewer \& Co., 1891. Johnson, Douglas P., Tyson, Alan and Winter, Robert. The Beethoven Sketchbooks: History, Reconstruction, Inventory. Berkeley: University of California Press, 1985. Kawabata, Maiko. 'Virtuoso Codes of Violin Performance: Power, Military Heroism and Gender (1789-1830)'. 19 $9^{\text {th }}$-Century Music, Vol. 28, No. 2, 2004, pp. 98-101.

Kawohl, Friedemann. 'Music Copyright and the Prussian Copyright Act of 1837', in J. Samson and B. Zon (eds.). $19^{\text {th }}$ Century Music Studies. London: Ashgate, 2002, pp. 279-292

Kinderman, William. Beethoven. New York: Oxford University Press, 2009.

Komlós, K. Fortepianos and their Music: Germany, Austria, and England, 1760-1800. Oxford: Clarendon Press, 1995.

Kramer, R. 'Sonate, que me veux-tu? Opus 30, Opus 31, and the Anxieties of Genre', in Lewis Lockwood and Mark Kroll (eds.). The Beethoven Violin Sonatas: History, Criticism, Performance. Urbana: University of Illinois Press, 2004, pp. 47-60.

Kroll, Mark. Johann Nepomuk Hummel: A Musician's Life and World. Lanham: Scarecrow Press, 2007.

Kuerti, Anton. 'Carl Czerny, Composer.', in David Gramit (ed.). Beyond the Art of Finger Dexterity: Reassessing Carl Czerny. Rochester: University of Rochester Press, 2008, pp. 139-144

Kuerti, Anton. 'Carl Czerny: In the Shadow of Beethoven'. Queen's Quarterly, Vol. 104, No. 3, 1997, pp. 487-497.

Le Guin, Elisabeth. Boccherini’s Body: An Essay in Carnal Musicology. Berkeley: University of California Press, 2005.

Leppert, Richard. The Sight of Sound. Berkeley: University of California Press, 1995. Lindeman, Stephan D. and Barth, George. 'Czerny, Carl': Grove Music Online. Oxford Music Online. Oxford University Press, available from http://www.oxfordmusiconline.com/subscriber/article/grove/music/07030; accessed October 27, 2012.

Lockwood, Lewis. Beethoven: The Music and the Life. New York: Norton, 2003.

Moore, Julia. 'Beethoven and Musical Economics'. PhD diss. University of Illinois, 1987. Morrow, Mary Sue. Concert Life in Haydn's Vienna: Aspects of a Developing Musical and Social Institution. New York: Pendragon Press, 1989. 
Newman, William. Beethoven on Beethoven: Playing His Piano Music His Way. New York: Norton, 1988.

— The Sonata in the Classic Era. Chapel Hill: University of North Carolina Press, 1963.

Olleson, Edward. 'Swieten, Gottfried Baron van': Grove Music Online. Oxford Music Online. Oxford University Press, available from http://www.oxfordmusiconline.com/subscriber/article/grove/music/27216; accessed January 02, 2013.

Pazdírek, Franz. The Universal Handbook of Musical Literature. Practical and Complete Guide to All Musical Publications. Vol. 5. Vienna: Pazdírek \& Co., 1904.

Reti, Rudolph and Cooke, Deryck. Thematic Patterns in Sonatas of Beethoven. New York: Macmillan, 1967.

Roberge, Marc-André. 'From Orchestra to Piano: Major Composers as Authors of Piano Reductions of Other Composers' Works'. Notes, Second Series, Vol. 49, No. 3, 1993, pp. 925-936.

Rosen, Charles. The Classical Style: Haydn, Mozart, Beethoven. New York: Viking, 1971.

Rosenblum, Sandra. Performance Practices in Classic Piano Music. Bloomington: Indiana University Press, 1988.

Scherer, F. M. Quarter Notes and Bank Notes: The Economics of Music Composition in the Eighteenth and Nineteenth Centuries. Princeton: Princeton University Press, 2004.

Schwarz, Boris. 'Beethoven and the French Violin School'. The Musical Quarterly, Vol. 44, No. 4, 1958, pp. 431-447.

Senner, Wayne M., Wallace, Robin and Meredith, William R. (eds.). The Critical Reception of Beethoven's Compositions by his German Contemporaries. Vol. 1. Trans. Wayne Senner. Lincoln: University of Nebraska Press, 1999.

Skowroneck, Tilman. Beethoven the Pianist. Cambridge: Cambridge University Press, 2010.

Somfai, László. 'Clever Orator vesus Bold Innovator', in Tom Beghin and Sander M. Goldberg (eds.). Haydn and the Performance of Rhetoric. Chicago: University of Chicago Press, 2007, pp. 213-228.

Speck, Christian and Sadie, Stanley. 'Boccherini, Luigi': Grove Music Online. Oxford Music Online. Oxford University Press, available from http://www.oxfordmusiconline.com/subscriber/article/grove/music/03337; accessed November 17, 2012. 
Stowell, Robin. Violin Technique and Performance Practice in the Late Eighteenth and Early Nineteenth Centuries. Cambridge: Cambridge University Press, 1985.

Thayer, Alexander W., ed. Forbes, Elliot. Thayer's life of Beethoven. Vol. 1. Princeton: Princeton University Press, 1967.

Tolstoy, L. The Kreutzer Sonata and Other Stories. Trans. Benjamin R. Tucker. New York: J. S. Ogilvie, 1890.

Walker, Alan et al. 'Liszt, Franz': Grove Music Online. Oxford Music Online. Oxford University Press, available from http://www.oxfordmusiconline.com/subscriber/article/grove/music/48265pg1; accessed November 23, 2012.

Winter, Robert. 'Performing the Beethoven Quartets in Their First Century', in Robert Winter and Robert Martin (eds.). The Beethoven Quartet Companion. Berkley: University of California Press, 1994, pp. 29-58.

Wright, Josephine. 'George Polgreen Bridgetower: An African Prodigy in England'. The Musical Quarterly, Vol. 66, No. 1, 1980, pp. 65-82. 